UCRL-LR-113891

Distribution Category UC-902

\title{
Pilot Study Risk Assessment for Selected Problems at the Nevada Test Site (NTS)
}

\begin{tabular}{llll}
\multicolumn{2}{c}{ J.I. Daniels, Editor } \\
Contibutors: & $\frac{\text { HEAD/LLNL }}{\text { L.R. Anspaugh }}$ & $\frac{\text { WRC/DRI }^{+}}{\text {R. Andricevic }}$ & $\frac{\text { BEAG/BNL }}{\text { A.F. Meinhold }}$ \\
& K.T. Bogen & R.L. Jacobson & S. Holtzman \\
J.I. Daniels & & S.C. Morris \\
D.W. Layton & & L.D. Hamilton \\
& T. Straume & &
\end{tabular}

*Health and Ecological Assessment Division

Lawrence Livermore National Laboratory

P.O. Box 808, L-453

Livermore, CA $94551-9900$

'Water Resources Center

Desert Institute

University and Community College System of Nevada

P.O. Box 19040

Las Vegas, NV 89132-0040

tBiomedical and Environmental Assessment Group

Brookhaven National Laboratory, Building 475

Upton, NY 11973

June 1993

\section{LAWRENCE LIVERMORE NATIONAL LABORATORY University of California • Livermore, California • 94551}

Available to DOE and DOE contractors from the Office of Scientific and Technical Information P.O. Box 62, Oak Ridge, TN 37831 Prices available from (615) 576-8601, FTS 626-8401

Available from: National Technical Information Service • U.S. Department of Commerce 5285 Port Royal Road - Springfield, VA 22161 - A04 • (Microfiche A01)

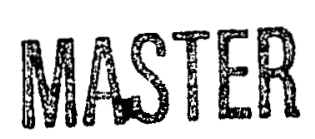




\section{DISCLAIMER}

This report was prepared as an account of work sponsored by an agency of the United States Government. Neither the United States Government nor any agency Thereof, nor any of their employees, makes any warranty, express or implied, or assumes any legal liability or responsibility for the accuracy, completeness, or usefulness of any information, apparatus, product, or process disclosed, or represents that its use would not infringe privately owned rights. Reference herein to any specific commercial product, process, or service by trade name, trademark, manufacturer, or otherwise does not necessarily constitute or imply its endorsement, recommendation, or favoring by the United States Government or any agency thereof. The views and opinions of authors expressed herein do not necessarily state or reflect those of the United States Government or any agency thereof. 


\section{DISCLAIMER}

Portions of this document may be illegible in electronic image products. Images are produced from the best available original document. 


\section{Acknowledgment}

This study was funded by the United States Department of Energy (DOE), Office of Environmental Restoration and Waste Management, Office of Technology Development. The Project Officer for the effort was Mr. Michael Barainca. This pilot study was a collaborative effort between Brookhaven National Laboratory (BNL) and Lawrence Livermore National Laboratory (LLNL). The principal investigator for the BNL effort was Dr. L. D. Hamilton. The principal investigators for the LLNL work were Dr. L. R. Anspaugh and Dr. D. W. Layton. Dr. R. Andricevic and Dr. R. L. Jacobson at the Water Resources Center of the Desert Research Institute of the University and Community College System of Nevada also participated in the assessment of radionuclide-contaminated ground water at the Nevada Test Site (NTS). We extend our appreciation and gratitude to the Nuclear Chemistry Division at the LLNL and particularly to Dr. Wataru Goishi, Dr. Greg Nimz, Dr. Doug Leich, and Mr. Ken Marsh for providing essential data and insight regarding the presence of radionuclides in ground water beneath the NTS. We also thank Dr. Andrew Tompson in the Earth Sciences Division of the Geoscience and Environmental Research Program at the LLNL for reviewing the travel-timetransport model used in the assessment of the movement of radionuclides in ground water beneath the NTS. Additionally, we are grateful for the comments we received from the external peer-reviewers and for the comments and cooperation provided by personnel at the DOE Nevada Operations Office in Las Vegas, NV; at DOE headquarters in Washington, DC, and at DOE contracting organizations familiar with the NTS. Finally, we thank Mr. Leo Duffy and Dr. Clyde Frank at the DOE for their encouragement and support. 


\section{Abstract}

The Nevada Test Site (NTS) is located in southwestern Nevada, about $105 \mathrm{~km}(65 \mathrm{mi})$ northwest of the city of Las Vegas. A series of tests was conducted in the late 1950s and early 1960s at or near the NTS to study issues involving plutonium-bearing devices. These tests resulted in the dispersal of about $5 \mathrm{TBq}$ of $239,240 \mathrm{Pu}$ on the surficial soils at the test locations. Additionally, underground tests of nuclear weapons devices have been conducted at the NTS since late 1962; ground water beneath the NTS has been contaminated with radionuclides produced by these tests. These two important problems have been selected for assessment. Regarding the plutonium contamination, because the residual ${ }^{239} \mathrm{Pu}$ decays slowly (half-life of $24,110 \mathrm{y}$ ), these sites could represent a long-term hazard if they are not remediated and if institutional controls are lost. To investigate the magnitude of the potential health risks for this no-remediation case, three basic exposure scenarios were defined that could bring individuals in contact with $239,240 \mathrm{Pu}$ at the sites: (1) a resident living in a subdivision, (2) a resident farmer, and (3) a worker at a commercial facility -all located at a test site. The predicted cancer risks for the resident farmer were more than a factor of three times higher than the suburban resident at the median risk level, and about a factor of ten greater than the reference worker at a commercial facility. At $100 \mathrm{y}$ from the present, the 5,50, and 95 th percentile risks for the resident farmer at the most contaminated site were $4 \times 10^{-6}, 6 \times 10^{-5}$, and $5 \times 10^{-4}$, respectively. For the assessment of $\mathrm{Pu}$ in surface soil, the principal sources of uncertainty in the estimated risks were population mobility, the relationship between indoor and outdoor contaminant levels, and the dose and risk factors for bone, liver, and lung. Concerning contaminated ground water, an increasing demand for water has been created by the continued population growth and expanding development in the region. This problem and the possible loss of institutional control at the NTS after $100 \mathrm{y}$ have led to a concern that individuals in future generations might become exposed to the radionuclide-contaminated ground water, and prompted this examination of the potential health risk to these individuals from drinking the contaminated ground water either at a location on the NTS (assuming loss of institutional control after $100 \mathrm{y}$ ) or at one offsite (considering groundwater migration). The maximum potential excess lifetime risk of cancer mortality estimated for individuals at the offsite location ranges from $7 \times 10^{-7}$ to $1 \times 10^{-5}$ and $3 \times 10^{-3}$ to $2 \times 10^{-2}$ at the onsite location. Both the offsite and onsite estimates of risk are dominated by the lifetime doses from tritium. For the assessment of radionuclides in ground water, the critical uncertainty is their concentration today under the entire NTS. 


\section{Contents}

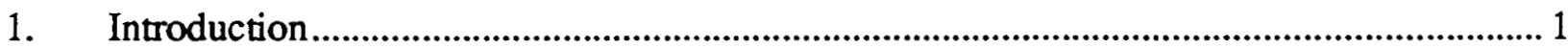

1.1. Risk Assessments for Department of Energy Sites ............................................. 2

1.1.1. Approaches to Risk Assessment.......................................................... 3

1.2. Pilot Study Approach to Realistic Risk Assessment for ....................................... 6

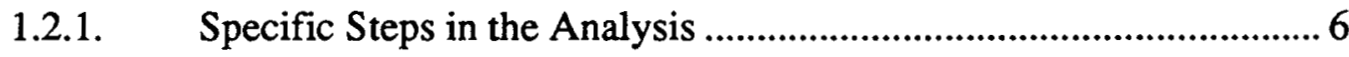

1.2.2. Methods and Assumptions ........................................................... 8

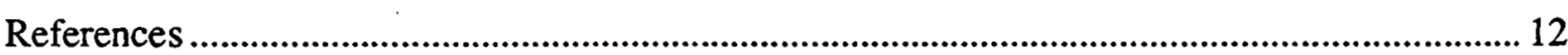

2. Overview of the Nevada Test Site and Identification of Problems to be

Addressed ....................................................................................................................... 13

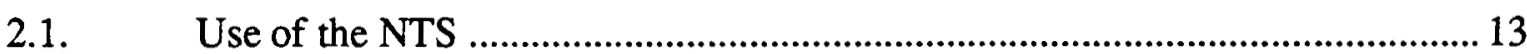

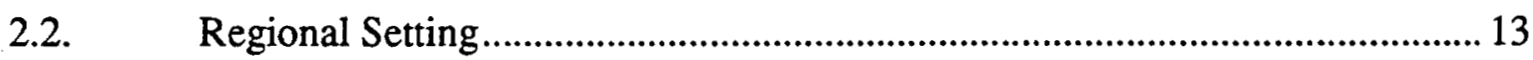

2.2.1. Site Description and Location ........................................................ 13

2.2.2. Climate, Meteorology, and Native Flora \& Fauna ............................. 14

2.2.3. Hydrology ....................................................................................... 14

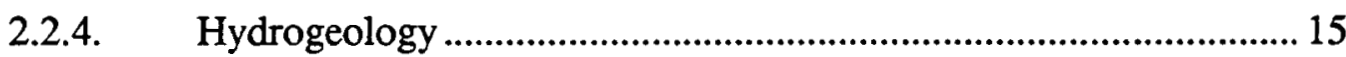

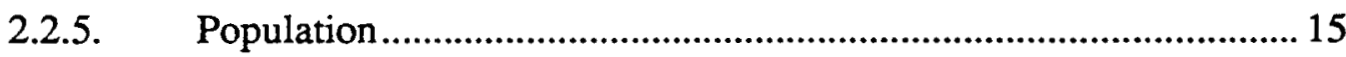

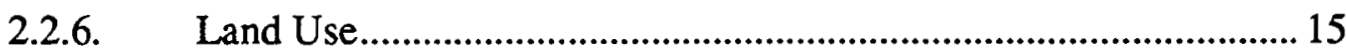

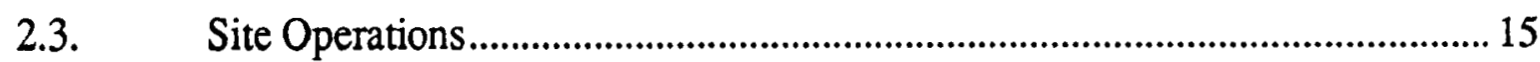

2.4. Environmental Problems ........................................................................... 15

2.5. Environmental Monitoring and Restoration ............................................... 16

2.6. Problems to be Studied in Risk Assessment .................................................. 16

2.6.1. Tritium and Fission Product Migration in Ground

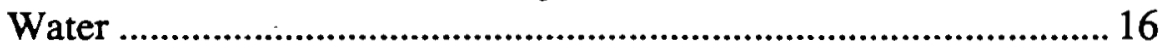

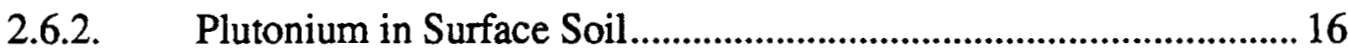

2.7. Future Assessments ............................................................................ 17

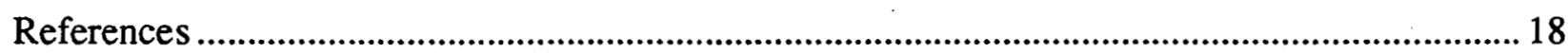

3. Risk Assessment of Soil-Based Exposures to Plutonium at Experimental

Sites Located on the Nevada Test Site and Adjoining Areas ................................................ 19

3.1. Methodology Overview .............................................................................. 19

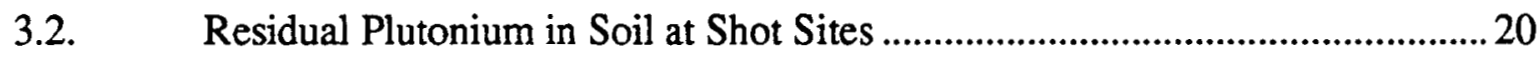

3.3. Conceptualization of Potential Exposure Pathways and

Screening Analyses 
3.4. Transport Processes for Plutonium at Shot Sites

3.4.1. Concentrations of Pu in Surficial Soils and Outdoor

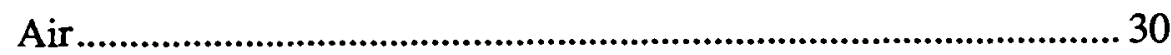

3.4.2. Concentrations of $\mathrm{Pu}$ in Indoor Air ................................................ 33

3.5. Human Factors Describing Exposure Scenarios................................................... 39

3.5.1. Activity Patterns ............................................................................. 39

3.5.2. Age-dependent inhalation rates ........................................................ 42

3.5.3. Residential and Occupational Mobility ............................................ 44

3.6. Organ-Specific Doses and Risk Factors............................................................ 45

3.6.1. Organ-Specific Doses from Inhalation Exposures .......................... 48

3.6.2. Organ-Specific Risk Factors ..............................................................53

3.7. Predicted Cancer Risks and Associated Uncertainties ......................................... 56

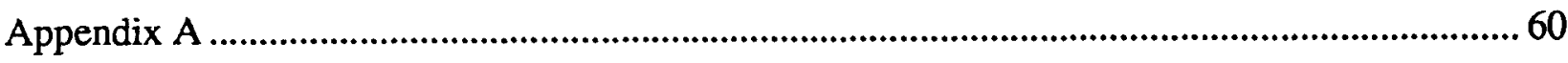

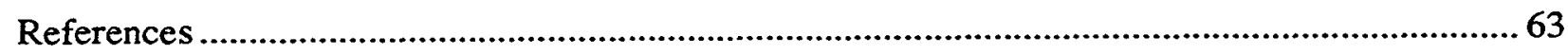

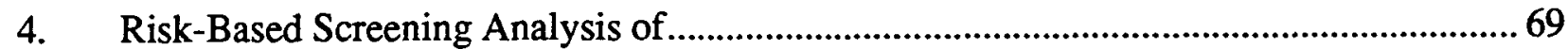

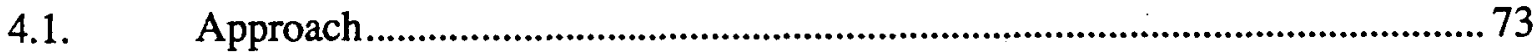

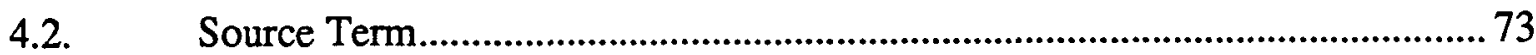

4.3. Estimation of Maximum Annual Concentrations of

Radionuclides in Ground Water at Locations of Interest ................................... 76

4.3.1. Radionuclide Concentrations at the Area 20

Boundary ....................................................................................... 76

4.3.2. Radionuclide Concentrations at Oasis Valley ...................................76

4.4. Intake of Radionuclide-Contaminated Ground Water ........................................ 81

4.5. Dose Corresponding To Intake ........................................................................ 82

4.5.1. Dose-Conversion Factors fór Intake by Ingestion ............................... 83

4.5.2. Maximum Dose and Associated Uncertainty .................................... 85

4.6. Estimate of Cancer Risk and Associated Uncertainty ........................................ 90

4.7. Discussion ................................................................................................... 92

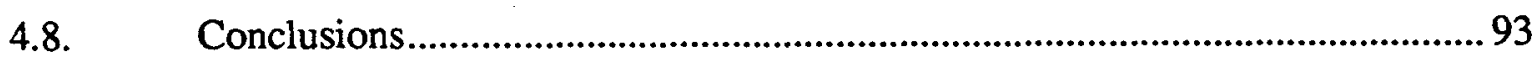

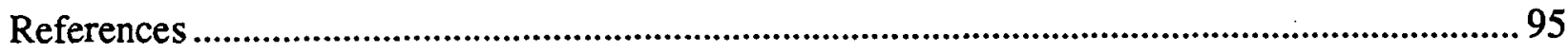




\section{Introduction}

\section{A. F. Meinhold*, S. Holtzman*, S. C. Morris, ${ }^{*}$ and L. D. Hamilton ${ }^{*}$}

Widespread environmental contamination has been documented at United States Department of Energy (DOE) facilities. Human health risk assessments are increasingly being used to support decisions concerning remediation at these sites.

This study assesses health risks for selected problems identified at three DOE facilities: (1) the Savannah River Site (SRS), near Aiken, South Carolina; (2) the Fernald Environmental Management Project (FEMP) in Fernald, Ohio; and (3) the Nevada Test Site (NTS), near Las Vegas, Nevada. The pilot study was a collaborative effort between the Biomedical and Environmental Assessment Group (BEAG) of Brookhaven National Laboratory (BNL) and the Health and Ecological Assessment Division (HEAD) of Lawrence Livermore National Laboratory (LLNL). BNL had primary responsibility for the risk assessments of the SRS and the FEMP, while LLNL took the lead in the assessment of the NTS. This volume of the report, Pilot Study Risk Assessment for Selected Problems at the Nevada Test Site presents risk assessments of impact on human health, for two potentially important problems identified at the NTS.

Current methods for assessing risk at DOE facilities are generally excessively conservative or simplistic. Generic models, conservative parameter default values and assumptions are often used, and unrealistic exposure and land use scenarios are embedded in the analyses. These approaches are appropriate only as first-level screening analyses and identify contaminants or pathways that are not important in terms of risk to human health.

Site and problem specific decisions about cleanup at DOE facilities should be based on sophisticated state-of-the-science approaches to human health risk assessment. A more detailed, site-specific approach, based on realistic exposure scenarios and up-to-date dose-response relationships would provide better information to DOE, to regulatory agencies, and to the public. Decisions concerning the need for remediation, the choices between remediation options, definition of cleanup goals, and funding and research priorities could then be assured of protecting the public health in a scientifically based way.

This pilot project has three principal objectives:

(1) to develop scholarly, realistic, and quantitative health-risk assessments based on state-ofthe-art scientific knowledge and methods for several of the more important environmental and hazardous waste problems at three DOE facilities;

(2) to provide and demonstrate methods for realistic risk analyses that can be adapted for application at other sites in the DOE complex;

(3) to improve significantly the scientific and technical foundation upon which remediation actions at DOE sites are based, so that such risk-management decisions are scientifically defensible and fiscally sound.

We define a realistic and objective risk assessment to be one that

\footnotetext{
* Brookhaven National Laboratory, Building 475; Upton, NY 11973
} 
(1) avoids unrealistic and conservative exposure scenarios, and focuses on the development of reasonable and sensible scenarios;

(2) replaces generic or inappropriate default assumptions with site-specific data;

(3) explicitly characterizes uncertainties in parameters and does not depend on conservative assumptions;

(4) uses site-specific transport and exposure models and depends on monitoring data for model calibration or input parameters;

(5) uses the latest scientific information in describing dose-response relationships;

(6) acknowledges that without additional data collection, situations with very little data available to describe source terms or exposure routes cannot be assessed in as realistic a manner as possible, but practically such situations can be addressed credibly using a scientifically defensible risk-based screening analysis.

The approaches to human health risk assessment commonly used at DOE facilities, and an outline of the general method of realistic and objective risk assessment developed and demonstrated in the pilot study are presented next. In the chapter that follows this one, an overview of the NTS is provided as background. Included in the overview is a brief description of the two problems at the NTS that are addressed in this document and the reasons for their selection. The remaining chapters in this document describe the assessments of the potential human health risks associated each problem: (1) radionuclides in ground water, and (2) plutonium in surface soil at locations where plutonium-bearing devices were tested.

\subsection{Risk Assessments for Department of Energy Sites}

Risk can be defined in different ways. Cohrssen and Covello (1989) technically define risk as the possibility of suffering harm from a risk agent (i.e., chemical substance, organism, radioactive material, or other potential hazard). Consequently, the analysis of risk must describe the discharge of the risk agent, its transport and fate in an environmental media (i.e., air, soil, food, water) and any associated human exposure. Human-health risks are then calculated based on data and models that relate exposures to risk (Till and Meyer, 1983). The scope of such a risk analysis can range from a qualitative discussion to a careful, realistic, and quantitative assessment of the likelihood of adverse human health effects (Cohrssen and Covello, 1989).

Several measures can be used to describe the probability that harm will result from exposure to a risk agent (adapted from Cohrssen and Covello, 1989):

- Individual lifetime risk: the estimated increase in probability that an individual will experience a specific adverse health effect over a lifetime as a result of exposure to a specified concentration of a risk agent; and

- Population risk: the number of deaths or adversely affected individuals in the exposed population.

The U.S. Environmental Protection Agency (EPA) currently considers excess individuallifetime cancer risks (assumed here to mean fatal cancer risks) within the range of $1 \times 10^{-4}$ (onein-ten-thousand) to $1 \times 10^{-6}$ (one-in-a-million) to be acceptable (USEPA, 1991). An excess individual-lifetime cancer-mortality risk of $10^{-6}$. for the entire United States population (240 
million in 1987, U.S. Department of Health and Human Servicés, USDHHS, 1990) would result in 240 premature deaths from cancer. Based on a lifetime expectancy of 70 years, this represents 3.4 deaths in addition to the 2.1 million annual deaths from all causes, including the 477,000 cancer deaths that occurred in the United States in 1987 (USDHHS, 1990).

\subsubsection{Approaches to Risk Assessment}

Risk assessments cover a spectrum of complexity and accuracy, depending on the aims of the assessment and the level of certainty required of the results. Figure 1 outlines this spectrum of approaches to risk assessment that can be used to address environmental problems at DOE facilities. The accuracy of the results of a risk assessment depends on the transport and exposure models used in the analysis, the variables used as input to the models, and the realism of the assumptions made concerning exposure scenarios, dose-response and risk factors, and receptors. Categorization and screening assessments are the approaches most frequently used at DOE facilities.

\section{Categorization Assessment}

The least complex and least accurate approach aims simply at identifying sites or problems of potential concern. In this report this approach is called a categorization assessment. The most widely used categorization assessment is the EPA Hazard Ranking System (HRS: USEPA, 1990) which generates numerical scores, based on general site information and a simple ranking model. Sites scoring above a certain level are included on the National Priorities List (NPL) under the Comprehensive Environmental Response, Compensation and Liability Act (CERCLA). This categorization system gives no information on the risks associated with environmental contamination at a site, and few site-specific data are required to generate an HRS score.

\section{Screening Assessment}

Screening assessments are the next level of complexity and accuracy in risk assessment. Assessments of this type can range from simple conservative assessments of risk, assuming worst-case conditions, to more sophisticated analyses, based on multiple-pathway models. The range of accuracy of the risk estimates produced by these approaches is driven by two major factors: the sophistication of the transport models and other algorithms used; and the accuracy of the input data and other assumptions that are employed in the analysis. These assessments give approximate estimates of individual and population risks but often rely on simplistic transport models. Conservative and unrealistic default assumptions are usually used to deal with uncertainty. The results of screening assessments can be used as a first step for identifying environmental problems requiring further assessment.

Two major kinds of screening risk assessments are commonly performed at DOE facilities. These are assessments using a Multimedia Environmental Pollution Assessment System (MEPAS) model (Droppo et al., 1990; USDOE, 1988), and baseline risk assessments performed as part of Remedial Investigation/Feasibility Studies (RI/FS) required for Superfund sites (USEPA, 1989).

The (MEPAS) model was designed to use the results of an environmental survey performed by DOE for a specific facility to rank environmental problems in terms of risk. The model is a 


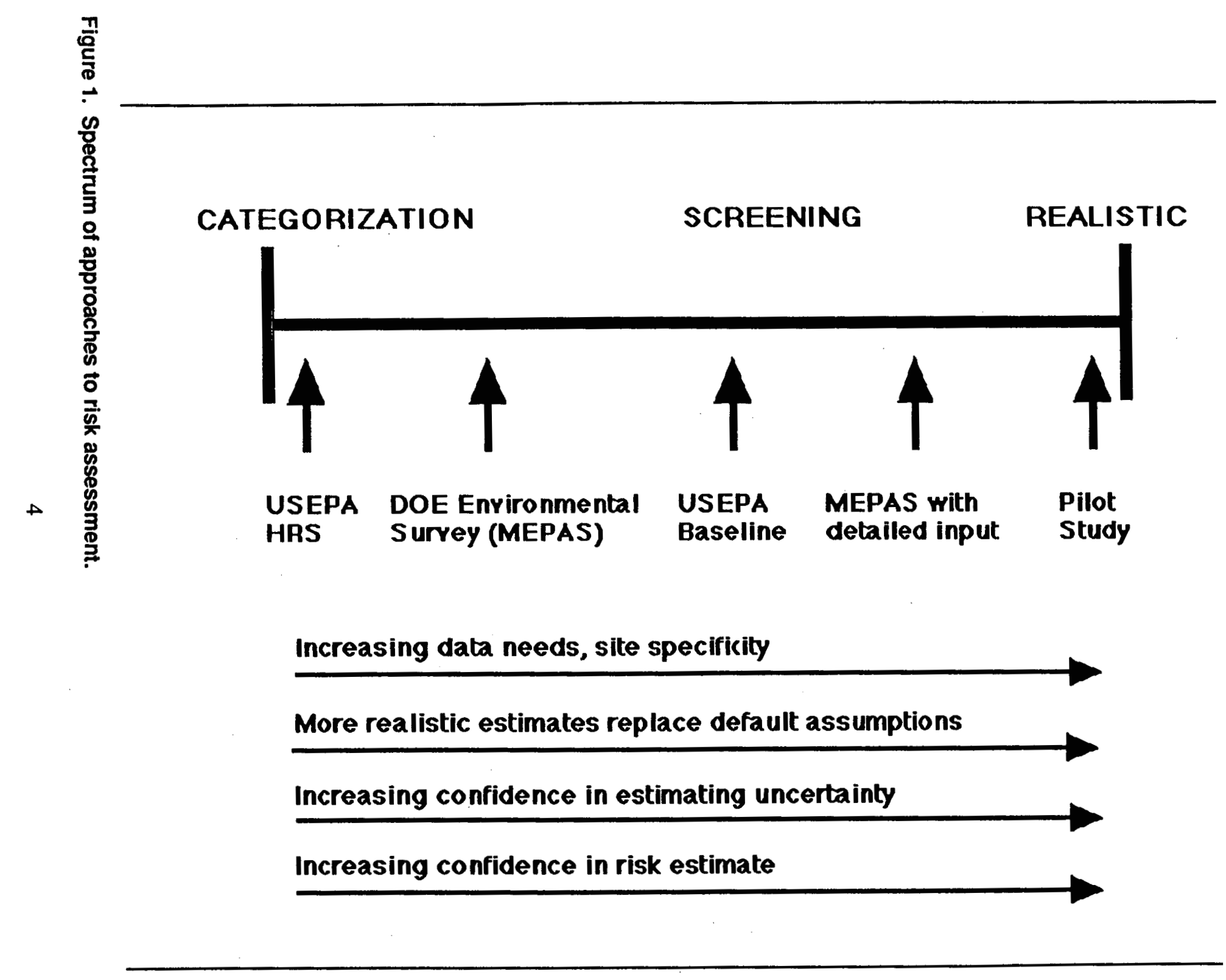


multiple-pathway model that follows a contaminant from the source through various environmental media to man. The MEPAS model was designed specifically to produce relative rankings among environmental problems - the Hazard Potential Index (HPI) produced by the model does not represent absolute estimates of health risk. There are a number of limitations to the model that make it inappropriate for use in a more detailed and accurate approach to risk assessment. These limitations include the simple groundwater model included in the package, treatment of both cancer and toxicity risk in the same way (assuming no threshold), and difficulty in describing the time associated with exposure (Morris, 1990; Morris and Meinhold, 1988). The MEPAS model also uses toxicity values recommended by the EPA that contain "safety factors" ranging from 10 to 1000 , and cancer risk factors that are based on a number of conservative assumptions.

The DOE environmental survey implemented the MEPAS model by using data and assumptions derived from initial investigations of potential problems at DOE facilities. The detailed data and analyses required for an accurate estimation of risk were not available across all DOE sites. Therefore, results of the survey were to be used simply to rank problems in terms of risk, and to help identify areas where further investigation and characterization were needed. For situations in which better data and more accurate assumptions are available, the MEPAS model can generate better estimates than those resulting from the DOE environmental survey. However, the model is limited by design to producing screening assessments only.

Baseline risks assessments are performed in accordance with EPA guidelines, and the specifics of the analyses are usually dictated by the EPA regional office responsible for the facility. Baseline risk assessments represent screening-level assessments because the conservative assumptions embedded in the analyses, and the common use of simplistic transport models produce approximate estimates of risk. A baseline risk assessment is conducted to estimate the risks associated with an identified operable unit prior to any remediation of a DOE site that is listed on the NPL. The assumptions used in the assessments are designed to protect public health and are generally conservative, and tend to overestimate risks. The EPA has identified a number of environmental transport models that it considers appropriate for use in these assessments. They range from simple 1-dimensional models to more complex computer codes.

The conservative assumptions contained in these baseline assessments include the previously described toxicity values and cancer-risk factors, the use of worst-case conditions for land use, predicted environmental concentrations and exposure rates. The identified receptor for a baseline risk assessment is an individual receiving the "reasonable maximum exposure" [sic] (USEPA, 1989), whether or not she or he exists.

\section{Realistic Assessment}

The highest level of accuracy and complexity in a risk assessment process is a realistic assessment. Realistic assessments are usually performed for environmental problems identified by a screening assessment as presenting potentially significant risks. Conservative assumptions and safety factors are replaced in a realistic assessment by best estimates and reasonable exposure scenarios. Environmental concentrations, exposures and risks are presented in the form of distributions, where appropriate. More sophisticated transport models may be used, and predicted concentrations are compared to environmental monitoring data. Uncertainties and conservative assumptions are explicitly described. When data are not available for a realistic 
assessment, a screening analysis is performed instead. Even then, the bases for assumptions and conservatisms are stated and uncertainties are defined and, where possible, distributions are used to represent exposures and risks.

The screening assessments commonly used at DOE facilities are appropriate for use as initial tools, or to satisfy EPA Remedial Investigation/Feasibility Study requirements. Realistic assessments are the only way to produce reasonable, scientifically-defensible estimates of risk. Realistic assessments: provide better risk estimates to the EPA, DOE and to the public; form a better basis for remedial action decisions; and support cost-effective clean-up planning.

\subsection{Pilot Study Approach to Realistic Risk Assessment for DOE Facilities}

The risk assessments in this document and in the companion documents for the FEMP and SRS are based on a realistic and objective approach to risk assessment. The results of the assessments of the health risks associated with important environmental problems at the three DOE facilities are well-documented, and scientifically-defensible. Where realistic assessments were not appropriate because of a lack of site- and problem-specific information, detailed credible screening assessments were performed to estimate the magnitude of potential health risks, and to determine what additional data collection is needed. The next section outlines the methods used for developing realistic risk estimates for problems at DOE sites, and subsequent sections provide additional descriptions of the constituents of a "realistic" risk assessment.

\subsubsection{Specific Steps in the Analysis}

Figure 2 outlines the procedure developed in this pilot study for assessing human health risk at DOE sites. The steps in this procedure are described in more detail below.

1. Development of Site Overview. The first step is to develop a site description that includes relevant background information on the physical setting of the site, nearby populations and land uses, local meteorology, the direction of groundwater flow, and where applicable, the uses of ground and surface water.

2. Problem and Contaminant Identification. The important potential problems and related contaminants in terms of potential human exposures and risks are identified.

3. Source Term Characterization/ Environmental Fate and Transport. The major chemical fate and transport pathways are described for the contaminants of concern. The temporal and/or spatial variations of a contaminant's concentration in environmental media are predicted. Monitoring data and other available information are used to estimate the source term. Environmental transport models, adapted to the specific site, are used to predict contaminant concentrations.

4. Realistic Estimates of Exposure Rates. Predicted concentrations of a particular contaminant in environmental media are used to estimate potential human exposure to the substance of concern. These estimates are based on reasonable estimates of exposure parameters such as water intake, food intake, and time of residence. Site-specific data are used when available. This step also includes the development of reasonable land-use scenarios. 
Derelopment of site overview

Identification of principal problems and related contaminants

Source-term characterization

Enyironmental fate and transport

Realistic estimates of exposure rates

Realistic dose-response relationships

Risk characterization

Figure 2. Steps in the assessment. 
5. Realistic Dose-response Relationships. Dose-response relationships, which relate toxic endpoints to exposures or doses are constructed or are identified in the literature. The safety factor approach used by the EPA for describing the relationship between dose and effect for many toxicants is replaced by an explicit consideration of uncertainty. Cancer risk factors are described as distributions about the best estimate available.

6. Risk Characterization. Finally, the potential individual and or population health risks and/or hazards for a specific environmental contaminant are quantified. Where possible, these risks are described as probability distributions.

\subsubsection{Methods and Assumptions}

\section{Identification of Receptors}

Receptors are either people who are currently exposed to the pollutant of interest, or people who have a potential for such exposure. Currently exposed people may include onsite populations (i.e., workers), and local or regional populations that are exposed because of environmental transport processes (e.g., wind, surface and groundwater movement). Potentially exposed people include people that reside in the path of a plume that is expected to reach them in the future, people that gain entry to the site as a result of a loss of institutional control, and additional people who will be exposed as a result of population growth.

\section{Development of Exposure and Land Use Scenarios}

It is assumed that land uses in the future conform to current activities, or to current activities on nearby land, unless there is compelling evidence to the contrary. Either ground water or nearby surface water is assumed to be the source of drinking water, unless there is evidence indicating the use of other sources.

The assumption of the maintenance or loss of institutional control at a DOE facility can be critical to the results of a risk assessment when the bulk of the identified contamination is onsite in soil or water. A loss of institutional control may require the use of an intruder scenario, and a scenario assuming the possibility of farming or a family living onsite. For problems for which institutional control affects the risk assessment, two analyses are done. The first assumes a maintenance of institutional control in perpetuity. The second assumes loss of institutional control after 100 years.

\section{Environmental Transport}

Contaminant concentrations in air, ground water, surface water and/or food are predicted by using environmental transport models appropriate to each site, each problem, and the available data. Where complex site-specific transport models were developed by the DOE or site contractors, these models are considered for use in the assessments. When a large amount of historical data is available, empirical models are used in place of physics-based models to relate site contaminant discharges to environmental concentrations at locations of receptors.

When sites and source terms are poorly characterized, more elementary models are used. For use in a screening analysis, such models provide appropriate estimates of future environmental concentrations of the principal contaminants of concern. 


\section{Exposure Routes and Parameters}

Each route of exposure is analyzed for its contribution to the total exposure of a person to a contaminant. The analysis relates the concentration of contaminant in a medium (e.g., $\mathrm{Bq} / \mathrm{L} \mathrm{H}_{2} \mathrm{O}$, $\left.\mathrm{mg} / \mathrm{kg}_{\text {soil }}\right)$ to the total amount of the medium to which an individual is exposed. The data used in the analyses include distributions of personal exposure factors (e.g., rates of breathing, rates of water intake, ingestion of fish, and other applicable activities). These distributions reflect population characteristics in the United Sates, either obtained from published sources or developed from available data. Specific pathways of exposure are not analyzed further, when documented evidence or supporting calculations show that they are not relevant to the specific problem.

\section{Dose-response Relationships and Risk Characterization}

Dose-response functions per unit of contaminant exposure are obtained from the literature, or are developed from the available data. For each contaminant, a dose-response function is applied to the total exposure to determine the total dose.

Hazards are characterized qualitatively and quantitatively for carcinogenicity and/or toxicity. Risk functions (factors) are also obtained from the literature, or are developed from the available data. These risk factors, expressed as risk per unit dose, or risk per unit intake, are applied to the total doses of contaminants to estimate the risks. In most cases the risks are estimated for cancer mortality, including individual lifetime risks and population risks. These risks are expressed as central values (average and/or median) and uncertainties (standard deviation and cumulative upper $95 \%$ probability value).

Where toxic effects other than cancer are evaluated, the risks are expressed as the probability of an individual incurring the effects. Both a central value and the uncertainty in the expression are provided.

\section{Probabilistic Assessment and Uncertainty}

A realistic and probabilistic assessment uses the range of possible values for parameters and variables, rather than relying on single values. When this is done, outcomes of the risk assessments appear as distributions of values, rather than single estimates, yielding probabilistic analyses of risk (as demonstrated simplistically in Fig. 3). For example, the rate of drinking water intake by individual receptors is represented by a distribution of values, instead of the average (or maximum) rates commonly used in EPA and DOE risk calculations. This approach to risk assessment allows an estimate of the uncertainty associated with an "average" or "worstcase" risk estimate. As described above, the result of such an assessment for cancer mortality risk is a distribution that can be presented numerically (by a confidence interval, usually $90 \%$ ) and/or shown graphically (Fig. 3).

Many of the probabilistic analyses in the pilot study were produced with a Monte Carlo analysis, using software available for desktop computers. In a Monte Carlo analysis, a sample from the distribution of a variable is placed into a simulation run (iteration) to interact with samples from other variables.

\section{Inadequate Data and Screening Assessment}

Part of the risk assessment process developed in this pilot study is the exercise of professional judgment concerning the amount (and quality) of site characterization and source- 
Step 1. a). Develop an assumption about the distribution of tritium concentations in drinking water $\left(\left[{ }^{3} \mathrm{H}\right]_{\text {water }}\right)$.

b). Develop an assumption about the distribution of drinking water intake (WI).

c). Calculate exposure to tritium in drinking water (WIE).

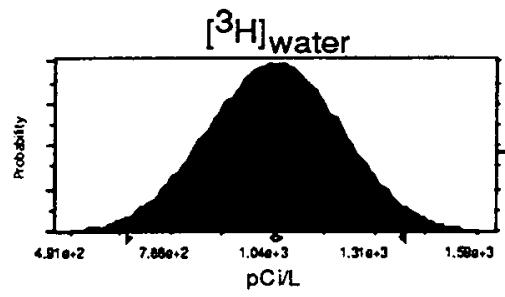

Calculate:

$[\mathrm{BH}]_{\text {water }} \times \mathbf{W I}=$ WIE
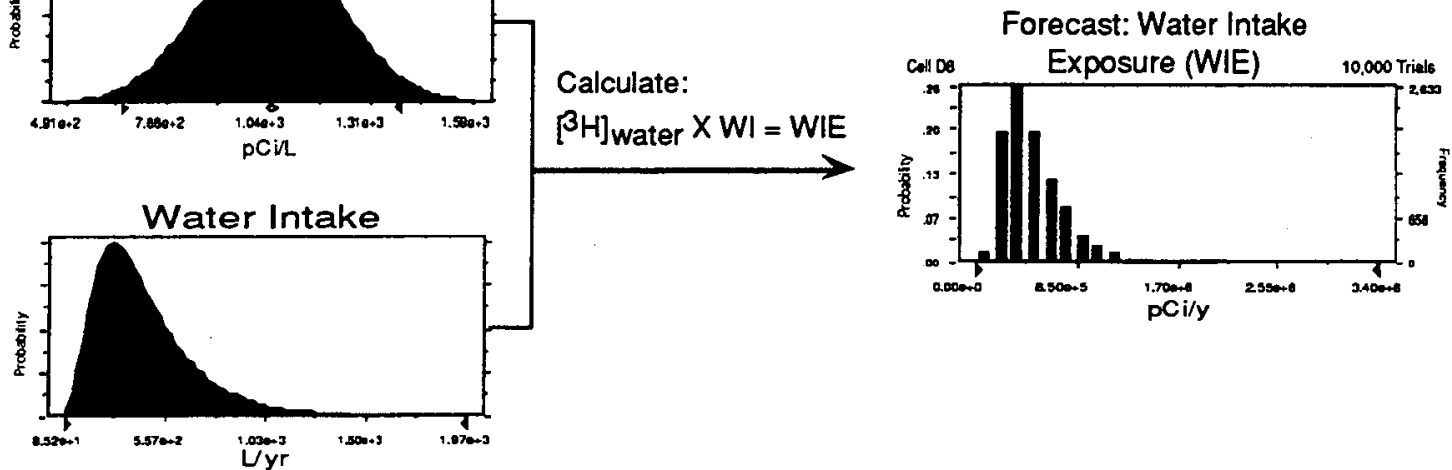

Step 2. a). Develop an assumption about the dose factor for tritium ingestion (Df).

b). Develop an assumption about the risk factor for tritium ingestion (Rf).

c). Calculate incremental individual lifetime risk for cancer mortality (IR).

Forecast: Water Intake
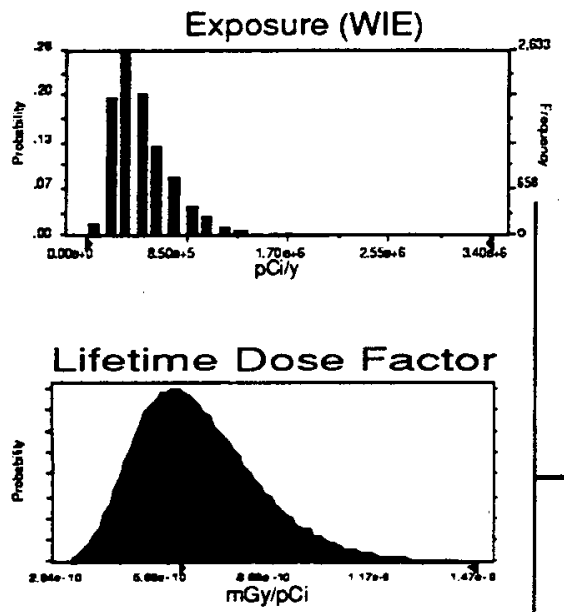

Calculate:

WIE X Df X Rf $=\mathbb{I R}$

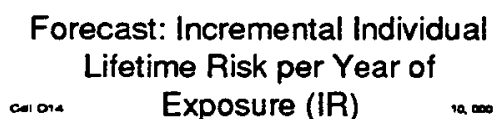

Lifetime Risk per Year of
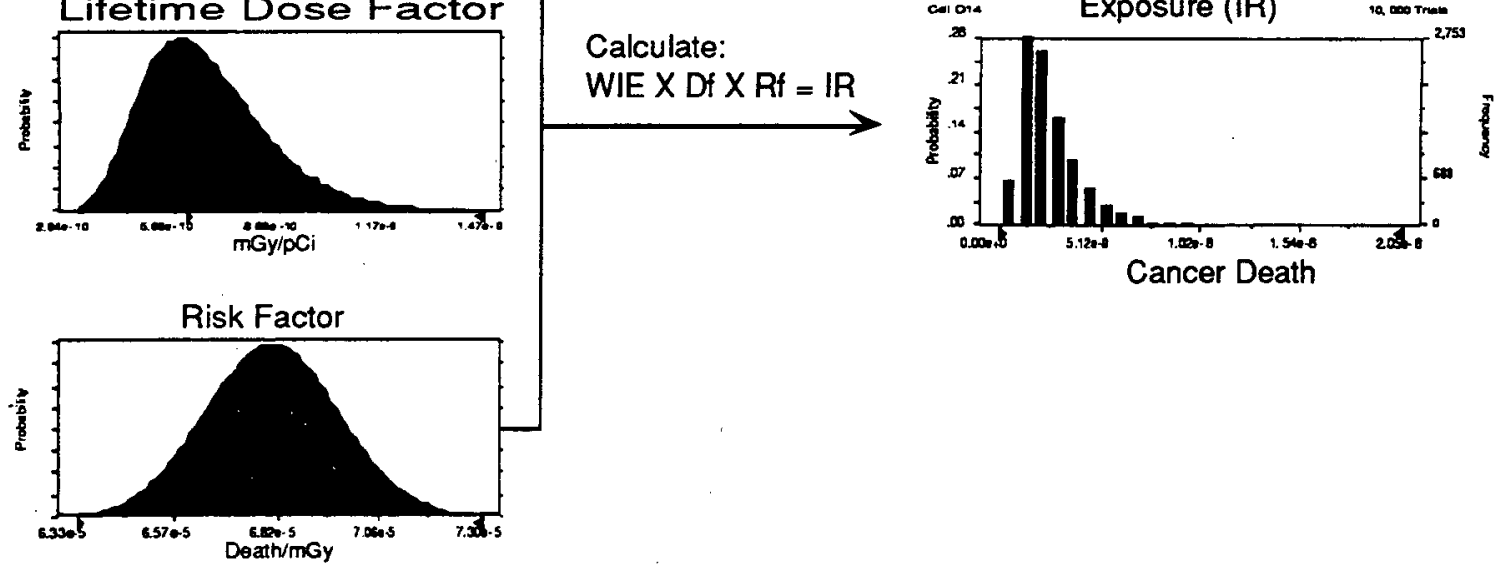

Figure 3. Probabilistic Risk Assessment Example: Estimation of individual lifetime risk of cancer mortality from ingestion of tritium in drinking water. 
term data and the models and probabilistic methods that are credible and practical for analyzing that data. When source-term or site-characterization data are minimal, a defensible risk-based screening-level assessment is the only feasible initial approach for evaluating the problem. The approach used in this pilot study was: to perform such screening assessments whenever the available data were limited (eliminating unnecessary conservatism where possible); to document explicitly all assumptions used in the analysis; and to draw conclusions on the need for relevant additional data collection. 


\section{References}

Cohrssen, J.J., and V.T. Covello (1989), Risk Analysis: A Guide to Principles and Methods for Analyzing Health and Environmental Risks. United States Council on Environmental Quality, Executive Office of the President, Washington, DC.

Droppo, J.G., Jr., J.W. Buck, D.L. Strenge, and M.R. Siegel (1990), Analysis of Health Impact Inputs to the U.S. Department of Energy's Risk Information System. Pacific Northwest Laboratory, Richland, WA, PNL-7432.

Morris, S.C. (1990), Baseline Risk Information for Formal Priority System Fiscal Year 1992 Interim System Application, Brookhaven National Laboratory, Upton, NY.

Morris, S.C. and A.F. Meinhold (1988), Report of Technical Support for the Hazardous Waste Remedial Program on Health and Environmental Risks of Inactive Hazardous Waste Sites, Brookhaven National Laboratory, Upton, NY, BNL-42339 Informal Report.

Till, J.E., and H.R. Meyer, Eds. (1983), Radiological Assessment: A Textbook on Environmental DoseAnalysis. U.S. Nuclear Regulatory Commission, Washington, DC, NUREG/CR-3332; ORNL-5968.

U.S. Department of Energy (USDOE) (1988), Environmental Survey Preliminary Summary Report of the Defense Production Facilities, Environment, Safety and Health, Office of Environmental Audit, U.S. Department of Energy, Washington, DC, DOE/EH-0072.

U.S. Department of Health and Human Services (USDHHS) (1990), Vital Statistics of the United States, 1987, U.S. Department of Health and Human Services, U.S. Public Health Service, Hyattsville, MD.

United States Environmental Protection Agency (USEPA) (1989), Risk Assessment Guidance for Superfund., Volume I Human Health Evaluation Manual (Part A), Interim Final., Office of Emergency and Remedial Response, United States Environmental Protection Agency, Washington, DC, EPA/540/1-89/002,

United States Environmental Protection Agency (USEPA) (1990), "National Oil and Hazardous Substances Pollution Contingency Plan, Final Rule (40 CFR Part 300), Fed. Regist. 55(46), 8666-8865.

United States Environmental Protection Agency (USEPA) (1991), National Primary Drinking Water Regulations; Radionuclides; Proposed Rule (40 CFR Parts 141 and 142), Fed. Regist. 56 (138), 33050-33127. 


\title{
2. Overview of the Nevada Test Site and Identification of Problems to be Addressed
}

\author{
J. I. Daniels, ${ }^{*}$ D. W. Layton*, and L. R. Anspaugh*
}

The Nevada Test Site (NTS) is located in Nye County, Nevada, about $105 \mathrm{~km}$ (65 mi) northwest of the city of Las Vegas. Since 1951, the NTS has been used primarily for nuclearweapons related tests. Details of the history, location, regional setting, and current operations of the NTS are described in the Nevada Test Site Annual Site Environmental Report-1989, Volume I (Wruble and McDowell, 1990). This information is summarized to provide an overview of the characteristics of the NTS that are relevant to this pilot health and environmental risk assessment.

\subsection{Use of the NTS}

Even though the NTS has been used primarily for testing nuclear explosives since 1951, open-air nuclear reactor, nuclear engine, and nuclear furnace tests were conducted there as well between 1959 and 1973. Also located at the NTS is the Liquefied Gaseous Fuels Spill Test Facility, where limited non-nuclear tests involving spills of hazardous material were performed in the latter half of the 1980s. Additionally, the NTS is the site of radioactive- and mixed-waste disposal facilities for U.S. defense waste.

During the $1950 \mathrm{~s}$, the tests of nuclear explosives were predominantly atmospheric (i.e., devices were detonated either on the ground, on a steel tower, suspended or tethered from balloons, or dropped from aircraft). However, since late 1962, nearly all tests have been conducted in sealed vertical shafts or in horizontal tunnels, although six earth-cratering tests that involved the shallow burial of a nuclear explosive were performed between 1962 and 1968. There were also special experiments conducted in the 1950s and 1960s on the NTS or nearby on U.S. Air Force property involving plutonium-bearing devices.

\subsection{Regional Setting}

This section describes the NTS and its location, climate, hydrology, and hydrogeology. Information is presented about the offsite population, current land use, and current and potential use of surface and ground water.

\subsubsection{Site Description and Location}

The NTS covers an area of about $3,500 \mathrm{~km}^{2}\left(1,350 \mathrm{mi}^{2}\right)$. It varies from 46 to $56 \mathrm{~km}$ (28 to $35 \mathrm{mi}$ ) across its width (east to west) and from 64 to $88 \mathrm{~km}$ (40 to $55 \mathrm{mi}$ ) along its length (north to south). The city of Las Vegas is approximately $105 \mathrm{~km}(65 \mathrm{mi})$ to the southeast.

The Nellis Air Force Base Bombing and Gunnery Range and the Tonopah Test Range surround the NTS and form public-access exclusion areas around its western, northern, and eastern borders. This exclusion or buffer zone between public lands and the NTS ranges in size

\footnotetext{
* Lawrence Livermore National Laboratory, Livermore, CA.
} 
from 24 to $104 \mathrm{~km}$ ( 15 to $65 \mathrm{mi}$ ). The NTS and the buffer zone of restricted access formed by the surrounding U.S. Air Force range complex occupy an area of about $14,200 \mathrm{~km}^{2}\left(5,470 \mathrm{mi}^{2}\right)$, one of the largest unpopulated land areas in the United States.

The elevation at the NTS ranges from approximately $910 \mathrm{~m}(3,000 \mathrm{ft})$ above mean sea level (MSL) in the south and east to $2,100 \mathrm{~m}(6,900 \mathrm{ft})$ above MSL in the mesa areas near the northern and northwestern perimeters.

\subsubsection{Climate, Meteorology, and Native Flora \& Fauna}

The climate at the NTS is typical of the Great Basin deserts of the southwestern United States. Precipitation varies temporally and spatially and is a function of topography. For example, at higher elevations snow can accumulate and average annual precipitation, including snowfall, is 9 inches; however, at lower elevations, average annual precipitation is 6 inches, with snow accumulation that is infrequent and not lasting more than a few days. Furthermore, precipitation not only occurs and varies in amount within isolated shower areas, but it can occur between July and August as a result of thunderstorms, and during September and/or October as a result of northeastward movement of tropical storms that have developed in the Pacific Ocean west of Mexico.

Temperatures also are influenced by elevation on the NTS. On Pahute Mesa in the northwestern part of the NTS, the average daily high and low temperatures at about $2,000 \mathrm{~m}$ $(6,565 \mathrm{ft})$ range from 4 and $-2^{\circ} \mathrm{C}\left(40\right.$ and $\left.28^{\circ} \mathrm{F}\right)$ in January, to 27 and $17^{\circ} \mathrm{C}\left(80\right.$ and $\left.62^{\circ} \mathrm{F}\right)$ in July. However, on Yucca Flat, which is on the northeastern part of the NTS, the average daily high and low temperatures at about $1,200 \mathrm{~m}(3,924 \mathrm{ft})$ range from about 11 and $-6^{\circ} \mathrm{C}(51$ and $\left.21^{\circ} \mathrm{F}\right)$ in January, to about 36 and $14^{\circ} \mathrm{C}\left(96\right.$ and $\left.57^{\circ} \mathrm{F}\right)$ in July.

Changes in wind-direction frequencies are dictated seasonally by movements of large-scale pressure systems; southerly winds dominate in summer and northerly winds dominate in winter. However, wind direction at the NTS is also influenced by the general downward slope in terrain, which typically causes wind direction to reverse from southerly during the day to northerly at night, especially during the summer. In fact, this diurnal pattern of reversing wind direction can be so intense in the summer as to override the wind direction dictated by large-scale pressure systems. The average annual wind speed at the higher elevations of Pahute Mesa is about 17 kilometers per hour (10.5 mph), and is about 11 kilometers per hour ( $7 \mathrm{mph}$ ) on the flats.

Desert shrubs typical of the Mojave or Great Basin Deserts cover most of the land area of the NTS. However, at higher elevations there are areas of desert woodland.

The animals on the NTS generally are small and nocturnal; rodents account for nearly half of all known species. Among the larger mammals are feral horses, burros, deer, mountain lions, bobcats, coyote, kit foxes, and rabbits.

\subsubsection{Hydrology}

No continuous flowing surface-water streams exist on the NTS. Yucca Flat and Frenchman Flat drain onto dry lake beds (playas) in each valley. Arroyos and dry stream beds drain the remainder of the NTS during unusually intense or persistent storms. In the northern portions of the NTS, an integrated channel system carries runoff beyond NTS boundaries onto the U.S. Air 
Force range complex. Channel systems in the western half and southernmost area of the NTS ultimately carry runoff from intense storms to Death Valley, California.

\subsubsection{Hydrogeology}

The depth of ground water beneath the NTS varies from about $200 \mathrm{~m}(660 \mathrm{ft})$ under the valleys in the south to over $625 \mathrm{~m}(2,050 \mathrm{ft})$ at Pahute Mesa in the northwest. The ground water flow on the eastern side of the NTS is toward the valleys of Yucca and Frenchman Flats. At these valleys, the ground water deflects downward to join regional drainage that carries water to the southwest.

Ground water along the western side of the NTS generally moves toward the west. The overall regional flow of ground water is from recharge areas in the northern and eastern parts of the NTS to discharge areas southwest of the NTS in the direction of Death Valley.

\subsubsection{Population}

Clark County, Nevada, with more than 631,000 people, is the largest populated county bordering the NTS. However, if the population of Clark County living within a $150 \mathrm{~km}(93 \mathrm{mi})$ radius of the NTS is excluded, then the population density is only about 0.5 persons $/ \mathrm{km}^{2}$. In comparison, the estimated average population density of the state of Nevada is 2.8 persons $/ \mathrm{km}^{2}$ (based on the 1980 census).

Several small rural communities are located in the immediate vicinity of the NTS. The Pahrump Valley to the south, with a population of about 6,000; the Amargosa Farm area to the southwest, with a population of about 950 ; and the largest town in the vicinity of the NTS, Beatty, to the west, with about 1,500 people.

\subsubsection{Land Use}

The offsite areas beyond the perimeters of the NTS and U.S. Air Force range complex possess a great diversity of land use. This land use includes farming, mining, grazing, camping, fishing, and hunting.

\subsection{Site Operations}

As mentioned before, the NTS is primarily used for the testing of nuclear explosives. Since late 1962 the vast majority of these tests have been conducted in sealed vertical shafts drilled into the floor of Yucca Flat and the top of Pahute Mesa or in horizontal tunnels mined into the face of Rainier Mesa.

Other activities include research at the Liquefied Gaseous Fuels Spill Test Facility, and operation of waste disposal facilities for radioactive and mixed waste.

\subsection{Environmental Problems}

The Environmental Survey (U.S. DOE, 1988) divided the environmental problems identified at the NTS into ranking units. Included among these ranking units are "tunnel ponds" (perched ground water that is stored after being intercepted during the mining of nuclear testing tunnels in 
Rainier Mesa), a fuel spill at the Desert Rock airstrip, soil contamination by hazardous chemicals, contamination of subsurface soil and ground water from underground nuclear testing, wastewater lagoons in drainage swales, waste disposal to dumps, muck piles, trenches, and landfills, discharges to land surfaces and drainage ditches, and potential for leaks from underground storage tanks. However, this document contains a preliminary analysis that does not provide a quantitative evaluation.

\subsection{Environmental Monitoring and Restoration}

Environmental monitoring at the NTS is conducted onsite and offsite. Onsite, environmental media are monitored for radioactive and non- radioactive contaminants. Offsite, a radiological monitoring program for environmental media, including livestock and wildlife, is conducted by the U.S. Environmental Protection Agency (U.S. EPA) Environmental Monitoring Systems Laboratory in Las Vegas.

Environmental restoration activities at the NTS include corrective actions for improper drilling mud disposal, and study of a fuel leak from an underground storage tank.

\subsection{Problems to be Studied in Risk Assessment}

Two potential environmental problems at the NTS are evaluated in detail in this pilot risk assessment. These problems are the potential migration of tritium and fission products in ground water, and the elevated levels of plutonium in surface soil at the NTS. Our reasons for focusing this pilot risk assessment on these two problems are described next, and stem from a critical examination of the meaningful information available regarding the NTS and discussions with U.S. Department of Energy personnel.

\subsubsection{Tritium and Fission Product Migration in Ground Water}

It is generally considered reasonable that the deep aquifers, slow ground water movement, and exceedingly slow downward movement of water in the overlying saturated zone serve as significant barriers to transport of radioactivity from underground sources to offsite areas. However, the transfer and subsequent migration of tritium and fission products in ground water may be accelerated by forced pumping, which might occur should population increases and land use changes occur as development expands in the general vicinity of the NTS. As a consequence of this important concern and the possibility for loss of institutional control of the NTS after $100 \mathrm{y}$, the potential public health risk to individuals in the future associated with possible exposures to radionuclide contaminated ground water either at a location on the NTS or at one offsite in the direction of ground water flow are both examined.

\subsubsection{Plutonium in Surface Soil}

Although the public is excluded from the NTS today, the time frame for institutional control is not clear. Thus, human occupation at some time in the distant future needs to be considered, especially with respect to locations containing elevated concentrations of Plutonium-239 in the surface soil, a result of tests conducted in the 1950 s and 1960 s involving plutonium-bearing devices. Because the residual Pu-239 decays slowly (half-life of approximately $24,000 \mathrm{y}$ ), there is concern that the sites where such contaminated surface soil exists could represent a long-term 
hazard, if they were not remediated and if institutional control were lost. Consequently, the magnitude of the potential health risks that could result from three different, but conceivable exposure scenarios, are investigated.

\subsection{Future Assessments}

Consideration needs to be given to the other potential environmental problems at the NTS with regard to potential health risks. Among the most important are the radionuclide inventory of the soils on the NTS and their potential for resuspension and transport offsite, the significance of the tritium in the surface water ponds and tunnel ponds, and the potential problems related to the underground storage tanks. 


\section{References}

U.S. Department of Energy (1988), Environmental Survey Preliminary Summary Report of the Defense Production Facilities, Environment, Safety and Health, Office of Environmental Audit, U.S. Department of Energy, Washington, DC, DOE/EH-0072.

Wruble, D. T., and E. M. McDowell, Eds. (1990), Nevada Test Site Annual Site Environmental Report-1989, Volume I, U.S. Department of Energy, Nevada Operations Office, Las Vegas, NV, DOE/NV/10630-11 Volume 1. 


\title{
3. Risk Assessment of Soil-Based Exposures to Plutonium at Experimental Sites Located on the Nevada Test Site and Adjoining Areas
}

\author{
D. W. Layton*, L. R. Anspaugh*, K. T. Bogen*, T. Straume*
}

Residual plutonium (Pu) in surficial soils at the Nevada Test Site (NTS) is the result of the above-ground testing of nuclear weapons and special experiments involving the detonation of plutonium-bearing devices. The latter experiments were conducted for four basic reasons (Stannard, 1988): (1) to study the behavior of $\mathrm{Pu}$ as it was being explosively compressed, (2) to ensure that the accidental detonation of the chemical explosive in a production weapon would not produce a nuclear yield, (3) to evaluate the ability of personnel to handle large-scale Pu dispersal accidents, and (4) to develop criteria for transportation and storage of weapons. The first set of experiments were called "hydrodynamic" or "equation of state" tests. Twenty-two such tests were conducted above ground at the GMX location in Area 5 (see Fig. 1) between December 1954 and February 1956. Many tests were conducted to determine whether nuclear yields could be produced from accidental detonations. The largest ones carried out on the surface were Project 56 in Area 11 (now known as Plutonium Valley); here four devices were detonated in 1956 , one with a slight nuclear yield. The final large, surface experiment was conducted as Project 57 in Area 13, just off the NTS. Experiments performed to evaluate cleanup and weapons-handling issues consisted of Operation Roller Coaster, Double Tracks, and Clean Slate I, II, and III. The locations of these detonations off of the NTS are also indicated in Figure 1.

All of the sites where these tests were conducted were contaminated with Pu. At the present time, these sites do not pose a health threat to either workers or the general public because they are under active institutional control. Specifically, inadvertent human intrusion onto the test sites (referred to here as "shot sites") is deterred by the use of fences and warnings, coupled with the fact that the shot sites are within test ranges, all of which have restricted access. However, because the half-lives of ${ }^{239} \mathrm{Pu}$ and ${ }^{240} \mathrm{Pu}$ are 24,110 and $6,560 \mathrm{y}$, respectively, the residual contamination could indeed pose a long-term health hazard if it were not remediated and industrial, agricultural, or residential land uses emerged following a loss of institutional control. In order to develop relevant cleanup-options for the test sites, it is important to assess the nature and magnitude of the potential health risks associated with naive uses of the affected lands. Accordingly, the following risk analysis examines the distribution of plutonium in soils at these sites, potential exposures and resulting doses, and finally, incremental cancer risks for those potentially exposed.

\subsection{Methodology Overview}

The basic methodology for estimating the potential health risks of residual $239,240 \mathrm{Pu}$ in the soils of the NTS is shown in Figure 2. The initial task involves the characterization of the concentrations of $239,240 \mathrm{Pu}$ in surface soils in the vicinity of each test shot. That effort is

\footnotetext{
${ }^{*}$ Lawrence Livermore National Laboratory, Livermore, CA.
} 
followed by a conceptualization of how an individual could come in contact with the residual plutonium under various land-use scenarios following loss of institutional control of unremediated lands. Knowledge of route-specific toxicity is also needed to identify potentially important exposure pathways, and hence we have shown a feedback loop between the doseresponse assessment and the conceptualization of potentially important exposure pathways.

Before preparing a detailed dose assessment of an environmental contaminant, it is often helpful to prepare a screening-level analysis to identify the exposure pathways that contribute the most to absorbed doses, and conversely, to eliminate from further consideration those pathways that contribute little to absorbed doses. Information from the first two analyses is then used to examine the transport pathways of concern and afterwards, to calculate the doses to key organs.

To relate the internal doses to potential health risks, we next examine dose-response data for estimating the probability of incurring cancer per unit dose to target organs. We have included in Figure 2 additional feedback loops between the dose-response assessment, dose assessment, and exposure assessment tasks to indicate that there is a need to exchange information at each point in the assessment process. The final task in the methodology is to characterize the cancer risks resulting from the exposures to $239,240 \mathrm{Pu}$-contaminated soils/dusts at the different sites along with the uncertainties of the estimated risks. To quantify the overall uncertainty in calculated cancer risks, we use a Monte-Carlo simulation technique to propagate the uncertainties associated with the $239,240 \mathrm{Pu}$ source terms (i.e., concentrations in soil), plutonium transport, human exposures, absorbed doses, and dose-response relationships for target organs. Each of the following discussions evaluates separately the uncertainties of key assessment parameters and the concluding section on risk characterization presents the overall results.

\subsection{Residual Plutonium in Soil at Shot Sites}

The tests resulting in Pu dispersal were not always conducted in the same manner. A review (U.S. DOE, 1988) indicates that some device detonations occurred on concrete pads and in concrete bunkers. For example, Double Tracks and Clean Slate I were conducted by detonating one or more warheads on concrete pads, while in Clean Slate II and III warheads were exploded within bunkers. Post-shot cleanup operations also varied among the test series. For the Operation Roller Coaster tests, remediation efforts included the scraping of soils and other debris around the ground-zero (GZ) area to a single location where they were covered with clean soil. Decontamination efforts at the Plutonium Valley sites included the excavation of trenches in which contaminated soils and other test-related materials were buried. In contrast, there were no remediation efforts associated with the Project 57 (Area 13) test.

Systematic efforts to characterize the residual ${ }^{239,240} \mathrm{Pu}$ contamination of soils at the various shot sites were completed under the auspices of the Nevada Applied Ecology Group. The concentrations of $239,240 \mathrm{Pu}$ in soils at the shot sites and estimates of the associated $239,240 \mathrm{Pu}$ inventories are given in Gilbert (1977), but are based in part on earlier work given in Gilbert and Eberhart (1974) and Gilbert et al. (1975). The plutonium content of soils at each of the sites was characterized statistically using a stratified, random sampling approach. In this approach the area to be sampled was subdivided into separate strata or sampling areas in such a way that the variability of plutonium concentrations in soil samples taken from within a given stratum is smaller than the variability of the concentrations in samples taken across strata. Strata were 


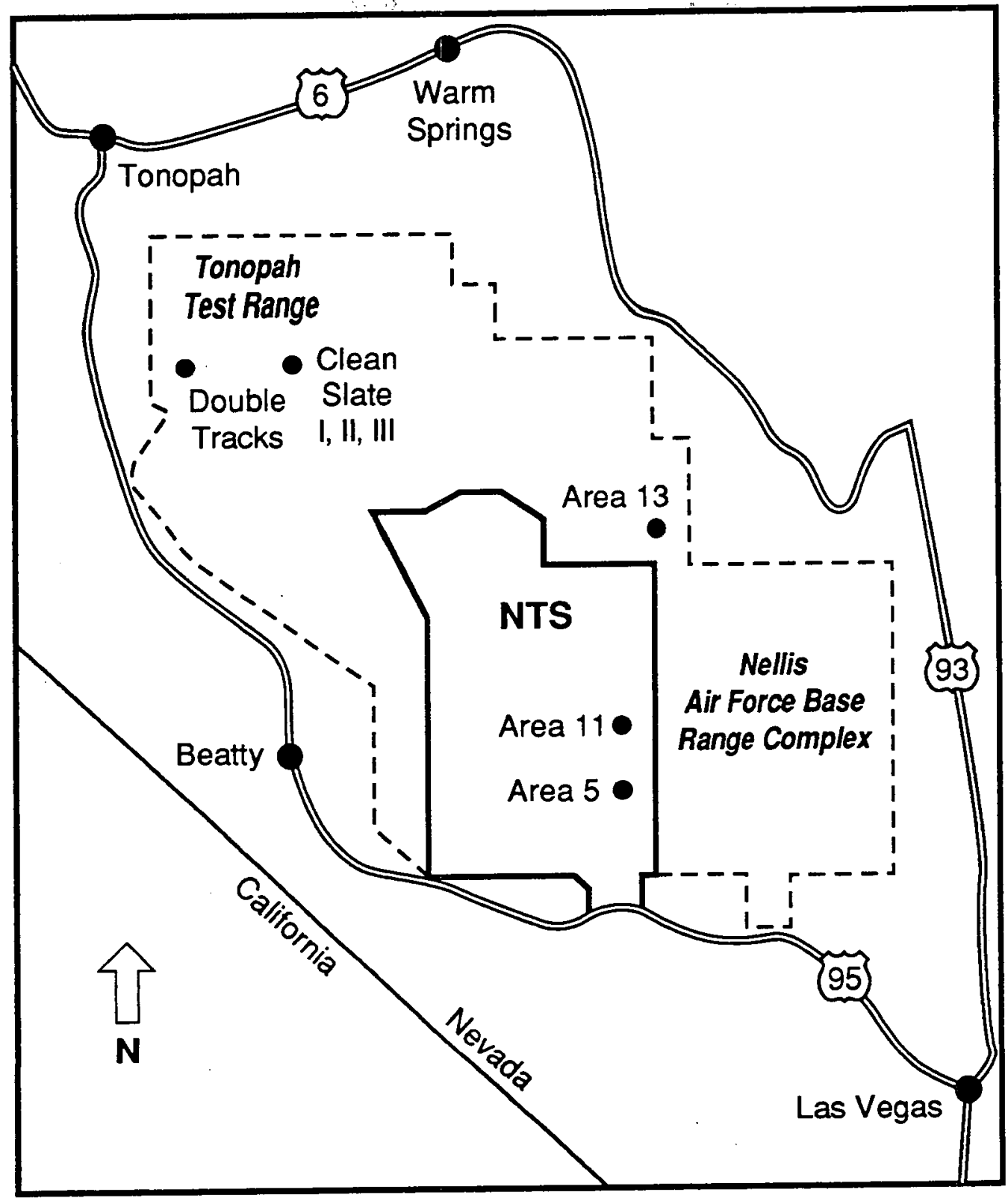

Figure 1. Locations of experiments at the Nevada Test Site and adjoining areas where plutoniumbearing devices were detonated. 
Process

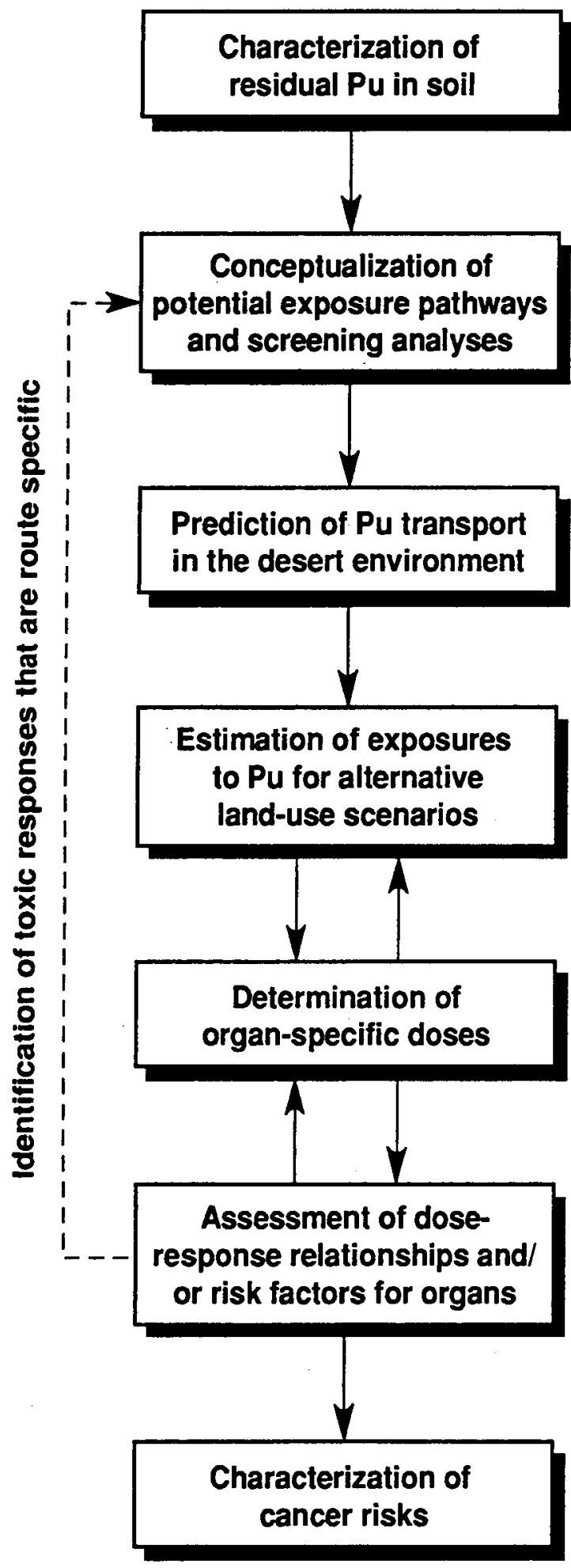

Content

Obtain and analyze data on the concentrations and inventories of $\mathrm{Pu}$ in soil.

Identify potential exposure pathways and conduct screening analyses to identify salient pathways.

Determine the time-dependent concentrations of $\mathrm{Pu}$ in air and soil.

Based on the screening analyses and evaluation of potential land uses, estimate exposures to Pu for alternative scenarios and routes of exposure.

Determine doses to critical organs addressed in the dose-response assessment.

Review pertinent animal studies and epidemiological data to construct dose-response relationships or risk factors for specific organs.

The final step involves the integration of all of the previous steps to estimate potential health risks and associated uncertainties.

Figure 2. Methodology used to assess the risks associated with residual $239,240 \mathrm{pu}$ in solls at the various shot sites. 
defined for each of the shot sites using data obtained from FIDLER (Field Instrument for the Determination of Low-Energy Radiation) surveys. This particular field instrument uses a 5-in. $\mathrm{NaI}$ detector to measure $60-\mathrm{keV}$ gamma emissions from the decay of ${ }^{241} \mathrm{Am}$ (432-y half-life), which is a decay product of $241 \mathrm{Pu}$ (14.4-y half-life). Although most of the plutonium in nuclear weapons occurs as ${ }^{239} \mathrm{Pu},{ }^{241} \mathrm{Pu}$ is also present. As a result, ${ }^{241} \mathrm{Am}$ activities in contaminated soils are expected to provide a reasonable indication of the levels of $239,240 \mathrm{Pu}$ in soils. FIDLER surveys were conducted across uniform grids for all sites, except GMX where measurements were made on a radial grid. Isopleths of gamma activity (counts per minute of $60-\mathrm{keV}$ gamma rays) based on the survey data were then used to designate strata for subsequent soil sampling to determine concentrations of $239,240 \mathrm{Pu}$. Figures 3 through 6 present the isopleths of $241 \mathrm{Am}$ activity and associated strata for the various areas. The sampling locations within the irregular boundaries of each stratum were determined using a stochastic procedure in which the horizontal and vertical distances on a grid over a site were selected randomly to define a sampling coordinate (i.e., the intersection of the two random distances). The number of soil samples in the strata varied depending on the areal extent of the strata and the expected sample variability for a given stratum. However, at least 10 soil samples were taken in each stratum, regardless of its size. Soil samples were taken to a depth of $5 \mathrm{~cm}$ and later 10-gram aliquots of soil were homogenized by ball-milling prior to analysis. Other soil samples were taken to depths of $25 \mathrm{~cm}$ in order to evaluate the distribution of $239,240 \mathrm{Pu}$ concentrations with depth. Gilbert et al. (1975) reported that between 68 and $97 \%$ of the total plutonium in soil to $25 \mathrm{~cm}$ was present in the top 5 $\mathrm{cm}$. Thus, the inventories based on the $5-\mathrm{cm}$ depth may slightly underestimate the total amount of $239,240 \mathrm{Pu}$ present in the near-surface soils. In addition, the estimated inventories exclude an unknown amount of Pu present in the soils and other shot-related debris that were put in trenches or otherwise covered with clean soil during cleanup operations.

Table 1 summarizes the results of the analyses of the inventories of $239,240 \mathrm{Pu}$ in soils at the shot sites. An estimated $5.1 \mathrm{TBq}$ of $239,240 \mathrm{Pu}$ is distributed in the upper $5-\mathrm{cm}$ soils at the sites. The location with the highest inventory is Area 13 (33\% of the total), however, the highest levels of contamination of surface soils occur at Area 11 (Plutonium Valley), where as much as $3070 \mathrm{~Bq} \mathrm{~g}^{-1}$ is present in one of the survey strata. The concentrations of $239,240 \mathrm{Pu}$ in the soils of each of the sites were determined by dividing the estimated inventory for a site by the mass of contaminated soil (based on a density of $1.5 \mathrm{~g} / \mathrm{cm}^{3}$ ). Appendix A contains the strata-specific data on $239,240 \mathrm{Pu}$ at each of the shot sites. In later work, scientists associated with the Radionuclide Inventory and Distribution Program (RIDP), which was designed to characterize the spatial distribution and inventory of selected radionuclides at the NTS, made measurements of ${ }^{241} \mathrm{Am}$ at the GMX and Plutonium Valley sites using in-situ gamma spectrometry (McArthur, 1991). Those measurements were converted to estimates of $239,240 \mathrm{Pu}$ activity in soil and then estimates were made of the $239,240 \mathrm{Pu}$ inventories at those two sites. The resulting RIDP estimates were 0.052 and $1.1 \mathrm{TBq}(1.4$ and $29 \mathrm{Ci})$ for $\mathrm{GMX}$ and Plutonium Valley, compared with the NAEG estimates of 0.056 and $1.3 \mathrm{TBq}(1.5$ and $36 \mathrm{Ci})$, indicating close agreement. 


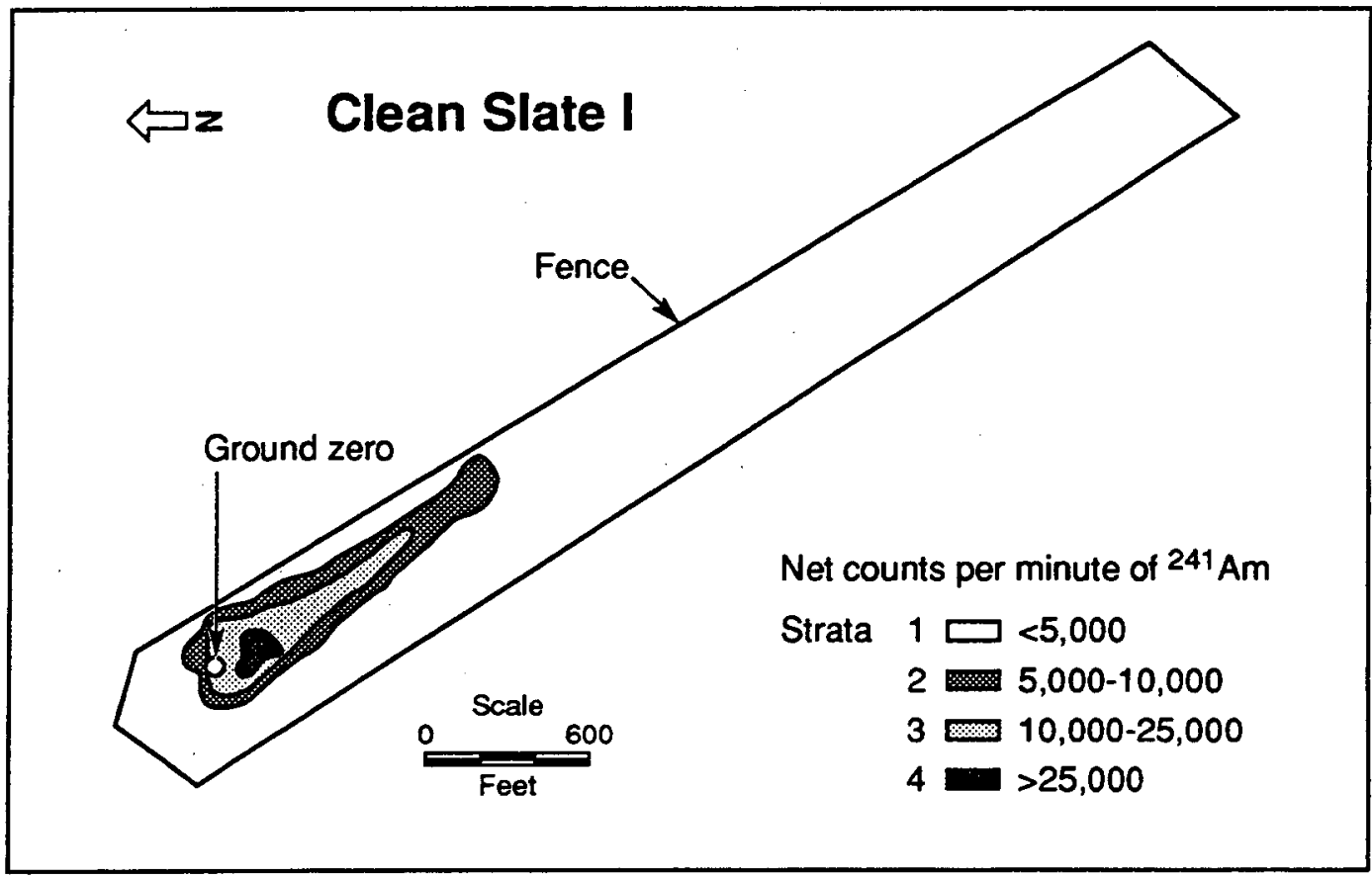

Clean Slate II Net counts per minute of ${ }^{241} \mathrm{Am}$
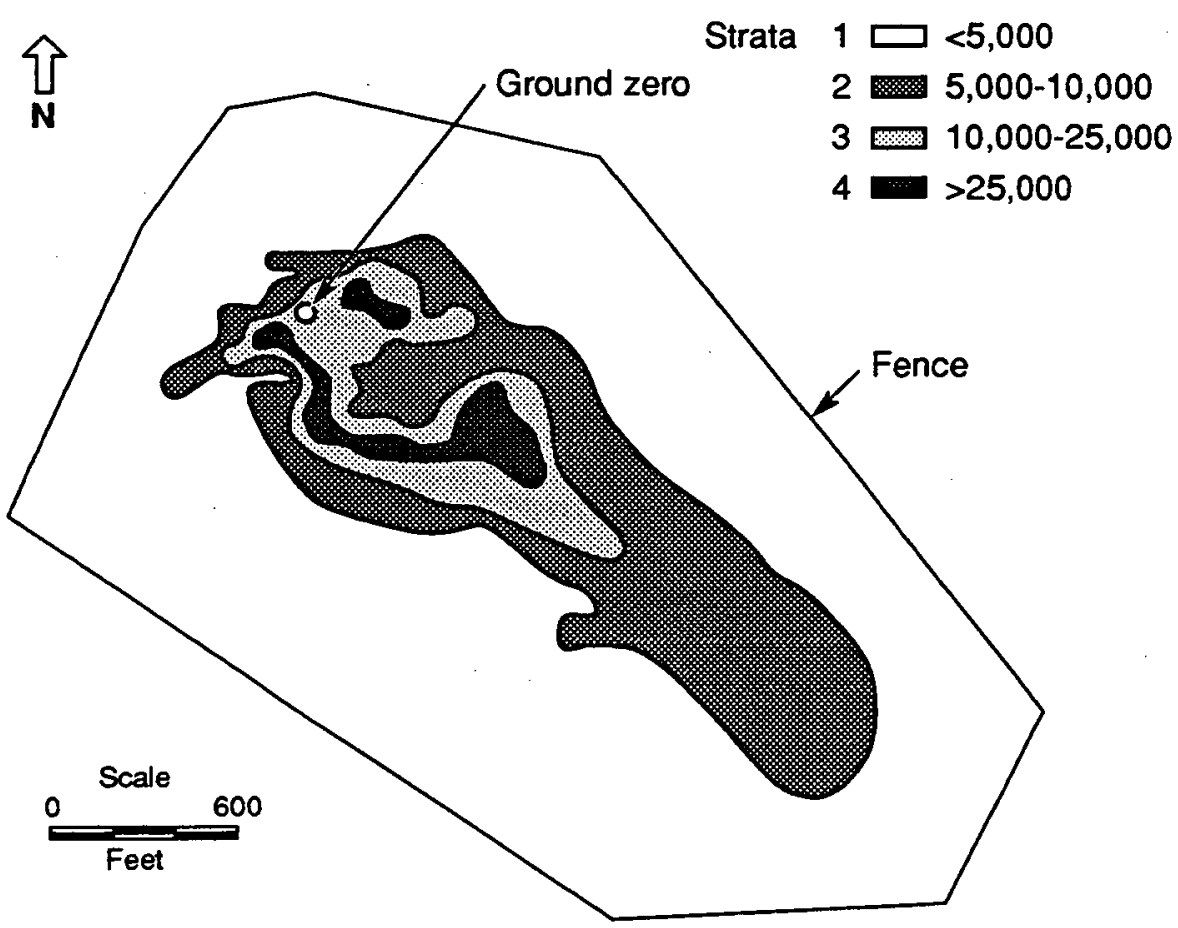

Figure 3. Areal extent of the contamination of 241 Am in soils at Clean Slate I and II. The measured 241 Am is used as a surrogate for $239,240 \mathrm{Pu}$ (adapted from Gilbert et al., 1975). 

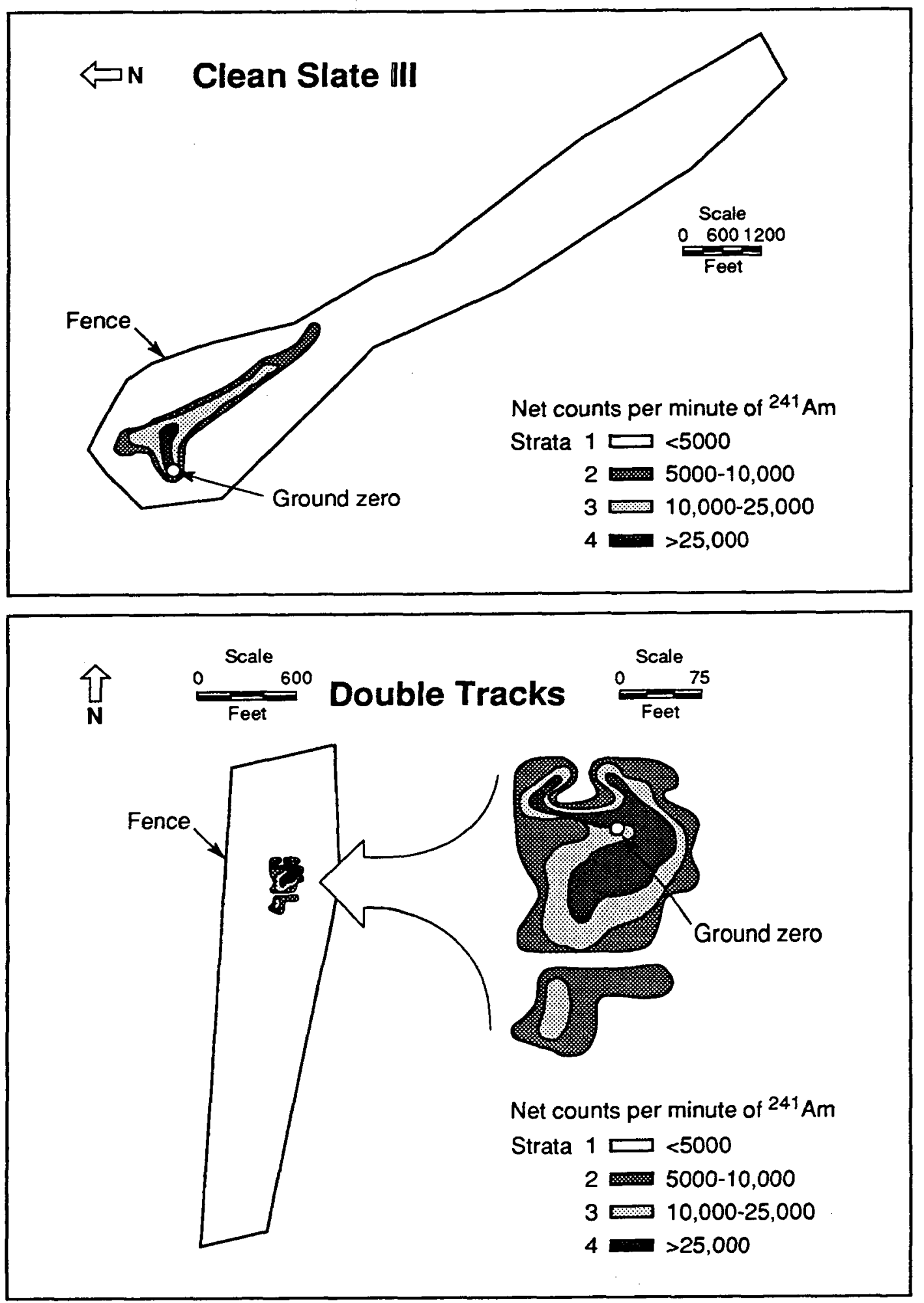

Figure 4. Areal extent of the contamination of ${ }^{241} \mathrm{Am}$ in soils at Clean Slate III and Double Tracks. The measured ${ }^{241} \mathrm{Am}$ is used as a surrogate for ${ }^{239,240} \mathrm{Pu}$ (adapted from Gilbert et al., 1975). 

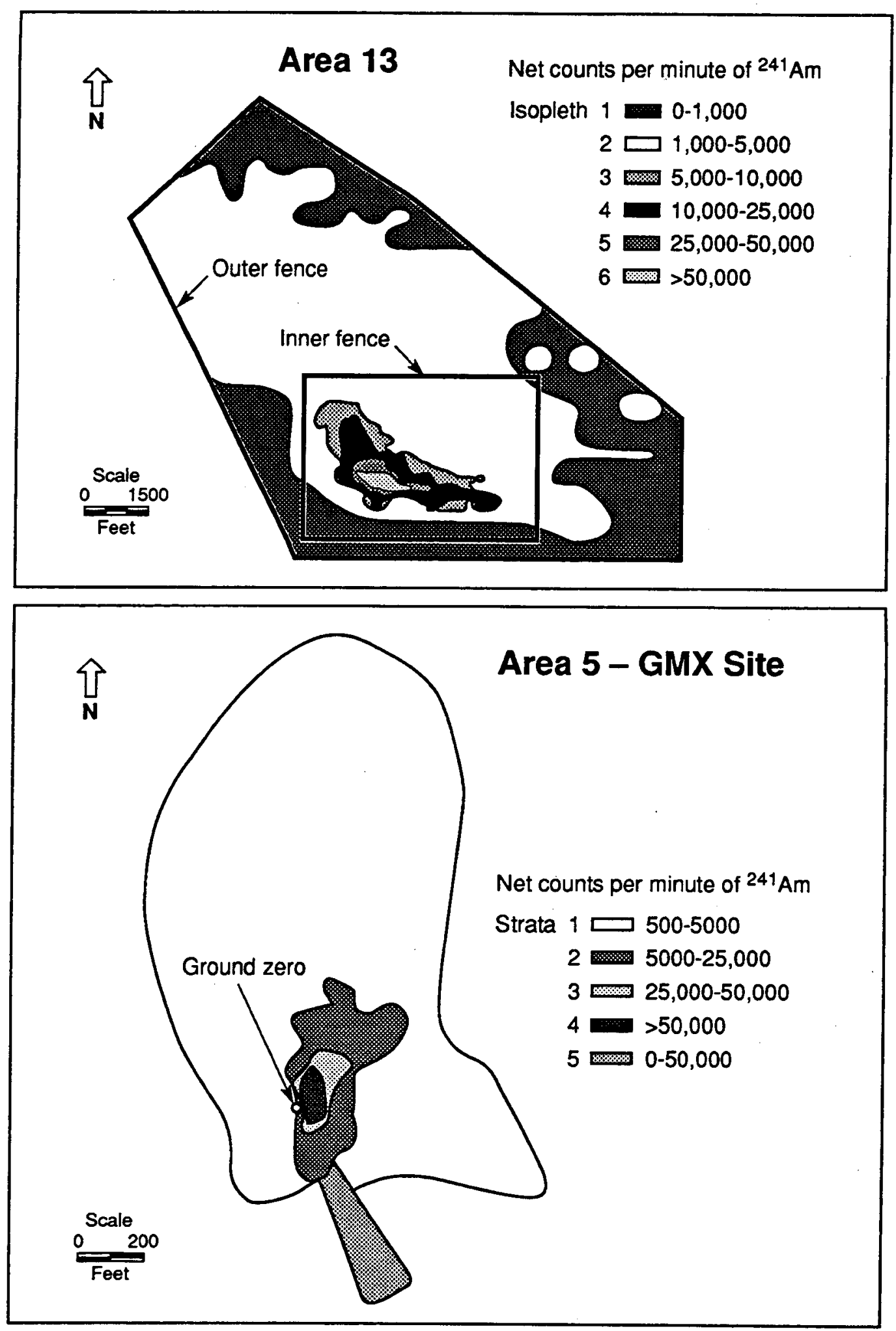

Figure 5. Areal extent of the contamination of ${ }^{241} \mathrm{Am}$ in soils at Area 13 and Area 5 (GMX). The measured ${ }^{241} \mathrm{Am}$ is used as a surrogate for ${ }^{239,240} \mathrm{Pu}$ (adapted from Gilbert et al., 1975). 


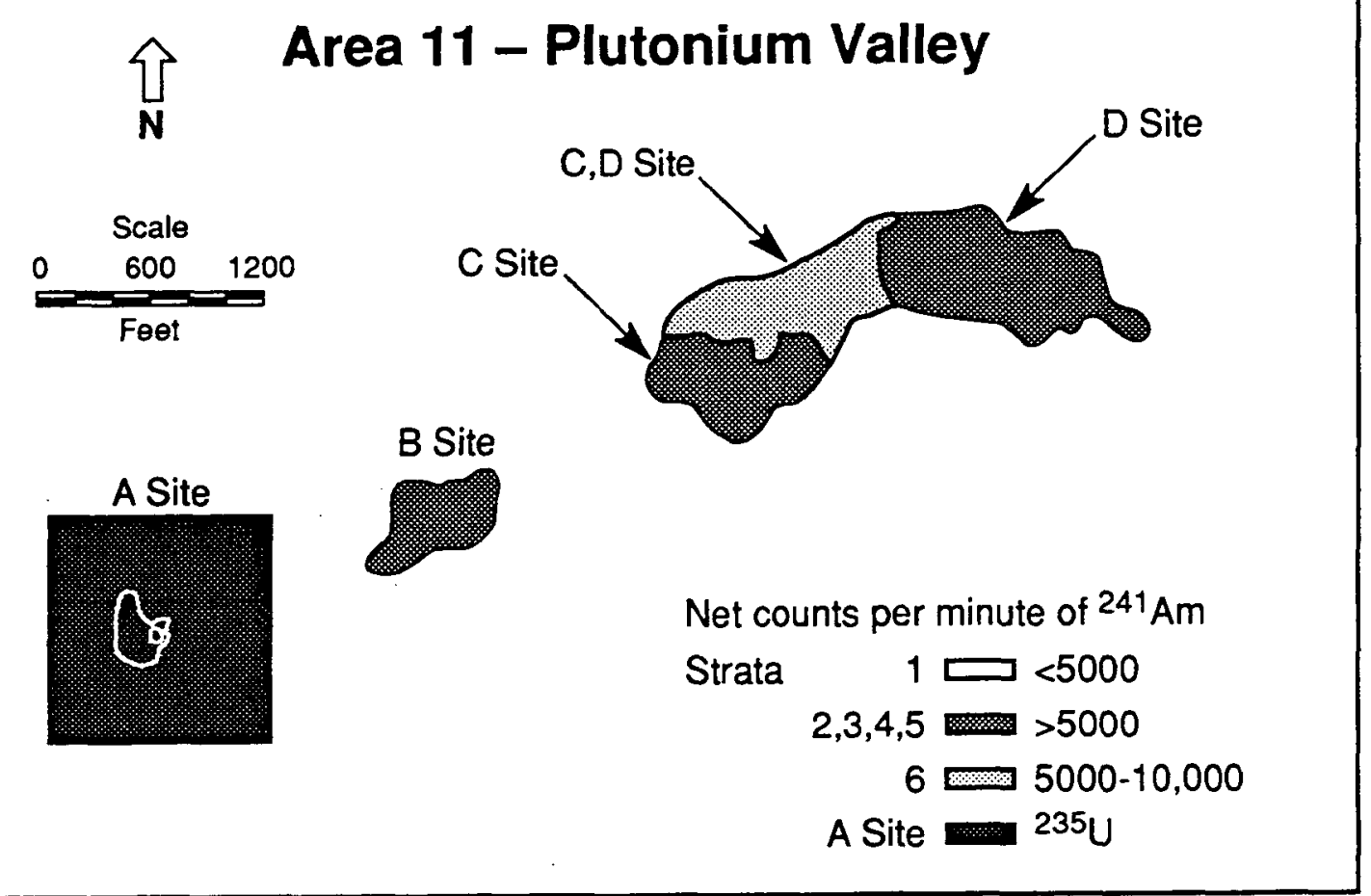

Figure 6. Areal extent of the contamination of ${ }^{241} \mathrm{Am}$ in soils at Area 11 (Plutonium Valley). The measured ${ }^{241} \mathrm{Am}$ is used as a surrogate for ${ }^{239,240} \mathrm{Pu}$ (adapted from Gilbert et al., 1975).

\subsection{Conceptualization of Potential Exposure Pathways and Screening Analyses}

From an exposure-assessment standpoint, one of the most important determinants affecting the nature and magnitude of future contacts with residual contaminants in soils is the type of land use that eventually occurs at a given location. We have identified four plausible land uses for the desert region where the test shots were located: (1) cattle grazing, (2) resident ranching, (3) residential housing, and (4) commercial development. Grazing is currently practiced throughout the Basin and Range province of Nevada and is therefore likely to occur at the NTS as well. The other three land uses are more dependent on the availability of ground water. The resident rancher, for example, would use well water to support beef cattle and dairy cows as well as a family garden. Residential and commercial developments could obtain potable water from one or more wells supplying multiple users.

The conceptualization of the basic exposure pathways that could bring individuals in contact with the $239,240 \mathrm{Pu}$ derived from soils at the shot sites is shown in Figure 7. Exposure pathways include ingestion of garden vegetables, consumption of animal products derived from contaminated soils, soil ingestion, and inhalation of airborne particles. Ingestion and inhalation exposures result in the uptake of $239,240 \mathrm{Pu}$ and subsequent transfer to body organs, which are then irradiated by the emission of alpha particles during the radioactive decay of $239,240 \mathrm{Pu}$. An 
Table 1. Summary of the ${ }^{239,240} \mathrm{Pu}$ inventories at the shot sites and associated concentrations in soil (from Gilbert, 1977).

\begin{tabular}{lcllcc}
\hline \multicolumn{1}{c}{ Site } & \multicolumn{2}{c}{ Inventory } & \multicolumn{3}{c}{ Concentration in soil } \\
& Area ha & TBq & \pm SE & Bq g-1 & \pm SE \\
\hline Area 13 & 400 & 1.7 & 0.33 & 5.6 & 1.1 \\
Area 5 (GMX) & 12 & 0.056 & 0.007 & 5.9 & 0.75 \\
Double Tracks & 18 & 0.13 & 0.035 & 9.9 & 2.6 \\
Clean Slate I & 18 & 0.16 & 0.044 & 12 & 3.3 \\
Clean Slate II & 47 & 0.63 & 0.137 & 18 & 3.9 \\
Clean Slate III & 170 & 1.4 & 0.20 & 10 & 1.5 \\
Area 11 & & & & & \\
B site & 1.8 & 0.23 & 0.041 & 175 & 31 \\
C site & 2.6 & 0.29 & 0.063 & 149 & 32 \\
D site & 5.3 & 0.63 & 0.12 & 158 & 30 \\
C/D Overlap & 6.2 & 0.028 & 0.012 & 6 & 2.5 \\
\hline \hline
\end{tabular}

a The area encompassing the region where there was less than $5,000 \mathrm{cpm}$ of ${ }^{241}$ Am contained an additional $0.17 \mathrm{~Bq}$ of $239,240 \mathrm{Pu}$.

integrated exposure and dose model that addresses the pathways shown in Figure 7 was developed specifically for the NTS by the Nevada Applied Ecology Group (NAEG) (see Martin and Bloom, 1980). Kercher and Anspaugh (1991) have performed subsequently a series of sensitivity and uncertainty analyses of the NAEG model. They found that the inhalation pathway produces the greatest doses to individual organs. For example, inhalation of $239,240 \mathrm{Pu}$ contaminated particles resuspended from soils produced $100 \%$ of the dose to the upperrespiratory tract, lungs, and lymph nodes; and $94.9 \%$ of the dose to the liver, kidneys, and bone. On a whole-body basis, inhalation represented $94.8 \%$ of the total dose and ingestion $5.2 \%$. The principal reason for the difference between the two routes of exposure is the limited uptake of $239,240 \mathrm{Pu}$ across the GI tract. Plutonium in oxide form has a very low solubility, and since only dissolved species are effectively transported across the epithelial lining of the intestines, the biouptake of $\mathrm{Pu}$ is small. After $\mathrm{Pu}$ is deposited in the lungs, though, it is slowly translocated to other systemic organs, resulting in higher organ doses than for ingestion exposures.

The analyses that Kercher and Anspaugh performed of the sensitivity of organ doses (i.e., lung, liver, bone, and kidney) to changes in model parameters indicated that doses were most sensitive to changes in the concentration of $239,240 \mathrm{Pu}$ in soil, the mass-loading factor used to estimate the resuspension of $239,240 \mathrm{Pu}$ from soil to air, the respiration rate, and dose factors that convert the activity in an organ to the amount of energy deposited. Other less important parameters dealt mainly with biophysical factors such as the fraction of particles deposited in the lungs, clearance rates, and mass of target organs. These screening-level analyses indicate that the inhalation pathway should be the primary focus of the risk assessment for $239,240 \mathrm{Pu}$ in soils at the NTS. Consequently, our reference land-use scenarios will only consist of residential (suburban) housing, resident farming, and commercial development; cattle grazing is excluded on the basis that the ingestion of $239,240 \mathrm{Pu}$-contaminated meat products would not constitute a significant radiological health risk. 


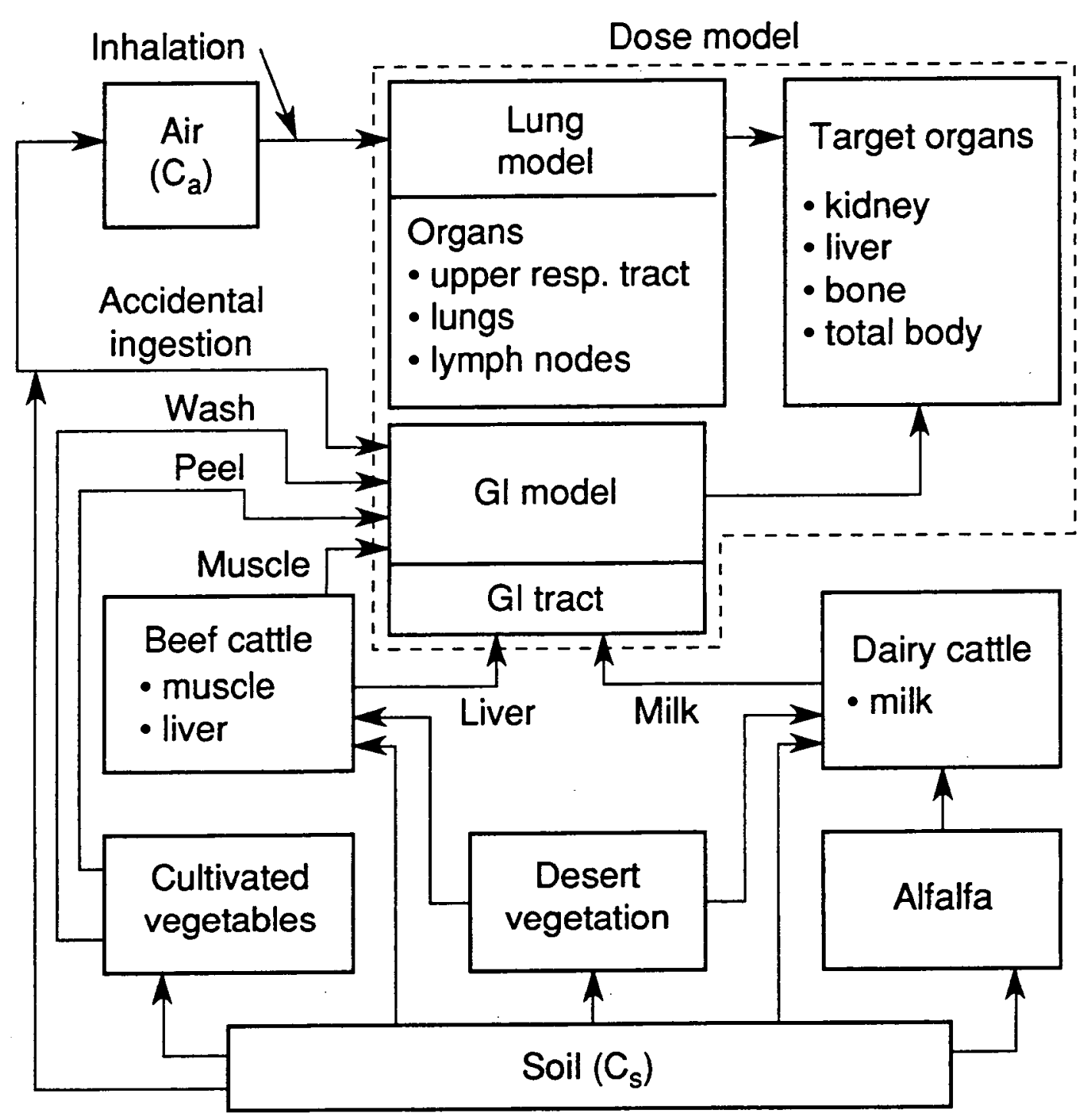

Figure 7. Conceptual diagram of the exposure pathways for ingesting and inhaling $239,240 \mathrm{Pu}$ in the desert environment of the NTS (adapted from Kercher and Anspaugh, 1991). 


\subsection{Transport Processes for Plutonium at Shot Sites}

In order to estimate potential inhalation exposures to residual $239,240 \mathrm{Pu}$ at the shot sites, we must determine the concentrations of $\mathrm{Pu}$ in both indoor and outdoor air. People spend routinely more than $90 \%$ of their time indoors, and hence differences between the concentrations of $239,240 \mathrm{Pu}$ in indoor and outdoor air will affect directly estimated inhalation exposures. While outdoors an individual can inhale soil particles containing ${ }^{239,240} \mathrm{Pu}$ that have been resuspended into air by wind action. Plutonium-contaminated soil can reach the indoor environment via three principal mechanisms: (1) infiltration of airborne soil particles through the shell of a house, (2) inflow with makeup air drawn into a building by a ventilation system, and (3) tracking of contaminated soil onto floors, followed by resuspension into indoor air by human activities. Suspended particles in indoor air can be removed by filters that are part of air-handling systems in homes and commercial establishments. In the following subsections we estimate concentrations of $239,240 \mathrm{Pu}$ in outdoor air at the shot sites and then determine the levels indoors for the buildings associated with the residential, farm, and commercial exposure scenarios.

\subsubsection{Concentrations of $\mathbf{P u}$ in Surficial Soils and Outdoor Air}

The primary loss mechanism of $239,240 \mathrm{Pu}$ in surficial soils in the dry environs of the NTS is aeolian erosion. In locations where there are no human activities such as vehicular traffic over unpaved roads, excavation activities, etc., the suspension of soil particles is caused by the movement of wind over the land surface. Most of the early work on this transport mechanism for soil contaminants focused on the resuspension of radioactive substances deposited onto surface soils after nuclear testing. There are many environmental and contaminant-specific factors that affect the transfer of a soil contaminant from soil to air, and the complex nature of this transfer process has made it difficult to develop analytical approaches that provide accurate predictions of resuspension (see Nicholson, 1988; Sehmel, 1980; and Smith et al., 1982; for reviews of resuspension models). As an alternative, empirical approaches have been developed to estimate the average concentration of a soil contaminant in air. One commonly used method involves the calculation of a resuspension factor, which is the ratio of a contaminant's concentration in air to its concentration in soil expressed on an area basis (e.g., Bq or $\mu \mathrm{g} \mathrm{m}^{-3} \div \mathrm{Bq}$ or $\mu \mathrm{g} \mathrm{m}^{-2}$ ). The resuspension factor (denoted $S_{f}$ ) for a substance initially introduced to a surficial soil as a result of atmospheric deposition or aerial application decreases with time as the material undergoes various weathering processes. Anspaugh et al. (1975) proposed this time-dependent relationship for the resuspension factor

$$
S_{f}(t)=10^{-4} \times \exp (-0.15 \sqrt{t}) \mathrm{m}^{-1}+10^{-9} \mathrm{~m}^{-1} \text {, }
$$

where $t$ is time in days since initial addition to soil. This relationship was based on data from several sites measured at various times post deposition. The first term in Eq. 1 dominates during the early years following a contaminating event to reflect weathering processes, but diminishes with time to the second term, which Anspaugh et al. set equal to the resuspension factor determined for the GMX site at the end of a 17-year period. However, subsequent resuspension studies conducted by Shinn et al. (1986) in the early 1980s showed that the resuspension factor for contaminated soils at the GMX site had continued to decline to $2.0 \times 10^{-10} \mathrm{~m}^{-1}$. They also 
reported that the more erodable soils in Plutonium Valley had a resuspension factor of $6.1 \times 10^{-10} \mathrm{~m}^{-1}$.

An alternative approach for estimating the amount of a surface contaminant in air is termed the mass-loading method. With this method, the concentration of a soil contaminant in air is calculated as the product of the contaminant's concentration in soil and the mass loading of total suspended particles in air, or

$$
\mathrm{C}_{\mathrm{a}}=\mathrm{C}_{\mathrm{s}} \times \mathrm{TSP},
$$

where $\mathrm{C}_{\mathrm{a}}$ is the concentration in air ( $\mathrm{Bq}$ or $\left.\mu \mathrm{g} \mathrm{m}^{-3}\right), \mathrm{C}_{\mathrm{s}}$ is the concentration in soil $\left(\mathrm{Bq}\right.$ or $\left.\mu \mathrm{g} \mathrm{g}^{-1}\right)$, and TSP refers to the concentration of particles in the atmosphere $\left(\mathrm{g} \mathrm{m}^{-3}\right)$. Note that the value of $\mathrm{C}_{\mathrm{a}}$ for a contaminant in particulate form can be computed as the product of its concentration in suspended particles (denoted as $C_{p}$ ) and the mass loading of particles in the atmosphere. Anspaugh et al. (1974) found that there was good agreement between measured concentrations of several airborne radionuclides at four sites in the U.S. and concentrations predicted from the mass-loading method, based on measured values of $\mathrm{C}_{\mathrm{S}}$ at the sites and an assumed concentration of suspended particles of $100 \mu \mathrm{g} \mathrm{m}^{-3}$. An important premise of the mass-loading method is that the ratio of $C_{p}$ to $C_{s}$ is one. However, this is unlikely to be the case in all instances because the relationship between the concentrations of a contaminant in the different particle-size fractions of air and suspendable soil undoubtedly change from site-to-site, depending on the characteristics of indigenous soils, the physicochemical properties of the contaminant and host soils, ground cover, and climate. An alternative formulation is to calculate $C_{a}$ as the product of $C_{s}$; TSP, and an enhancement factor (EF), that is,

$$
\mathrm{C}_{\mathrm{a}}=\mathrm{C}_{\mathrm{s}} \times \mathrm{TSP} \times \mathrm{EF}
$$

Since $C_{a}$ is equal to $C_{p} \times T S P$, the enhancement factor is then simply the ratio of the concentrations of a contaminant in suspended particles and in soil. Shinn et al. (1986) reported that the enhancement factors for $\mathrm{Pu}$ aerosols at the GMX site and Plutonium Valley were 0.87 and 1.04 , respectively, while the mass loadings of particles were $1.7 \times 10^{-5}$ and $4.1 \times 10^{-5} \mathrm{~g} \mathrm{~m}^{-3}$. These measurements indicate that the enhancement factor is almost unity for the two sites.

Neither the resuspension-factor nor the mass-loading approach for estimating resuspension accounts directly for the wind-induced removal of a soil contaminant at a given site. This loss is estimated by a resuspension rate or the fraction of contaminant activity or mass that is lost per unit time. It is equal to the net emission rate from soil (i.e., mass or activity emitted per unit area and time) divided by the concentration of contaminant on an areal basis (i.e., mass or activity per unit area). This parameter is estimated indirectly using site-specific data on the changes of contaminant concentration with height above the ground surface, wind speed, and friction velocity (Anspaugh et al., 1975). Shinn et al. $(1986,1989)$ estimated a resuspension rate of $3.9 \times 10^{-11} \mathrm{~s}^{-1}$ for $239,240 \mathrm{Pu}$ in undisturbed soils in Plutonium Valley and $7.9 \times 10^{-13} \mathrm{~s}^{-1}$ for soils at GMX. In earlier experimental work at the GMX site, Anspaugh et al. (1976) calculated resuspension rates for $239,240 \mathrm{Pu}$ ranging from $2.7 \times 10^{-12}$ to $4.8 \times 10^{-10} \mathrm{~s}^{-1}$. As a comparison, Hartmann et al. (1989) reported a resuspension rate of $9 \times 10^{-11} \mathrm{~s}^{-1}$ for pre-Chernobyl $239,240 \mathrm{Pu}$ 
at rural sites in Germany, using a contamination depth of $1 \mathrm{~cm}$. Their rate would actually be lower, though, if a $5-\mathrm{cm}$ depth was used to represent the amount of $239,240 \mathrm{Pu}$ available for resuspension. Collectively, these studies indicate that the resuspension rates for the NTS shot sites probably range between $10^{-12}$ to $10^{-11} \mathrm{~s}^{-1}\left(3.15 \times 10^{-5}\right.$ to $\left.3.15 \times 10^{-4} \mathrm{y}^{-1}\right)$.

The time-dependent change in the concentration of $239,240 \mathrm{Pu}$ in soil resulting from resuspension and radioactive decay can be estimated from the initial concentration in soil as

$$
\mathrm{C}_{S}(t)=\mathrm{C}_{\mathrm{S}}(0) \exp \left[-\left(\lambda_{\mathrm{d}}+\lambda_{\mathrm{r}}\right) t\right]
$$

where $t$ is in years, $\lambda_{\mathrm{d}}$ and $\lambda_{\mathrm{I}}$ are the rate constants for radioactive decay and resuspension (both rate constants in $y^{-1}$ ). If we use a resuspension rate of $5.5 \times 10^{-12} \mathrm{~s}^{-1}$ (or $1.7 \times 10^{-4} \mathrm{y}^{-1}$ )(the mean of the limiting values $10^{-12}$ to $10^{-11} \mathrm{~s}^{-1}$ ) to represent the net loss of $239,240 \mathrm{Pu}$ from surface soils at the shot sites, the environmental half-life of $239,240 \mathrm{Pu}$ is $4000 \mathrm{y}$, or about $17 \%$ of the halflife due to radioactive decay alone.

The value of $C_{a}$ can be calculated as a function of time from $C_{s}$ using either the mass-loading or resuspension-factor approaches. With the mass-loading method the time-dependent concentration of $239,240 \mathrm{Pu}$ in air becomes

$$
\mathrm{C}_{\mathrm{a}}(t)=\mathrm{C}_{\mathrm{S}}(0) \exp \left[-\left(\lambda_{\mathrm{d}}+\lambda_{\mathrm{r}}\right) t\right] \times \mathrm{TSP} \times \mathrm{EH}
$$

and using a resuspension factor, it is

$$
\mathrm{C}_{\mathrm{a}}(t)=\mathrm{C}_{\mathrm{S}}(0) \exp \left[-\left(\lambda_{\mathrm{d}}+\lambda_{\mathrm{r}}\right) t\right] \times \eta \times \mathrm{S}_{\mathrm{f}}
$$

where $\eta$ is a factor that converts the concentration of $\mathrm{Pu}$ in soil on a mass basis to an areal basis, as a function of soil density and depth of contamination. With $\mathrm{C}_{\mathrm{s}}$ equal to $1 \mathrm{~Bq} \mathrm{~g}^{-1}$, the value of $\mathrm{C}_{\mathrm{a}}$ is $3 \times 10^{-5} \mathrm{~Bq} \mathrm{~m} \mathrm{~m}^{-3}$, assuming that the particulate mass loading at the shot sites is approximately $3 \times 10^{-5} \mathrm{~g} \mathrm{~m}^{-3}$ (the average of the two values reported in Shinn et al., 1986) and the enhancement factor is one. For a nominal soil density of $1.5 \mathrm{~g} \mathrm{~cm}^{-3}$ and a contamination depth of $5 \mathrm{~cm}$, the value of $\eta$ is $7.5 \times 10^{4} \mathrm{~g} \mathrm{~m}^{-2}$. By setting Eq. 5 equal to Eq. $6, \mathrm{~S}_{\mathrm{f}}$ can then be calculated as $($ TSP $\times E F) / \eta$. With TSP and EH values noted above, $S_{f}$ equals $4 \times 10^{-10} \mathrm{~m}^{-1}$, a result that is comparable to the resuspension factors reported above.

To quantify the uncertainties in the estimates of $\mathrm{C}_{\mathrm{a}}$ at the different shot sites, we will propagate the uncertainties associated with the individual parameters in Eq. 5, using a MonteCarlo technique (Crystal Ball, v. 2, Market Engineering Corp., 1991). The means and standard errors of the $C_{S}$ values for the shot sites are represented in Table 1. To avoid the generation of negative concentration values from the Monte-Carlo sampling of the normal distributions for $\mathrm{C}_{\boldsymbol{S}}$, we converted the mean and standard errors to their lognormal equivalents (i.e., geometric mean and geometric standard error) using the equations given in $\mathrm{Ng}$ et al. (1990). Resuspension rates are characterized using a triangular distribution with minimum and maximum values of $3.15 \times 10^{-5}$ to $3.15 \times 10^{-4} \mathrm{y}^{-1}$ (encompassing the range of resuspension rates discussed earlier) and with a mode at $1.7 \times 10^{-4} \mathrm{y}^{-1}$. We were only able to obtain two measurements of TSP at the NTS (see earlier discussion), and so we completed a statistical analysis of TSP levels in 20 rural 
locations in the U.S. reported by Shah et al. (1986) as a way of characterizing the variability in the particulate mass loadings at the shot locations. The geometric mean of the TSP data was $2.8 \times 10^{-5} \mathrm{~g} \mathrm{~m}^{-3}$ with a GSD of 1.6. The value of $\mathrm{EH}$ is set at 1 , based on the experimental studies noted above.

Since $239,240 \mathrm{Pu}$ at the shot sites could pose a radiological health hazard for thousands of years if not remediated, we computed values of $\mathrm{C}_{\mathrm{s}}$ for time periods of $100,10,000,50,000$, and $100,000 \mathrm{y}$ to cover the period of time when residual $239,240 \mathrm{Pu}$ in soils are likely to constitute a health hazard. At 100 y the 5, 50, and $95 \%$ cumulative percentile values of $C_{S}$ at Area 13 are 5.0, 5.4, and 5.7 $\mathrm{Bq} \mathrm{g}^{-1}$, respectively, based on 10,000 random samples (using the Latin hypercube sampling option) of the distributions for $C_{S}$ and $\lambda_{r}$. However, at $100,000 \mathrm{y}$ the percentile values are $1.8 \times 10^{-6}, 1.8 \times 10^{-5}$, and $1.5 \times 10^{-4} \mathrm{~Bq} \mathrm{~g}^{-1}$. These results indicate that as $t$ increases, the variation in $C_{s}$ becomes dominated by the variation in $\lambda_{r}$.

\subsubsection{Concentrations of $\mathrm{Pu}$ in Indoor Air}

The concentrations of certain airborne contaminants indoors will be less than those outdoors, but for others the concentrations indoors may be higher. A primary contributing factor is the source of each specific contaminant. For those contaminants whose primary source is outdoors, as would generally be the case for $\mathrm{Pu}$, the concentration indoors will generally be less than that outdoors. This is due, among other things, to the filtering effect of building shells (see Engelmann, 1992). To determine the levels of $239,240 \mathrm{Pu}$ in the indoor environment of a house (suburban residence and farmhouse) and a commercial facility as a function of the contamination of soil and outdoor air, we have implemented two simple compartmental models that predict the steady-state concentrations of $239,240 \mathrm{Pu}$ in the indoor air. As shown in Figure 8a, the transport processes for a house include the infiltration of contaminated outdoor air, exfiltration of building air, resuspension of tracked-in soil particles from floors to indoor air, the gravitational settling of airborne particles to floors, and the filtration of particles by a heating/cooling system. For a commercial facility (Figure $8 \mathrm{~b}$ ) with an air-handling system that exerts a positive air pressure indoors, there is no significant infiltration of outdoor air (and associated airborne particles). Instead, outdoor air is continuously introduced to the air-handling system and exhausted from the building. The concentration of $239,240 \mathrm{Pu}$ in the indoor air of a house under steady-state conditions (and with no internal sources of $239,240 \mathrm{Pu}$ other than resuspension) can be estimated from

$$
C_{\text {in }}=\frac{L_{f l} A_{f l} f_{a} R+A c h C_{a} P V}{\left(A_{f l} v_{g}+A c h V+Q_{r} f_{o n} E_{f}\right)}
$$

where

$$
L_{f l}=f_{o} M_{f 1} C_{s}
$$

and

$$
\mathrm{C}_{\mathrm{in}}=\text { concentration of } 239,240 \mathrm{Pu} \text { in indoor air, } \mathrm{Bq} \mathrm{m}^{-3} \text {; }
$$




$$
\begin{aligned}
& \mathrm{L}_{\mathrm{fl}}=\text { loading of } 239,240 \mathrm{Pu} \text { on floor surfaces, } \mathrm{Bq} \mathrm{m} \mathrm{m}^{-2} \text {; } \\
& f_{0}=\text { fraction of indoor floor dust derived from outdoor soil, unitless; } \\
& \mathrm{M}_{\mathrm{fl}}=\text { mass loading of particulate matter on floors, } \mathrm{g} \mathrm{m}^{-2} \text {; } \\
& \mathrm{C}_{\mathrm{s}}=\text { concentration of } 239,240 \mathrm{Pu} \text { in soil, } \mathrm{Bq} \mathrm{g^{-1 }} \text {; } \\
& A_{\mathrm{fl}}=\text { surface area of floors, } \mathrm{m}^{2} \text {; } \\
& f_{a}=\text { fraction of floor surface that is accessible for walking, playing, etc., unitless; } \\
& \mathrm{R}=\text { resuspension rate from floors, } \mathrm{h}^{-1} \text {; } \\
& \text { Ach }=\text { air-exchange rate, } \mathrm{h}^{-1} \text {; } \\
& \mathrm{C}_{\mathrm{a}}=\text { concentration of } 239,240 \mathrm{Pu} \text { in outdoor air, } \mathrm{Bq} \mathrm{m}^{-3} \text {; } \\
& \mathrm{P}=\text { fraction of outdoor } 239,240 \mathrm{Pu} \text { particles that infiltrate the building shell to indoor air, } \\
& \text { unitless; } \\
& \mathrm{v}_{\mathrm{g}}=\text { gravitational settling velocity, } \mathrm{m} \mathrm{h}^{-1} \text {; } \\
& \mathrm{V}=\text { volume of house (i.e., } \mathrm{A}_{\mathrm{fl}} \text { times the ceiling height, } \mathrm{h} \text { ), } \mathrm{m}^{3} \text {; } \\
& E_{\mathrm{f}}=\text { removal efficiency for particles, unitless; } \\
& \mathrm{Q}_{\mathrm{r}}=\text { recirculation rate of air through heat/cooling unit, } \mathrm{m}^{3} \mathrm{~h}^{-1} \text {; and } \\
& f_{\text {on }}=\text { fraction of a year that a heating/cooling unit is operating, unitless. }
\end{aligned}
$$

For a commercial facility the steady-state estimate of $C_{i n}$ is (based on Weschler et al., 1983; Sinclair et al., 1992):

$$
C_{i n}=\frac{L_{f l} A_{f l} f_{a} R+Q_{r}\left(1-E_{f}\right) f_{m} C_{a}}{\left(A_{f l} v_{g}+Q_{r} E_{f}\left(1-f_{m}\right)+Q_{r} f_{m}\right)}
$$

where

$$
\begin{aligned}
& \mathrm{f}_{\mathrm{m}}=\text { fraction of the air recirculation rate that is } \\
& \text { derived from outdoor air, unitless. }
\end{aligned}
$$

Because $L_{f l}$ and $C_{a}$ are both functions of $C_{s}$, Equations 7 and 9 can also be expressed as the ratios of $C_{i n} / C_{s}$ (in units of $g^{-3}$ ), or

$$
\frac{C_{\text {in }}}{C_{s}}=\frac{f_{o} M_{f l} A_{f l} f_{a} R+A c h \text { TSP EH P V }}{\left(A_{f l} v_{g}+A c h V+Q_{r} f_{o n} E_{f}\right)} \text { (for both suburban and farm houses) }
$$

and 

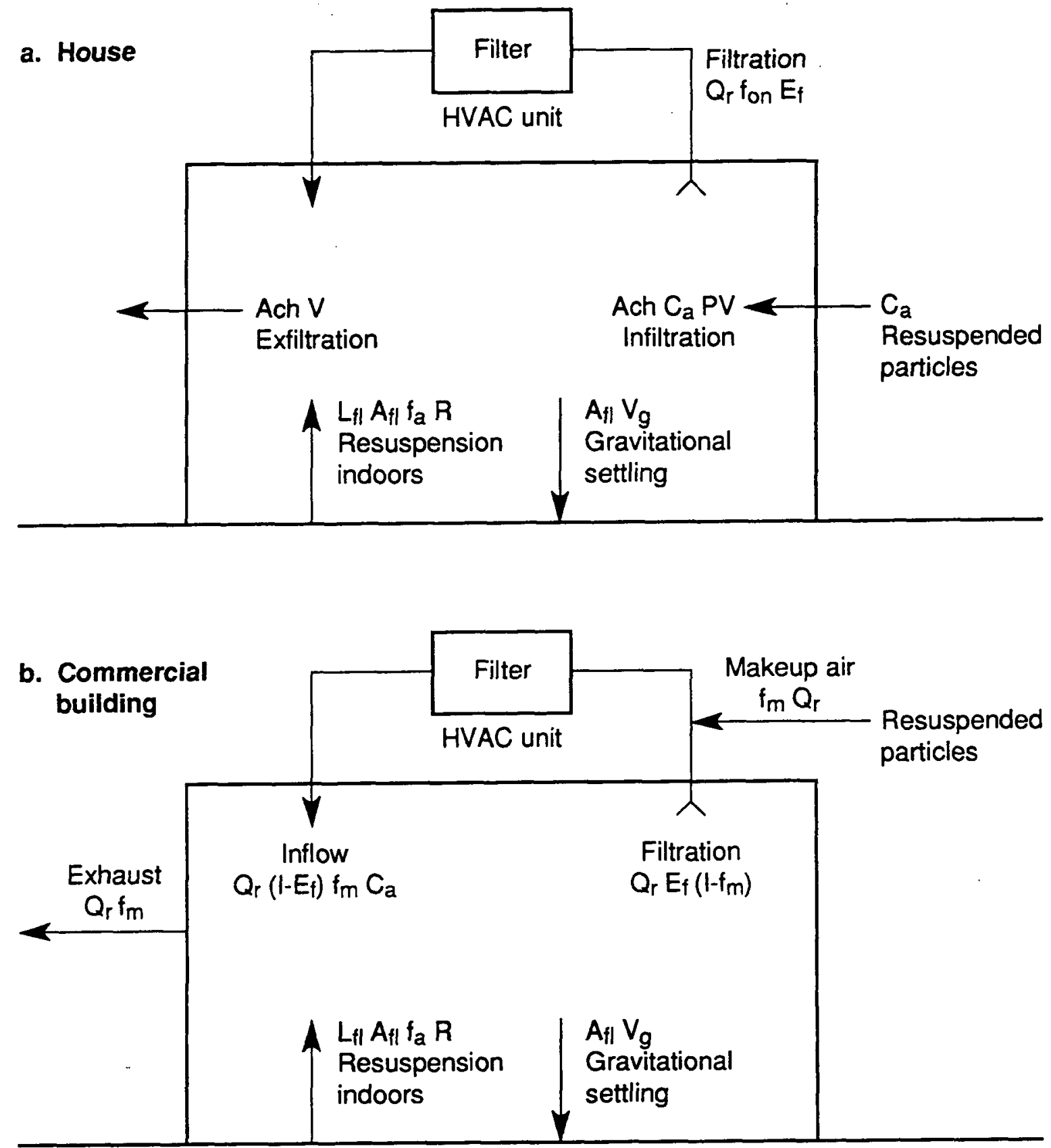

Figure 8. Transport of soil-derived particles in the indoor environment: (a) house with particle filtration in a heating/cooling unit, and (b) a commercial facility with constant filtration of recirculating air. Unlike the house shown in (a), the farm house is assumed to utilize a space heater for heating and so suspended particles are not removed by filtration. 


$$
\frac{C_{\text {in }}}{C_{S}}=\frac{f_{o} M_{f l} A_{f f} f_{a} R+Q_{r}\left(1-E_{f}\right) f_{m} T S P E H}{\left(A_{f l} v_{g}+Q_{r} E_{f}\left(1-f_{m}\right)+Q_{r} f_{m}\right)} \quad \text { (for a commercial facility). }
$$

The model parameters can be broken down into two basic groups, one dealing with movement of particles and the other building properties. Particulate-related parameters include the mass loading of soils/dust on floors, the resuspension rate, the settling rate of particles, and the penetration factor. Building properties include the surface area of floors, the air-exchange rate, building volume, the air-recirculation rate, and the particle-removal efficiency of filters in the air-handling system. Many of these parameters are best characterized as statistical distributions, while others can be considered as constants for the purposes of the exposure assessment. In the following discussion we describe the parameter distributions and values for the residential, farm, and commercial buildings.

The loading of $239,240 \mathrm{Pu}$ on floors $\left(\mathrm{L}_{\mathrm{fl}}\right)$ can be estimated as the product of the concentration of $239,240 \mathrm{Pu}$ in tracked-in soil, the fraction of indoor dust that is derived from outdoor soil, and the loading of soil/dust on floors. Fergusson et al. (1986) estimated that between 45 to $50 \%$ of the dust in a house is derived from soil, based on analyses they completed of the elemental compositions of soil and house dust. More recently, Calabrese and Stanek (1992) calculated that $31 \%$ of the dust indoors had an outdoor origin, and Allott et al. (1992) reported that concentrations of ${ }^{137} \mathrm{Cs}$ in indoor floor dust were between 18 and $48 \%$ of the ${ }^{137} \mathrm{Cs}$ concentrations in outdoor soil. Based on these literature values, we have adopted a uniform distribution between 0.2 and 0.5 (a range that encompasses the literature values) to represent the random values of $f_{o}$ for the three types of buildings. The loadings of soil/dust on floors reported in the literature vary from 0.136 to $0.870 \mathrm{~g} \mathrm{~m}^{-2}$ (see Appendix A). The geometric mean of the mass loadings is $0.42 \mathrm{~g} \mathrm{~m}^{-2}$ with a geometric standard deviation of 1.88 . The resuspension rate of particles from floors to indoor air depends largely on human activities, such as walking, playing, etc., that result in the mechanical disturbance of floor surfaces. Healy (1971) estimated a resuspension rate indoors of $5 \times 10^{-4} \mathrm{~h}^{-1}$, using a mix of vigorous, active, moderate, and quiet domestic activities. Murphy and Yocom (1986), in an analysis of the migration of particles into the indoor environment, concluded that the resuspension rate in houses was about $10^{-4} \mathrm{~h}^{-1}$. We will use a uniform distribution between $10^{-4}$ and $10^{-3}$ to reflect a range of human activities that resuspend particles from floor surfaces.

Removal of a particulate contaminant by gravitational settling onto floor surfaces is governed by its concentration in air and the average settling velocity of the contaminated particles. The deposition of fine particles onto wall and ceiling surfaces due to diffusion and other mechanisms is estimated using a deposition velocity. Settling/deposition velocities for fine (i.e., $<2.5 \mu \mathrm{m}$ ) to coarse $(2.5$ to $15 \mu \mathrm{m})$ particles suspended in indoor air range from about 0.18 to $25 \mathrm{~m} \mathrm{~h}^{-1}$ (i.e., 0.005 to $0.7 \mathrm{~cm} \mathrm{~s}^{-1}$ ) (Sinclair et al., 1992). Diemel et al. (1981) made concurrent measurements of airborne lead in homes and the rate of mass accumulation on horizontal collection plates, and from their data we estimate a settling velocity of lead of $1.2 \mathrm{~m} \mathrm{~h}^{-1}$, which is an intermediate value for fine and coarse particles. In contrast, we estimated that the average settling velocity for dust particles in that study was $2.7 \mathrm{~m} \mathrm{~h}^{-1}$. Raunemaa et al. (1989) reported a deposition velocity of $9.2 \mathrm{~m} \mathrm{~h}^{-1}$ for total coarse particles indoors and $4.9 \mathrm{~m} \mathrm{~h}^{-1}$ for total fine particles. Deposition velocities for individual elements can differ greatly. For the crustal element potassium, Raunemaa et al. reported deposition velocities of 15 and $8.8 \mathrm{~m} \mathrm{~h}^{-1}$ for coarse and fine particles, 
respectively. They estimated that the average mass-median aerodynamic diameters (MMAD) for all deposited particles was $5 \mu \mathrm{m}$. These data suggest that gravitational settling is a more important removal mechanism than deposition, and hence we assume the floor surface is the primary surface of dust accumulation. Settling velocities are represented as a triangular distribution with a mode at $6 \mathrm{~m} \mathrm{~h}^{-1}$ and lower and upper limits of 2 and $10 \mathrm{~m} \mathrm{~h}^{-1}$.

The median surface area of floors $\left(A_{f l}\right)$ in U.S. houses is about $150 \mathrm{~m}^{2}$ (U.S. Bureau of the Census, 1991), and if we assume that most ceilings are $2.4 \mathrm{~m}$ high $(8 \mathrm{ft})$, then the associated volume $(\mathrm{V})$ is $360 \mathrm{~m}^{3}$. These values will be used to represent both the farm and suburban dwellings. For this assessment we will assume that the commercial facility has $930 \mathrm{~m}^{2}$ of floor space (i.e., $10,000 \mathrm{ft}{ }^{2}$ ). Since only a portion of floors are actually accessible for walking, playing, etc., we need to adjust the value of $A_{f l}$ downward for the buildings to obtain an effective floor area that contributes to resuspension. We estimate that the fraction of floor space available for resuspension $\left(f_{a}\right)$ is 0.75 . Ventilation rates of houses vary according to climatic as well as building characteristics. Nazaroff $e t$ al. (1985) estimated that the geometric mean air-exchange rate (Ach) was $0.68 \mathrm{~h}^{-1}$, with a GSD of 2.01. The penetration factor, $\mathrm{P}$, can be estimated as the ratio of the indoor-air concentration of a contaminant to its outdoor concentration, provided that there are no significant sources or losses (e.g., filtration by heating and cooling equipment as well as deposition onto interior surfaces) indoors. Penetration factors for contaminants contained in airborne particles generally fall between 0.2 and 0.5 , with the highest values associated with substances enriched on fine particles. Cohen and Cohen (1980), for example, reported that the average indoor/outdoor ratios for $\mathrm{Ca}, \mathrm{Fe}, \mathrm{Pb}$, and $\mathrm{Br}$ in homes (which did not have indoor sources of these contaminants) were $0.23,0.25,0.53$, and 0.38 . These penetration estimates correspond directly with the MMAD for the four elements presented in a review by Milford and Davidson (1985) (i.e., 4.64, 3.42, 0.55, and $0.89 \mu \mathrm{m}$, respectively). The penetration factor can be estimated using the following power-law fit to the data:

$$
P=0.4 d^{-0.37}\left(r^{2}=0.96\right),
$$

where $d$ is the MMAD in micrometers. Shinn et al. (1989) reported that the activity-median aerodynamic diameter (AMAD) of 239,240 Pu sampled in the ambient air in Plutonium Valley was $5 \mu \mathrm{m}$ with a GSD of 8.5. Anspaugh and Phelps (1974) determined an AMAD of $3 \mu \mathrm{m}$ for airborne particulates collected by high-volume cascade impactors operating at the GMX site. Thus, we would expect that only about 20 to $30 \%$ of the resuspended Pu would penetrate a house. In our simulations we will characterize the variation in the AMAD values for resuspended $239,240 \mathrm{Pu}$ at the sites using a uniform distribution with minimum and maximum values of 3 and $5 \mu \mathrm{m}$.

Airborne particles indoors that are derived from infiltrating air and resuspension from floors can be removed by filters in heating, ventilation, and air-conditioning (HVAC) systems. For the purposes of our assessment, we will assume that the suburban residence is equipped with a central heating/cooling system that recirculates air within the building. The farmhouse, though, is not assumed to have a central heating/cooling unit, and as a result, there is no internal filtration of particles. The air-recirculation rate $\left(\mathrm{Q}_{r}\right)$ for a standard heating/cooling unit (i.e., the heating component has a heat input of $80,000 \mathrm{Btu} \mathrm{h}^{-1}$ ) in a suburban residence is approximately 
Table 2. Summary of the parameter values used to determine the concentrations of $239,240 \mathrm{Pu}$ in the indoor air of houses and commercial buildings.

\begin{tabular}{|c|c|c|c|c|c|}
\hline Variable & Units & Distribution & Residential & $\begin{array}{c}\text { Farm } \\
\text { Statistics }\end{array}$ & Commercial \\
\hline$P$ & unitless & Uniform & Min. (0.2) Max. (0.3) & Min. (0.2) Max. (0.3) & Min. (0.2) Max. (0.3) \\
\hline Ach & $h^{-1}$ & Lognormal & GM (0.67) GSD (2.0) & GM (0.67) GSD (2.0) & GM (0.67) GSD (2.0) \\
\hline$v_{g}$ & $\mathrm{~m} \mathrm{~h}^{-1}$ & Triangular & $\begin{array}{l}\text { Mode (6) Min. (2) } \\
\text { and Max. (10) }\end{array}$ & $\begin{array}{l}\text { Mode (6) Min. (2) and } \\
\text { Max. (10) }\end{array}$ & $\begin{array}{l}\text { Mode (6) Min. (2) and } \\
\text { Max. (10) }\end{array}$ \\
\hline$A_{f l}$ & $\mathrm{~m}^{2}$ & Constant & 150 & 150 & 930 \\
\hline $\mathrm{f}_{\mathrm{a}}$ & unitless & Constant & 0.75 & 0.75 & 0.75 \\
\hline $\mathrm{f}_{\mathrm{O}}$ & unitless & Uniform & Min. (0.2) Max. (0.5) & Min. (0.2) Max. (0.5) & Min. (0.2) Max. (0.5) \\
\hline $\mathrm{M}_{\mathrm{fl}}$ & $\mathrm{g} \mathrm{m}^{-2}$ & Lognormal & GM (0.42) GSD (1.88) & GM (0.42) GSD (1.88) & GM (0.42) GSD (1.88) \\
\hline $\begin{array}{l}\mathrm{h} \\
\mathrm{Q}_{\mathrm{r}}\end{array}$ & $m$ & $\begin{array}{l}\text { Constant } \\
\text { Constant }\end{array}$ & $\begin{array}{l}2.4 \\
2400\end{array}$ & $\begin{array}{l}2.4 \\
-\end{array}$ & $\begin{array}{l}2.4 \\
-\end{array}$ \\
\hline$Q_{r}$ & $m^{3} h^{-1}$ & Uniform & - & - & $\begin{array}{l}\text { Min. }(22,000) \\
\text { Max. }(44,000)\end{array}$ \\
\hline$f_{\text {on }}$ & unitless & Constant & 0.3 & - & - \\
\hline$E_{f}$ & unitless & Constant & 0.5 & - & 0.5 \\
\hline TSP & $\mu \mathrm{g} \mathrm{m}^{-3}$ & Lognormal & GM (28) GSD (1.6) & GM (28) GSD (1.6) & GM (28) GSD (1.6) \\
\hline $\mathrm{EH}$ & unitless & Constant & 1 & 1 & 1 \\
\hline $\mathrm{R}$ & $h^{-1}$ & Uniform & $10^{-4}$ to $10^{-3}$ & $10^{-4}$ to $10^{-3}$ & $10^{-4}$ to $10^{-3}$ \\
\hline
\end{tabular}

$2400 \mathrm{~m}^{3} / \mathrm{h}^{-1}$ (based on a typical air-handling rate of $1400 \mathrm{ft}^{3} \mathrm{~min}^{-1}$ ). If the unit operates an average of $30 \%$ per year (denoted $f_{o n}$ ), the effective recirculation rate is $1200 \mathrm{~m}^{3} \mathrm{~h}^{-1}$. The particle-removal efficiency $\left(E_{f}\right)$ of standard fibrous filters in domestic HVACs is approximately 0.5 (Lefcoe and Inculet, 1975). Air recirculation rates in the commercial facility are assumed to be for an office environment, with $\mathrm{Q}_{\mathrm{r}}$ defined as the product of the building volume $(\mathrm{V})$ and an air exchange rate (Ach), defined as a uniform distribution between 10 and 20 air-exchanges per hour. The resulting limits of the uniform distribution of $\mathrm{Q}$ for the commercial building volume of $2200 \mathrm{~m}^{3}$ (i.e., $930 \mathrm{~m}^{2} \times 2.4 \mathrm{~m}$ ) are $2.2 \times 10^{4}$ and $4.4 \times 10^{4} \mathrm{~m}^{3} \mathrm{~h}^{-1}$. The outdoor air makeup $\left(f_{m}\right)$ fraction is defined as a uniform distribution between 0.1 to 0.2 (from Hayes, 1989; Weschler et al., 1983). The filter efficiency for coarse particles is also assumed to be 0.5 . Table 2 summarizes the values used to represent the various input parameters to Eqs. 10 and 11 .

Monte-Carlo simulations of Eq. 10 using the appropriate parameter values and distributions for a suburban house (with central air conditioning and heating) resulted in a lognormal distribution of the $C_{i n} / C_{s}$ ratios with a GM of $6.8 \times 10^{-6} \mathrm{~g} \mathrm{~m}^{-3}$ and a GSD of 1.89. The GM and GSD of the $\mathrm{C}_{\mathrm{in}} / \mathrm{C}_{\mathrm{S}}$ ratios for the farm house (no central air conditioning or heating) were $9.1 \times 10^{-6} \mathrm{~g} \mathrm{~m}^{-3}$ and 1.95 , respectively. The larger ratio for the farm house was due primarily to the lack of indoor filtration of suspended particles by a central air conditioning/heating unit. The commercial facility, which has a continuously operating air ventilation and filtration system, achieved the lowest ratio of $\mathrm{C}_{\mathrm{in}} / \mathrm{C}_{\mathrm{s}}$, with a GM of $5.3 \times 10^{-6} \mathrm{~g} \mathrm{~m}^{-3}$ and a GSD of 1.56 . The geometric means of the ratios of $\mathrm{C}_{\mathrm{in}} / \mathrm{C}_{\mathrm{a}}$ (equivalent to the indoor/outdoor concentration ratios of 
airborne $239,240 \mathrm{Pu}$ ) for the suburban house, farmhouse, and commercial building were $0.24,0.32$, and 0.19 , respectively.

\subsection{Human Factors Describing Exposure Scenarios}

To quantify inhalation exposures to $239,240 \mathrm{Pu}$ from soil-derived aerosols in indoor and outdoor air and the cumulative doses resulting from those exposures, it is necessary to characterize the following parameters: (1) the age-dependent breathing rates for indoor and outdoor locations, (2) the fractions of time spent indoors and outdoors at residential and commercial sites where soil contamination occurs (i.e., the exposure frequency), and (3) the length of time spent at each location (i.e., the exposure duration). The locational aspects of human activities are important because the concentrations of $239,240 \mathrm{Pu}$ differ between indoor and outdoor air. Moreover, the amount of time people spend at a given location depends on its function (e.g., a residence or place of work). Inhalation rates change from location to location as a function of the physical activities carried out in the different locations. The four basic locations that people occupy are shown in Figure 9. For each location type we will now characterize exposure factors that will be used in the dose assessments for alternative land-use scenarios at the shot sites.

\subsubsection{Activity Patterns}

Important exposure factors that must be considered when addressing contacts with soil contaminants at a given location (i.e., nonubiquitous soil contaminants) is the amount of time an individual spends at indoor and outdoor locations at the site and the kinds of activities performed while there. Both of these lifestyle factors changes with age. We have characterized the agedependent changes in the amount of time an individual spends at indoor and outdoor locations at home using the results of activity surveys of children $(<12 \mathrm{y})$ and adults $(\geq 12 \mathrm{y})$ in California (Wiley, 1991; Wiley et al., 1991). The random sample of children included 1200 individuals, while the adult sample included 1,762 individuals. Figure 10 shows the fractions of each day that were spent indoors and outdoors at home. As might be expected, there are U-shaped functional relationships between age and the fractions of time spent indoors and outdoors at home. The fraction of time indoors decreases from birth to about age $20 \mathrm{y}$ and then gradually increases into the retirement years. By comparison, the amount of time outdoors at home averages less than $5 \%$ of a day for those under $10 \mathrm{y}$, decreasing to around $2 \%$ in middle age, and then increasing again in the retirement years. The amount of sleep time is presented in Figure 11. Children under age 10 sleep more than $10 \mathrm{~h}$ per day, and as individuals reach middle age, they sleep an average of eight hours per day. Small increases in sleep time occur after age $50 \mathrm{y}$. Unfortunately, we were unable to obtain similar age-dependent activity-pattern data for residents of farms. If such data were available, we would expect that farm residents would spend much more time outdoors adjacent to a farm house. We will examine the effect that increased time outdoors has on our dose estimates for the resident farmer in the section dealing with dose estimates. 


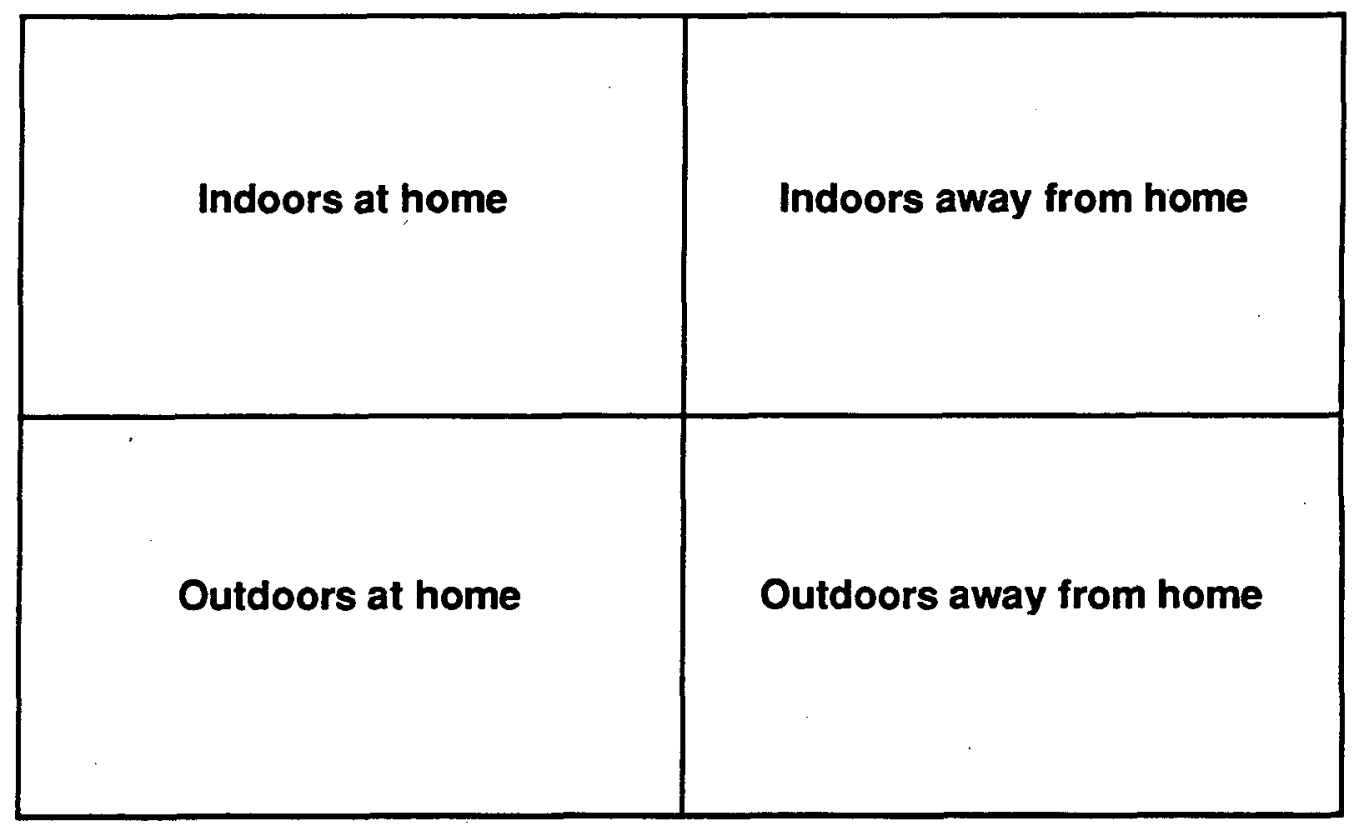

Figure 9. Four basic categorizations of indoor and outdoor locations for use in assessments of exposures to soll-derived contaminants at a given location.

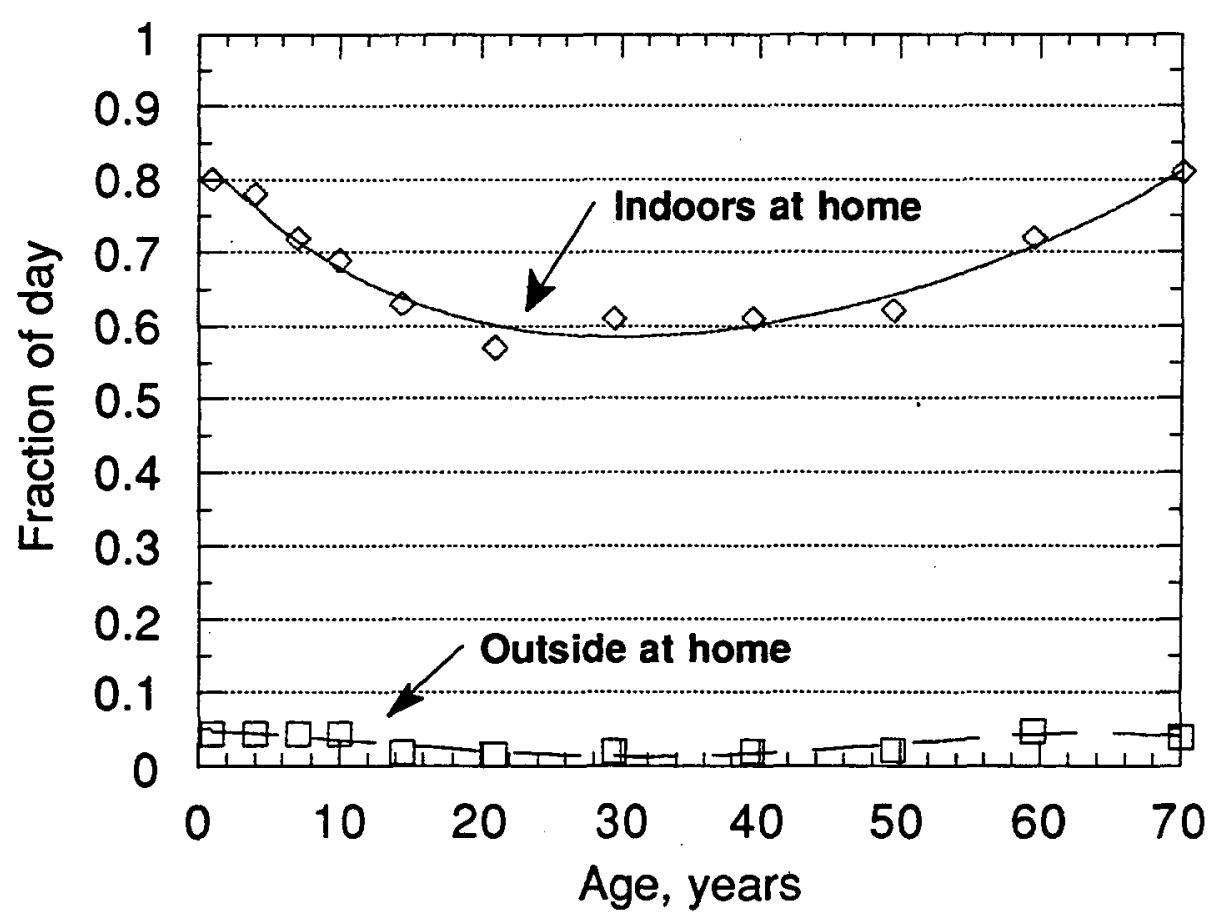

Figure 10. Fractions of time individuals spend indoors at home and outside at home (data are from Wiley, 1991; Wiley et al., 1991). 


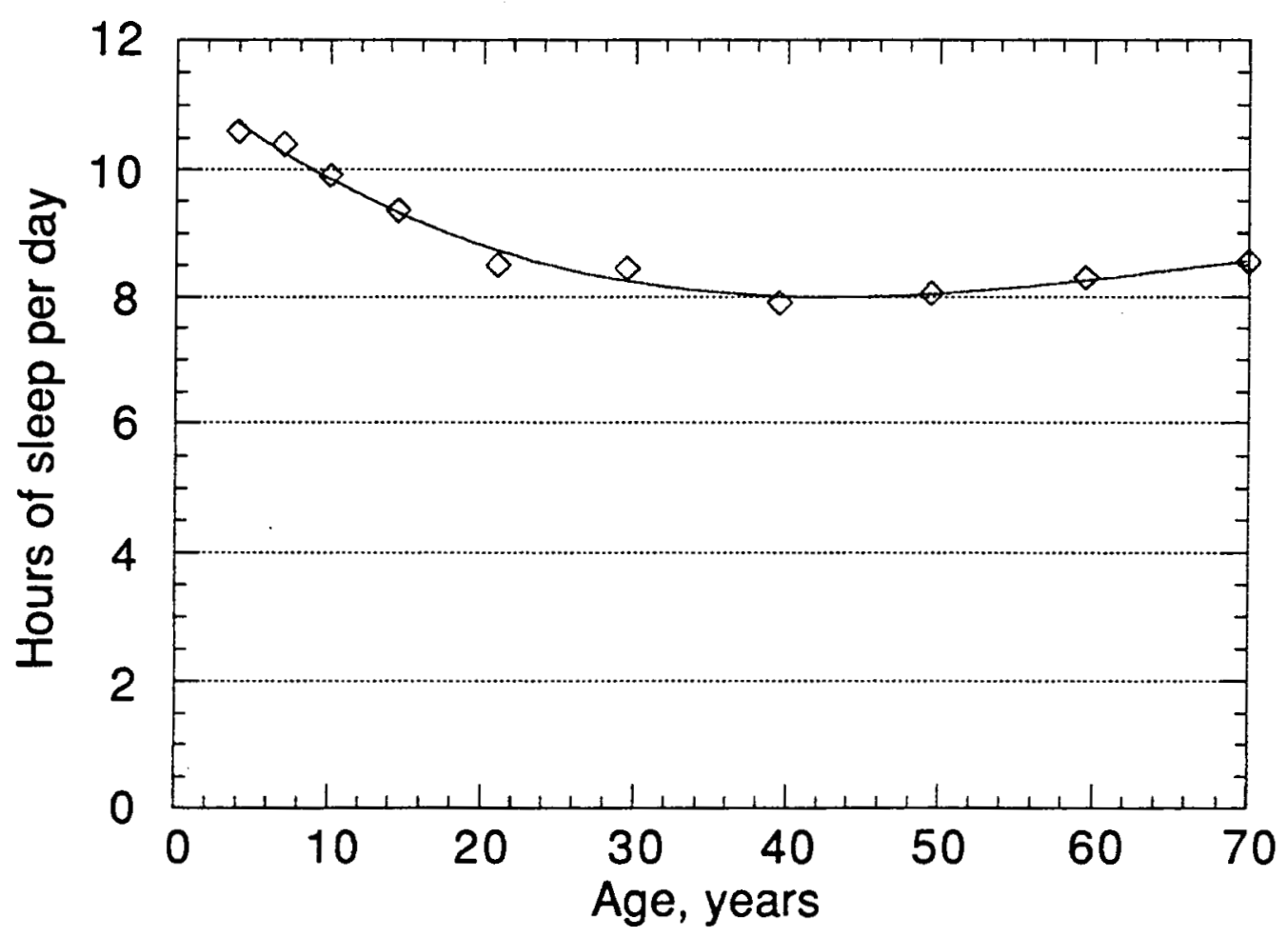

Figure 11. Hours of sleep as a function of age (data from Wiley, 1991; Wiley et al., 1991).

The amount of time spent at a commercial facility depends in part on an individual's employment status (i.e., full- or part-time worker) and the nature of the facility (e.g., retail, office, manufacturing, etc.). Because our commercial land-use scenario is not meant to represent any particular kind of commercial operation, we will use labor statistics for the employed civilian work force in the U.S. to characterize the time spent at an unspecified work location. Employment data (U.S. Bureau of the Census, 1991) show that the work week for wage and salary workers employed in nonagricultural work has averaged between 38 and $39 \mathrm{~h}$ since 1970. Expressed on the basis of a seven-day week, this translates to about $23 \%$ of an average day (or on an annual basis, $84 \mathrm{~d} \mathrm{y}^{-1}$ ). We were unable to obtain data on the amounts of time that workers spent outdoors at office, retail, and manufacturing locations. For the purposes of our exposure assessment, we have assumed simply that workers in the arid Nevada climate would spend $0.5 \mathrm{~h} \mathrm{~d}^{-1}$ outdoors at their place of employment (or $5.4 \mathrm{~d} \mathrm{y}^{-1}$, based on a 52-week working year). One additional consideration in characterizing the worker population is the age span of those employed. Although individuals can enter the workforce at age $16 \mathrm{y}$, we assume that full-time employment begins at age $19 \mathrm{y}$ and continues until age $64 \mathrm{y}$. Workers aged $65 \mathrm{y}$ and older and younger than 19 y accounted for less than $10 \%$ of the total civilian workforce in 1989 (U.S. Bureau of the Census, 1991). 


\subsubsection{Age-dependent inhalation rates}

Respiration provides the oxygen needed to metabolize food nutrients and therefore produce the energy needed to sustain our various activities. Inhalation rates can be subdivided into two basic categories, one representing inactive periods of sleep/rest and the other representing the range of various physical activities carried out each day. Thus, the inhalation rate used for individuals indoors at home must reflect the respiration rates associated with both active (i.e., waking hours) and inactive periods (i.e., sleep/rest); at other indoor/outdoor locations breathing rates are not assumed to reflect periods of sleep/rest. The breathing rate indoors at home (designated $\mathrm{BR}_{\text {in, }}$ ) can be expressed as a weighted-average value of the breathing rate for active and inactive hours, or

$$
\mathrm{BR}_{\mathrm{in}, \mathrm{h}}=\mathrm{P}_{\mathrm{r}} \mathrm{BR}_{\mathrm{r}}+\mathrm{P}_{\mathrm{a}} \mathrm{BR}_{\mathrm{a}} \text {, }
$$

where

$$
\begin{aligned}
& P_{r}=S /\left(T_{i n, h} \times 24\right), \\
& P_{a}=1-P_{r},
\end{aligned}
$$

and

$$
\begin{aligned}
\mathrm{BR}_{\mathrm{in}, \mathrm{h}} & =\text { breathing rate while indoors at home, } \mathrm{m}^{3} \mathrm{~d}^{-1} ; \\
\mathrm{P}_{\mathrm{r}} & =\text { fraction of time indoors at home that is spent at sleep/rest, unitless; } \\
\mathrm{P}_{\mathrm{a}} & =\text { fraction of time indoors at home that is spent at various activities, unitless; } \\
\mathrm{BR}_{\mathrm{r}} & =\text { breathing rate while at rest, } \mathrm{m}^{3} \mathrm{~d}^{-1} ; \\
\mathrm{BR}_{\mathrm{a}} & =\text { breathing rate while active, } \mathrm{m}^{3} \mathrm{~d}^{-1} ; \\
\mathrm{S} & =\text { sleep time, } \mathrm{h} ; \text { and } \\
\mathrm{T}_{\mathrm{in}, \mathrm{h}} & =\text { fraction of time spent indoors at home. }
\end{aligned}
$$

The average age-dependent inhalation rate for periods of sleep/rest (i.e., $\mathrm{BR}_{\mathrm{r}}$ ) for males and females is shown in Figure 12. This rate is based on a methodology presented by Layton (1993) in which inhalation at rest is determined from the oxygen uptake rate required to support basal metabolism and a ventilatory equivalent, which is the ratio of breathing rate to oxygen uptake. During active hours respiration increases to supply additional oxygen to yield metabolic energy that is equal to the energy expenditures for various activities (i.e., an individual's total daily energy expenditure less energy expended during sleep/rest). The breathing rate for active hours can be expressed as a function of the breathing rate at rest or,

$$
\mathrm{BR}_{\mathrm{a}}=\mathrm{H} \times \mathrm{BR}_{\mathrm{r}},
$$

where 


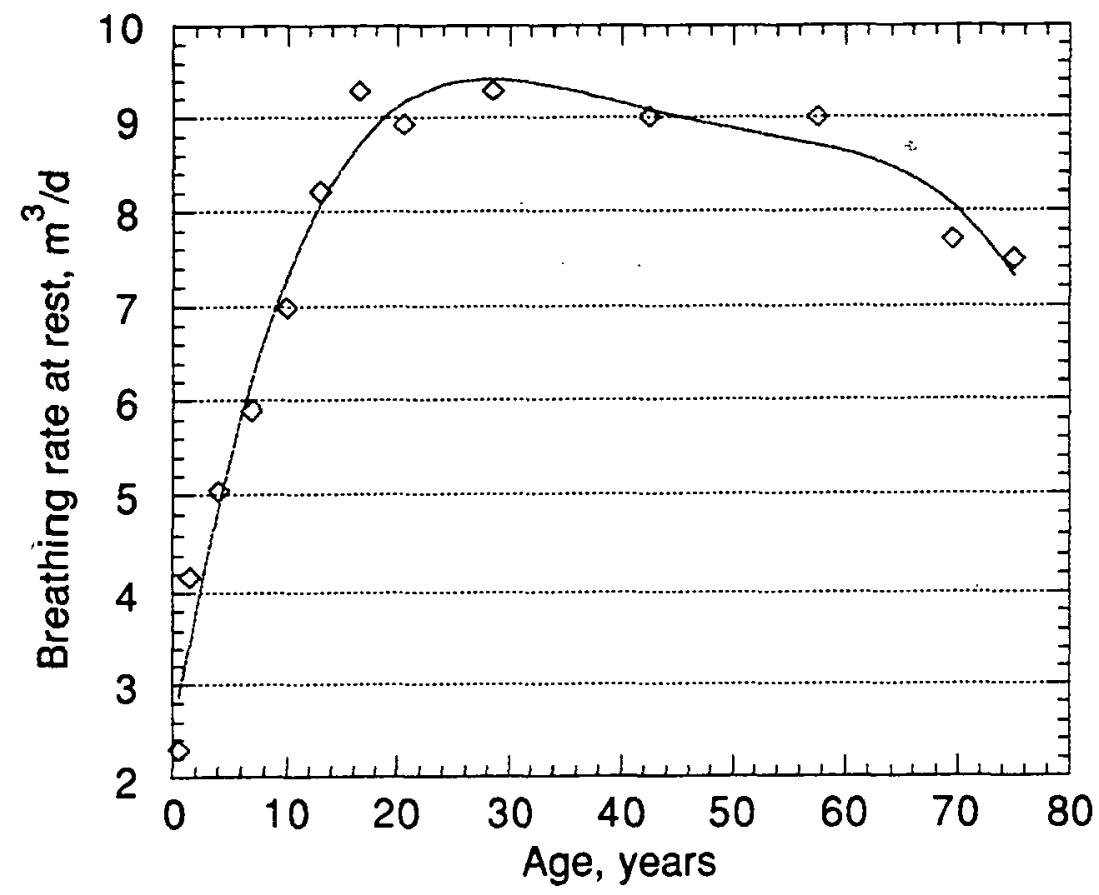

Figure 12. Average inhalation rate at rest for males and females as a function of age (derived from Layton, 1993).

$H=(24 M-S) /(24-S)$,

and

$\mathrm{H}=$ breathing-rate-multiplier used to calculate $\mathrm{BR}_{\mathrm{a}}$ as a function of $\mathrm{BR}_{\mathrm{I}}$, unitless; and

$\mathrm{M}=$ ratio of total energy expended each day to an individual's basal metabolic rate (BMR), unitless.

In this formulation $\mathrm{H}$ represents the factor that $B R_{\mathrm{r}}$ must be increased by to meet the increased metabolic requirements associated with waking hours. The two age-dependent parameters used to calculate $H$ are sleep time $(S)$ and the ratio of total energy intake to BMR (also referred to as the metabolic equivalent, denoted here as $M$ ). As sleep time decreases and $M$ increases, the amount of energy expended during active hours increases with respect to the resting inhalation rate, and there is a commensurate increase in the value of $\mathrm{H}$. Figure 13 shows the metabolic equivalents of the total energy expenditures for different ages (from Layton, 1993), 


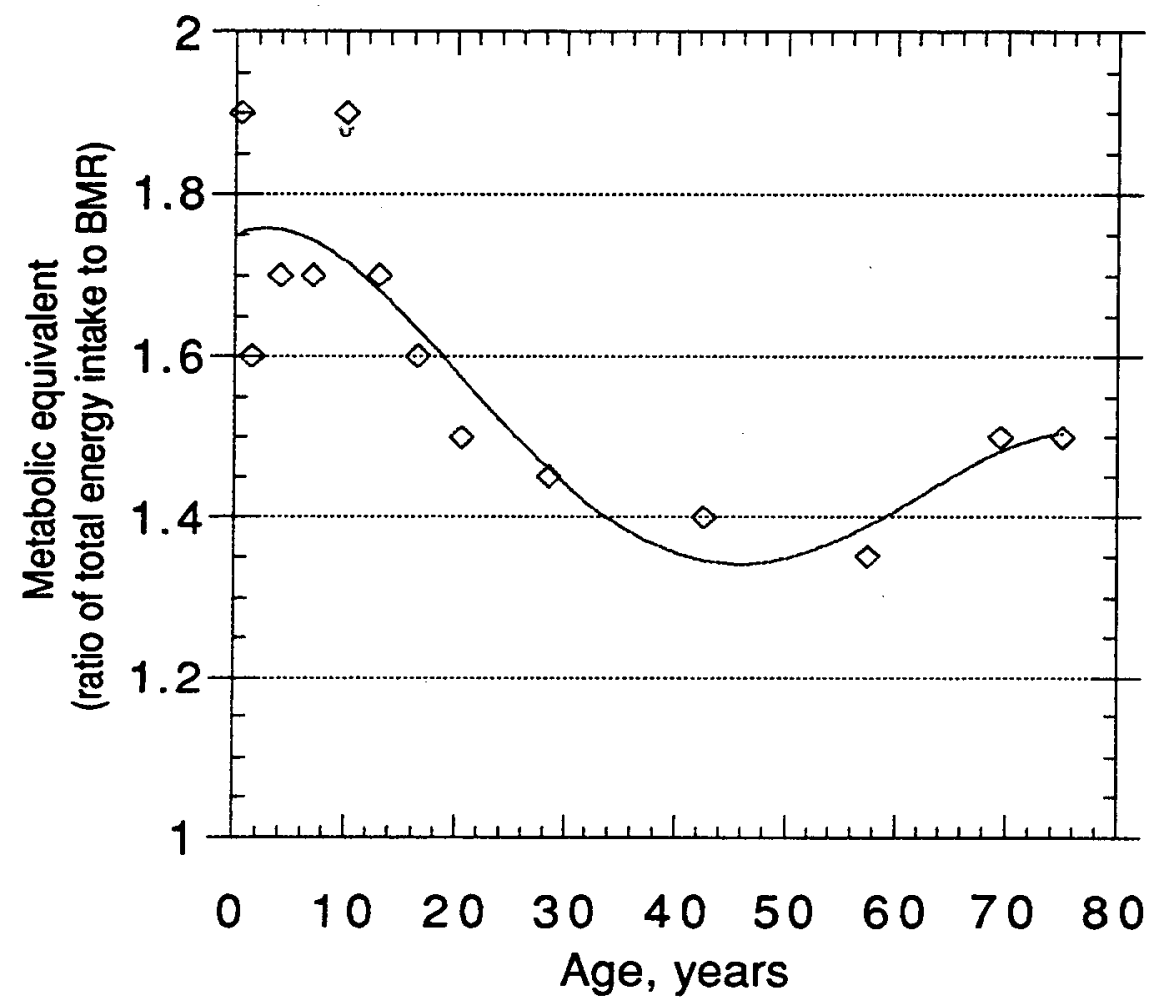

Figure 13. Average energy intakes for males and females expressed as metabolic equivalents (from Layton, 1993).

and a polynomial fit to the data. The breathing rates for sleep/rest, active hours, and indoors at home are depicted in Figure 14. Farmers are expected to have higher average energy expenditures than members of the general public and hence higher breathing rates as well. Riumallo et al. (1989), for example, reported that the average energy expenditure (in metabolic equivalents) for six males engaged in light agricultural tasks was about 1.8 , which is about 20 to $30 \%$ higher than the average values for both males and females depicted in Figure 13 . The increased inhalation for a farmer may also be associated with an increase in mouth breathing, which would lead to a larger deposition of particles in the lungs. As a default in our exposure and dose estimates, we will use the age-dependent inhalation values for the general population and estimate the increased exposures for the case of the resident farmer.

\subsubsection{Residential and Occupational Mobility}

The cumulative inhalation exposures to airborne $239,240 \mathrm{Pu}$ at a given residential or commercial location are not only a function of an individual's breathing rate and exposure frequency for the prescribed location, but also the duration of the exposure. To estimate the length of time spent at residences in different urbanizations (i.e., rural suburban and farm), we 


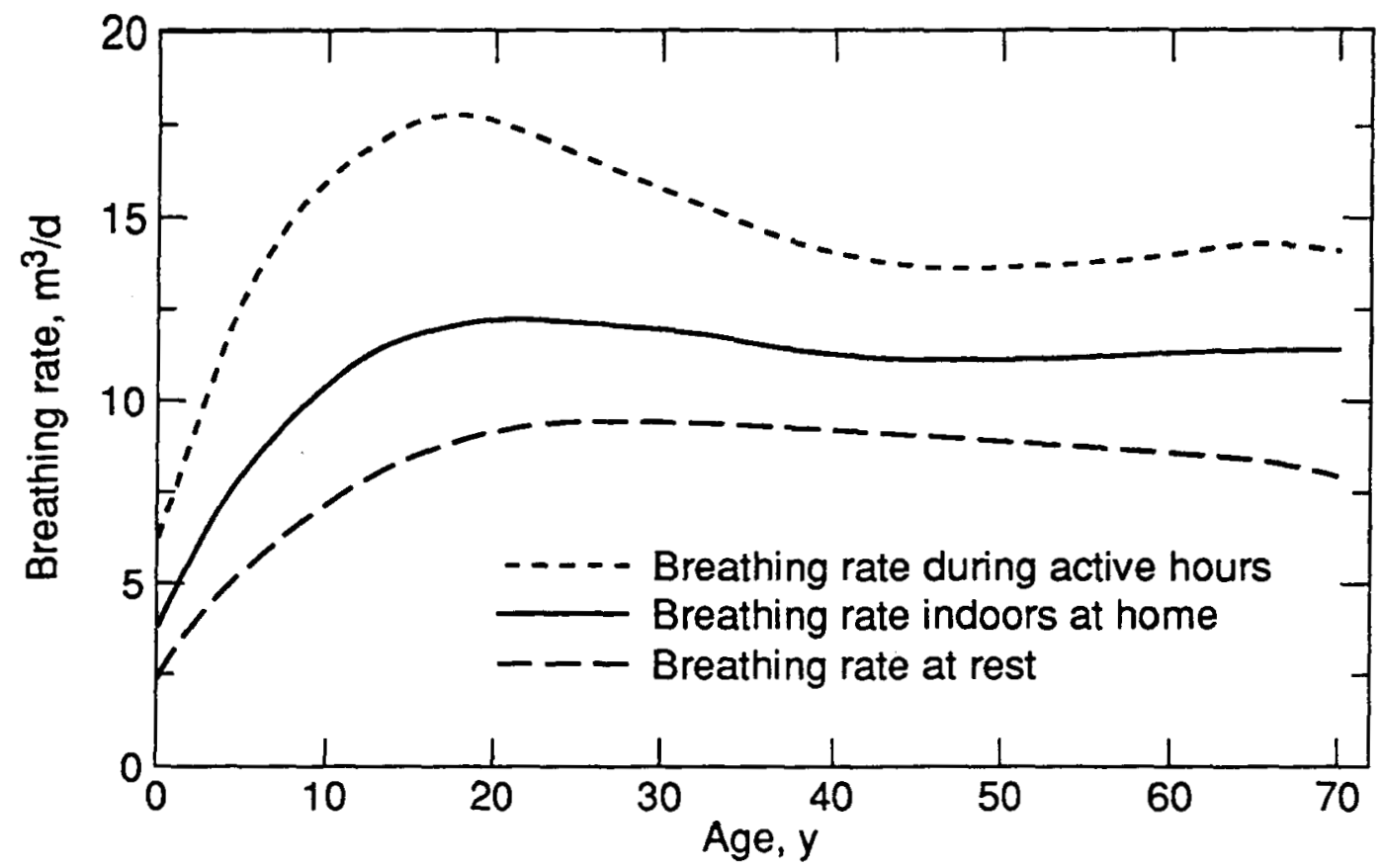

Figure 14. Age-dependent changes in the breathing rates at rest, indoors at home, and during active hours.

have analyzed statistical data from a national survey of U.S. housing in 1989 (U.S. Bureau of the Census, 1991). Figure 15 presents empirical probability distributions of the lengths of time that householders reside at domiciles situated in suburban areas or at farms in rural parts of the U.S. A substantial fraction (i.e., 0.45) of the suburban householders sampled in 1989 spent less than four years at their current residence. The mean residence time was about ten years. As might be expected, those living on farms were far less mobile. They resided an average of 20 years in their homes - twice the mean residence time for those suburbanites living in rural areas. The number of years that employees might work at an unspecified commercial facility can be estimated from survey data on workers from different occupations in the U.S. (U.S. Bureau of the Census, 1991). In 1987 the median occupational tenures for 27 major occupations (defined as those with 650,000 workers or more) ranged from 1.9 to 21.1 y (excluding occupations that are not associated with a single work location, such as truck drivers and carpenters). The geometric mean tenure of the occupations was 6 years and the geometric standard deviation was 1.74 (see Figure 16). These occupational tenures will tend to overestimate the number of years spent at a given commercial location because an individual may change work locations.

\subsection{Organ-Specific Doses and Risk Factors}

The cancer risk associated with the inhalation of $239,240 \mathrm{Pu}$ in environmental media is governed by the doses to various organs and the risk factor (i.e., the incremental probability of cancer per unit dose) for each organ. Accordingly, we have developed estimates of organspecific doses and risks for the exposure pathways discussed in the previous section. The basic 

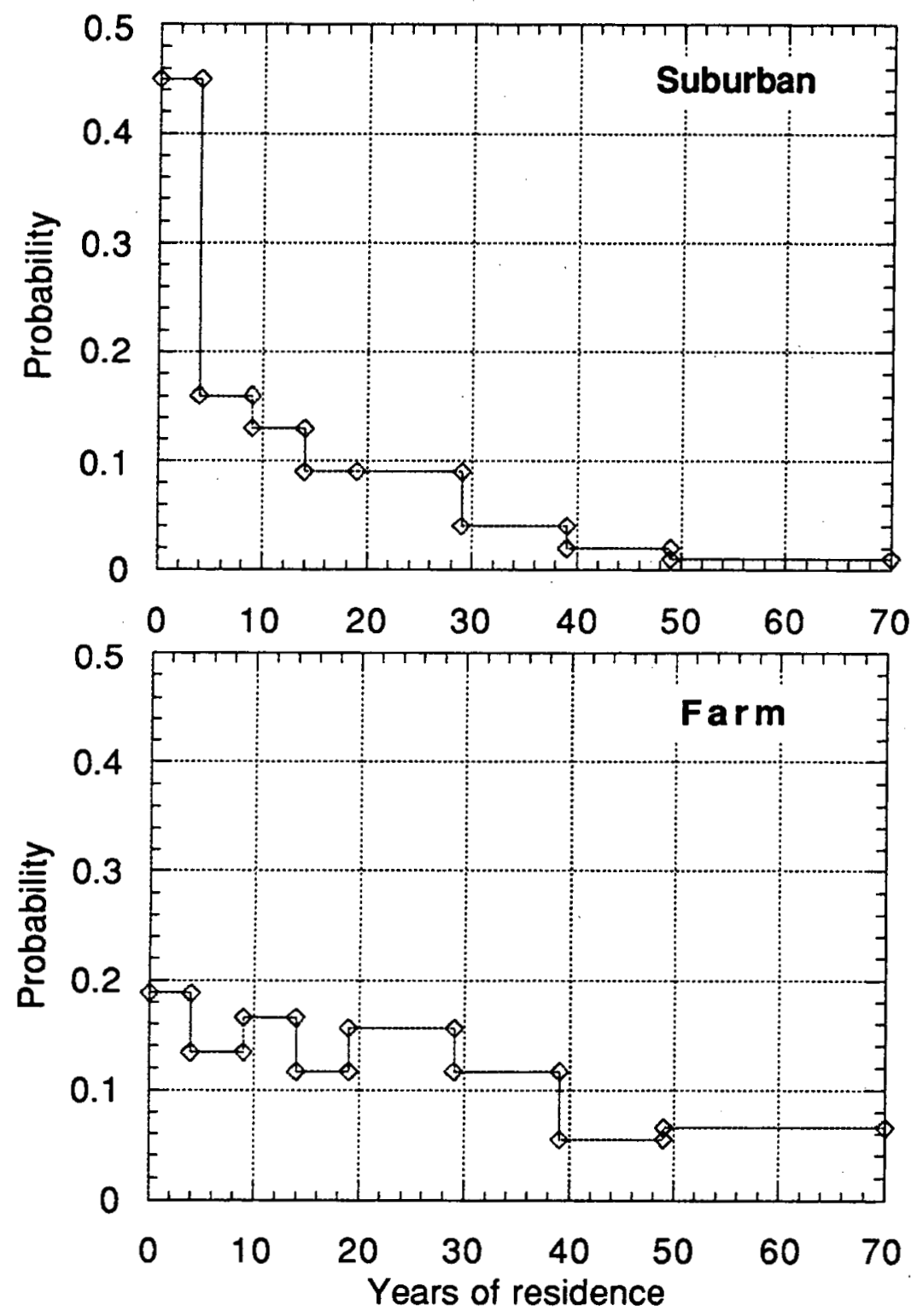

Figure 15. Mobility of persons living in rural suburban residences and farms (derived from U.S. Bureau of the Census, 1991). 


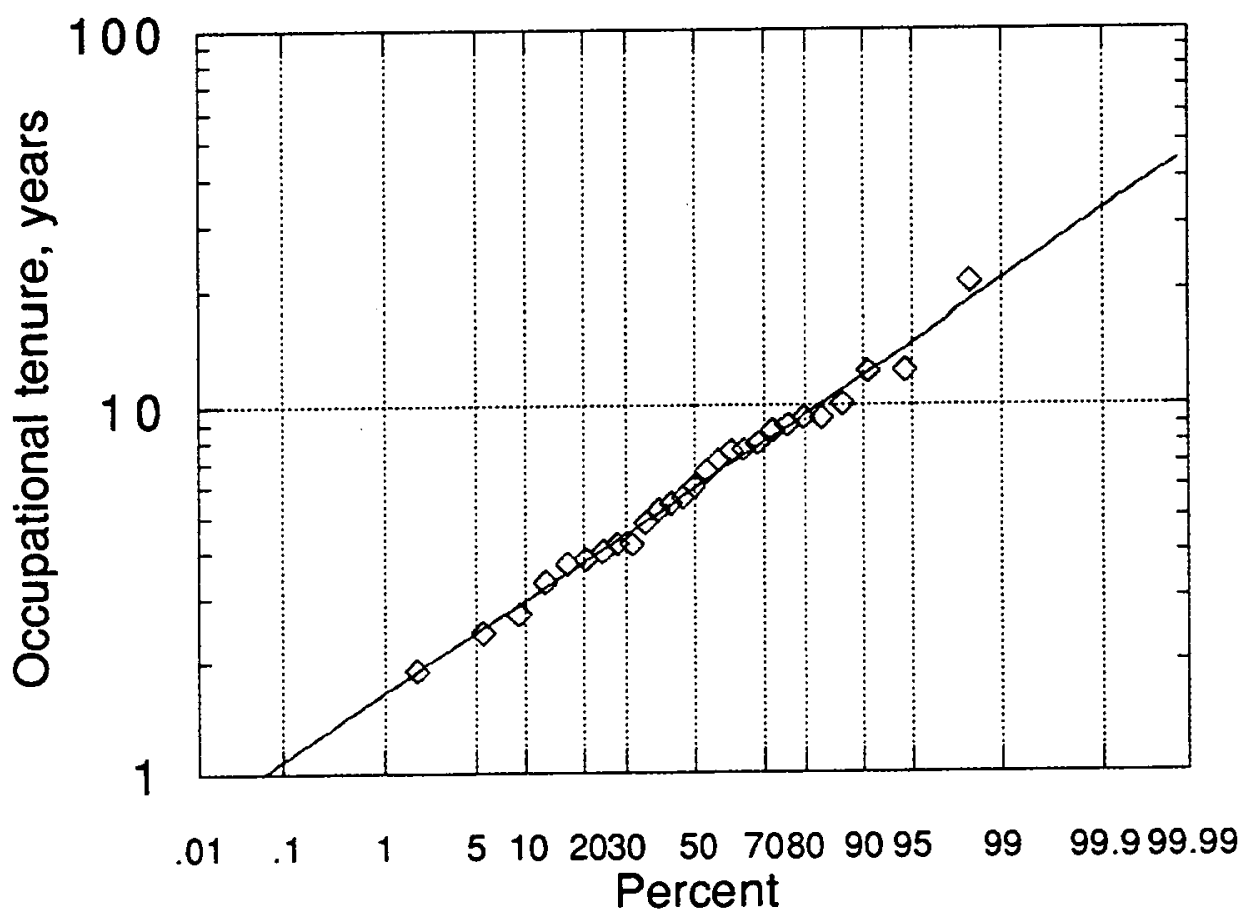

Figure 16. Logprobability plot of the median occupational tenures for 27 major, nonfarm occupations in 1987 (data from U.S. Bureau of the Census, 1991). The geometric mean is 6 y and the geometric standard deviation is 1.74.

objective of the dose assessment is to determine the cumulative doses of $239,240 \mathrm{Pu}$ to critical organs in individuals as a function of the concentrations of $239,240 \mathrm{Pu}$ in environmental media, human factors (e.g., land use, inhalation rates, activity patterns, mobility, and diet), and the agedependent retention, translocation, and excretion of plutonium.

The cancer risk of exposures to $239,240 \mathrm{Pu}$ can be expressed as

$$
R=\sum_{i=1}^{n} D_{i}^{70} \times R_{i}
$$

where

$$
\begin{aligned}
R & =\text { the incremental risk of incurring cancer, unitless; } \\
D_{i}^{70} & =\text { the cumulative lifetime dose to age } 70 \text { y for the ith organ of } n \text { critical organs, Gy; } \\
& \text { and }
\end{aligned}
$$




$$
R_{i}=\text { the linear risk factor for the ith organ, } G y^{-1} \text {. }
$$

With this methodology, cancer risk is calculated directly from the quantities of energy deposited in key organs resulting from the decay of retained $239,240 \mathrm{Pu}$ and the dose-response relationship between deposited energy and the probability of cancer for those organs. In contrast with this approach, ICRP (1991) methodology relies on the determination of equivalent doses to individual organs (i.e., doses that are adjusted to account for the biological effectiveness of different radiations, in units of sieverts, Sv) and the use of tissue-weighting factors, which reflect the different probabilities of developing cancer in various organs of a body uniformly irradiated by external gamma radiation (based largely on cancer-mortality data for A-Bomb survivors). In the sections below we present our estimates of organ-specific doses resulting from the inhalation exposures to $239,240 \mathrm{Pu}$ derived from contaminated soils associated with the alternative land uses discussed earlier, and we also assess risk factors for estimating the probability of cancer for internally irradiated organs.

\subsubsection{Organ-Specific Doses from Inhalation Exposures}

Doses to specific organs are calculated from the exposure conditions used to define the frequency and duration of an individual's inhalation of airborne $239,240 \mathrm{Pu}$ and its concentrations in the indoor and outdoor environments. The lifetime cumulative dose to age $70 \mathrm{y}$ for a given organ resulting from an inhalation exposure over a specified period of time (defined by the integration limits $a$ and $b$ ) can be calculated from

$$
D_{i}^{70}=\int_{a}^{b} C_{\text {out }}(t) B R_{\text {out }}(t) T_{\text {out }}(t) D C_{i}^{70}(t) d t+\int_{a}^{b} C_{i n}(t) B R_{\text {in }}(t) T_{\text {in }}(t) D C_{i}^{70}(t) d t
$$

where

$$
\begin{aligned}
& \mathrm{D}_{\mathrm{i}}^{70}=\text { lifetime cumulative dose to age } 70 \mathrm{y} \text { for the ith organ resulting from } \\
& \mathrm{C}_{\mathrm{in}}(\mathrm{t}), \mathrm{C}_{\text {out }}(\mathrm{t})=\text { time-varying concentration of } 239,240 \mathrm{Pu} \text { in indoor or outdoor air, } \mathrm{Bq} \mathrm{m^{-3 }} \text {; } \\
& \mathrm{BR}_{\mathrm{in}}, \mathrm{BR}_{\mathrm{out}}=\text { age-dependent breathing rate while indoors or outdoors, } \mathrm{m}^{3} \mathrm{~d}^{-1} \text {; } \\
& \mathrm{T}_{\mathrm{in}}, \mathrm{T}_{\mathrm{out}}=\text { age-dependent amount of time spent indoors or outdoors at a given } \\
& \text { location, } \mathrm{d} \mathrm{y}^{-1} \text {; } \\
& D C_{i}^{70}(t)=\text { cumulative lifetime dose to age } 70 \mathrm{y} \text { for the ith organ for inhalation } \\
& \text { exposure at time } \mathrm{t}, \mu \mathrm{Gy} \mathrm{Bq}^{-1} \text {. }
\end{aligned}
$$

One difficulty with the formulation of Eq. 19 is that it cannot be used easily to simulate the residential and occupational mobility of individuals, that is, the lengths of time spent at a given location as a function of age (as defined by the integration limits). A simpler formulation can be 
derived by treating the indoor/outdoor concentrations of $239,240 \mathrm{Pu}$ as constants over exposure periods and by assuming that the residence times of individuals at a given location are distributed randomly with age. The revised formulation then becomes

$$
D_{i}^{70}=M\left[C_{\text {out }} \bar{F}_{i, \text { out }}+C_{i n} \bar{F}_{i, \text { in }}\right]
$$

where

$$
\begin{aligned}
& \bar{F}_{i, \text { out }}=\frac{1}{(b-a)} \int_{a}^{b} B R_{\text {out }}(t) T_{\text {out }}(t) D C_{i}^{70}(t) d t, \\
& \bar{F}_{i, \text { in }}=\frac{1}{(b-a)} \int_{a}^{b} B R_{\text {in }}(t) T_{\text {in }}(t) D C_{i}^{70}(t) d t, \text { and }
\end{aligned}
$$

where

$$
\begin{aligned}
M= & \text { the residence time at a given residential, farm, or occupational } \\
& \text { location, } y \text {; and } \\
\overline{\mathrm{F}}_{\mathrm{i}, \text { in }} \text { and } \overline{\mathrm{F}}_{\mathrm{i} \text {, out }}= & \text { exposure-normalized dose-conversion factors for indoor and outdoor } \\
& \text { inhalation exposures over the period defined by the integration limits } \\
& \text { a and } b, \mathrm{~m}^{3}-\mu \mathrm{Gy} \mathrm{y}^{-1}-\mathrm{Bq}^{-1} ;
\end{aligned}
$$

For workplace exposures to $\mathrm{Pu}$ aerosols, the parameters $\mathrm{T}_{\text {out }}$ and $\mathrm{T}_{\text {in }}$ are treated as constants (i.e., 5.4 and $84 \mathrm{~d} \mathrm{y}^{-1}$, respectively) and the breathing rate for active hours is used as the effective inhalation rate for both indoor and outdoor locations.

The age-dependent dosimetry for $239,240 \mathrm{Pu}$ is based on a model that was developed by Leggett (1985) and later modified for use in ICRP Publication 56 (ICRP, 1990). Our implementation of the modified model (illustrated schematically in Figure 17) utilizes the agespecific physiologic and biokinetic parameter values given in Tables $1 .-1$ and A-1 of ICRP Publication 56, respectively. In addition, our model includes a modified version of the ICRP (1979) lung model, as shown in Figure 17. In the respiratory portion of the model, inhaled 239,240 Pu aerosols (i.e., Class $\mathrm{Y}$ aerosols with an AMAD of $1 \mu \mathrm{m}$ ) are deposited on the surfaces of the nasal passages (denoted NP) and the trachea and bronchial tree (denoted TB) and are transferred instantaneously to blood and the GI tract via lung subcompartments $a, b, c$, and d. The standard ICRP lung model integrates the dose to these subcompartments; however, because they are cleared rapidly, little accuracy is lost in omitting them. The parameters $f_{a}, f_{b}, f_{c}$, and $f_{d}$ indicate the fractions of the deposited $239,240 \mathrm{Pu}$ transferred to blood or lungs (see Fig. 17). Aerosols reaching the pulmonary region that are deposited (determined from the deposition fraction $f_{p}$ ) are transferred to lung $e, h$, and $g$ subcompartments (the quickly cleared $f$ subcompartment is omitted in our model). The lung subcompartment $\mathrm{h}$ clears to the pulmonary lymph nodes, while the e and g subcompartments clear to blood and the GI tract, respectively. 
Once in the blood, some $239,240 \mathrm{Pu}$ is distributed to the systemic organs shown in Figure 17 , but most is translocated to skeleton and liver. The Leggett model divides the skeleton into cortical bone and trabecular bone. These bone types are subdivided into three biologically-relevant compartments for estimating doses: (1) bone surface, (2) bone volume, and (3) bone marrow. The liver is treated as a single compartment in the modified Leggett model.

The portion of the model used dealing with bone dosimetry is based entirely on the bonerecirculation approach of Leggett (1985) as implemented in ICRP Publication 56. In this approach, specified fractions of all $\mathrm{Pu}$ circulating in blood continuously enter compartments representing cortical-bone and trabecular-bone surfaces, respectively, and the $\mathrm{Pu}$ is then lost (with first-order kinetics) to the volume and marrow portions of those types of bone. The cortical and trabecular marrow also receives $239,240 \mathrm{Pu}$ directly from blood, again through firstorder processes. Integrated $239,240 \mathrm{Pu} \alpha$-particle dose to bone is calculated as summarized in Table 7.4 of ICRP Publication 30 (ICRP, 1979). According to this dosimetry model for $\alpha$ emitters in bone, all bone surfaces plus all trabecular (i.e., red) bone marrow comprise the biologically relevant set of bone-related target organs. Thus integrated dose to bone surfaces includes (a) dose delivered to that surface from $239,240 \mathrm{Pu}$ situated within cortical and trabecular surfaces plus (b) the doses delivered from $239,240 \mathrm{Pu}$ situated within cortical and trabecular bone volumes, appropriately discounted for the limited range of $239,240 \mathrm{Pu} \alpha$-particles and the geometric properties of the source and target compartments involved. Similarly, integrated dose to red marrow includes $100 \%$ of the $239,240 \mathrm{Pu}$ dose contained within trabecular marrow plus those doses (again, appropriately adjusted) delivered to that marrow from trabecular-bone surface and volume compartments.

Four target organs (liver, lung, bone surface, and red bone marrow) were selected for analysis based on a preliminary review of dose-response data on those organs. The uptake, translocation, deposition, and excretion of $\mathrm{Pu}$ through the various compartments and corresponding integrated doses to the target organs was calculated using a system of ordinary differential equations, which we have solved numerically using Mathematica (Version 2.0, Wolfram, 1991). These equations included time-dependent parameters, as noted above. The continuous relationships between age at exposure and cumulative dose to age $70 \mathrm{y}$ to target organs per unit respiratory intake $\left(\mathrm{DC}_{\mathrm{i}}^{70}(\mathrm{t})\right.$ in $\mu \mathrm{Gy} \mathrm{Bq}{ }^{-1}$ ) are illustrated in Figure 18. The cumulative doses to the four organs decrease with age at exposure as the period of integration decreases. Nonmonotonic changes in the shape of the curves are due to corresponding age-dependent changes in organ weights, organ-specific transfer fractions, and excretion rates. The curves are in the form of interpolating functions for cumulative doses determined at various ages of exposure. Our cumulative dose estimates for each of the target organs are all within a few percent of the inhalation dose coefficients (in Sv $\mathrm{Bq}^{-1}$ ) for ${ }^{239} \mathrm{Pu}$ given in ICRP Publication 56 for six ages when exposure is assumed to occur [i.e., $3 \mathrm{mo}, 1 \mathrm{y}, 5 \mathrm{y}, 10 \mathrm{y}, 15 \mathrm{y}$, and adult (> $17 \mathrm{y})$ ].

For the residential and farm exposure scenarios, the integration period $(a-b)$ encompasses the ages of 0 to $70 \mathrm{y}$, whereas for a commercial land use the integration period encompasses the age span of the worker population (i.e., 19 to $65 \mathrm{y}$ ). Table 3 contains the average doseconversion factors for the two types of domestic exposure scenarios as well as the commercial exposure scenario. For a unit concentration of $239,240 \mathrm{Pu}$ in air and exposure period, bone surfaces receive the greatest doses, followed by the lungs, liver, and bone marrow. The bone 


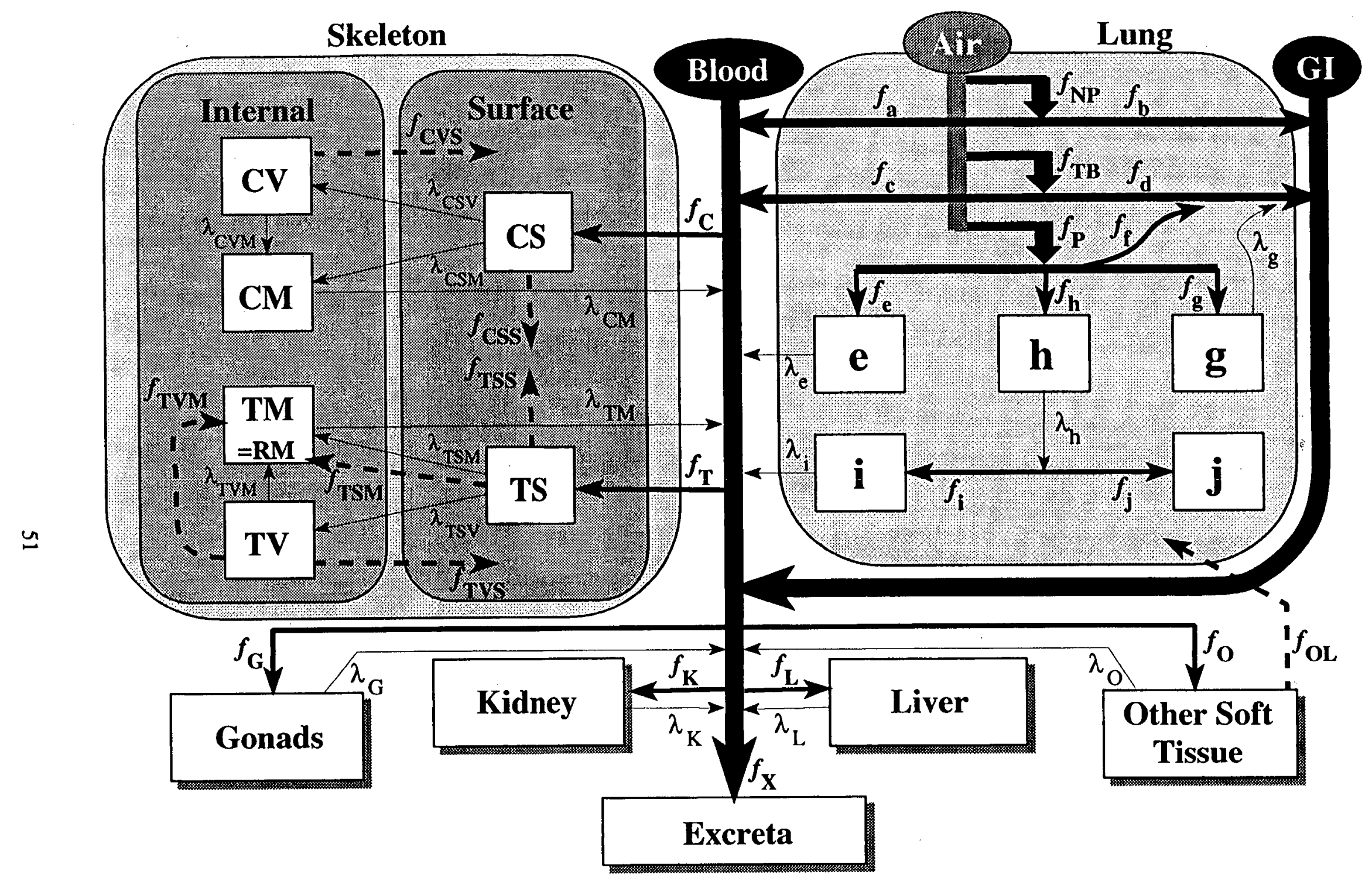

Figure 17. Modified Legget-ICRP dosimetry model for inhaled and/or ingested plutonium. $\mathrm{C}=$ cortical, $\mathbf{T}=$ trabecular, $\mathrm{R}=$ Red, $\mathrm{M}=$ marrow, $\mathrm{S}=$ surface, $\mathrm{V}=$ volume, $\mathrm{e}-\mathrm{j}=\mathrm{ICRP}$ lung compartments, $f(\lambda)=$ fraction deposited via (or loss constant for) processes presumed instant (or 1st-order exponential, indicated by thinnest arrows and typeface). Dashed arrow signifies a deposition of radiation dose without mass transfer. See text for further details. 


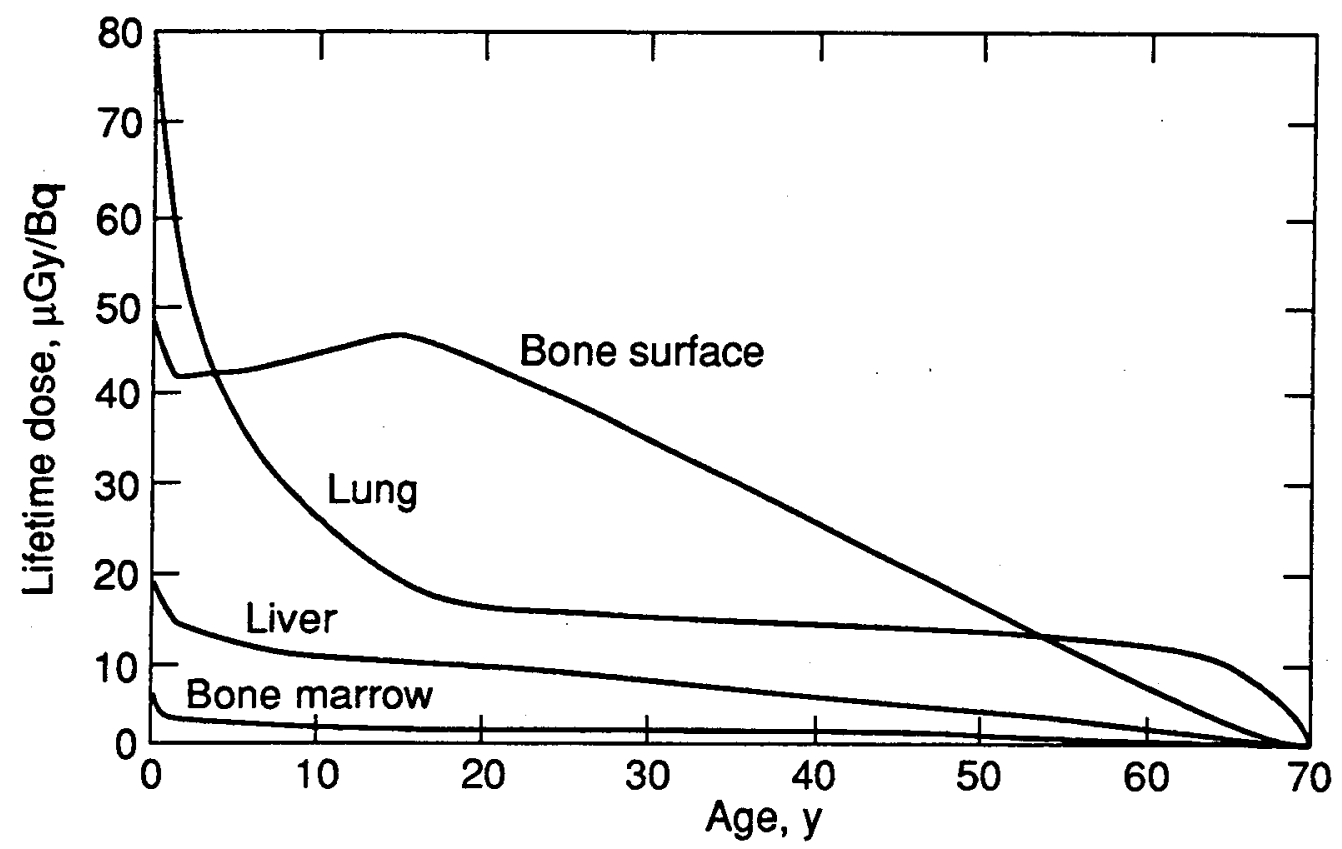

Figure 18. Cumulative lifetime doses to age 70 y for selected body organs based on instantaneous respiratory exposures at different ages.

Table 3. Exposure-normalized dose-conversion factors calculated for different exposure scenarios and organs.

\begin{tabular}{lcc}
\hline \hline & \multicolumn{2}{c}{ Exposure-normalized dose-conversion factors } \\
& $\overline{\mathrm{F}}_{\mathrm{i} \text { in }}$ & $\overline{\mathrm{F}}_{\mathrm{i} \text { out }}$ \\
\cline { 2 - 3 } Exposure scenario/tissue & \multicolumn{2}{c}{$\mathrm{m}^{3}-\mu \mathrm{Gy} \mathrm{y}^{-1}-\mathrm{Bq}^{-1}$} \\
\hline Residential/Farm & & \\
Bone surfaces & $6.7 \times 10^{4}$ & $3.9 \times 10^{3}$ \\
Liver & $1.6 \times 10^{4}$ & $9.4 \times 10^{2}$ \\
Lung & $4.1 \times 10^{4}$ & $2.7 \times 10^{3}$ \\
Bone marrow & $3.8 \times 10^{3}$ & $2.3 \times 10^{2}$ \\
Commercial & & \\
Bone surfaces & $3.1 \times 10^{4}$ & $2.0 \times 10^{3}$ \\
Liver & $6.7 \times 10^{3}$ & $4.3 \times 10^{2}$ \\
Lung & $1.7 \times 10^{4}$ & $1.1 \times 10^{3}$ \\
Bone marrow & $1.7 \times 10^{3}$ & $1.1 \times 10^{2}$ \\
\hline \hline
\end{tabular}


marrow receives less than $10 \%$ of the dose to the other organs. Differences between the $\overline{\mathrm{F}}_{\mathrm{i}, \mathrm{in}}$ and $\bar{F}_{i, \text { out }}$ variables are due to breathing rates used for indoor/outdoor locations and the amounts of time spent indoors and outdoors. The values of $\bar{F}_{i, \text { out }}$ for a resident farmer would increase by a factor of approximately five if the value of $\mathrm{T}_{\text {out }}$ were equivalent to $3 \mathrm{~h} \mathrm{~d}^{-1}$ (12.5\% of a day) spent outside in the immediate vicinity of a farmhouse. An increased breathing rate associated with a metabolic equivalent energy expenditure of 1.8 would only increase the active breathing rate by about $25 \%$.

Variability in the $\overline{\mathrm{F}}_{\mathrm{i}, \text { in }}$ and $\overline{\mathrm{F}}_{\mathrm{i} \text {,out }}$ parameters between individuals will be due to interindividual variations in breathing rates, time spent indoor/outdoors, and biodosimetric parameters such as the fractions of inhaled Pu deposited in different tissues, residence times in organs, etc. As a means of characterizing the variability of the exposure-weighted doseconversion factors, we reviewed data from various studies that included measurements of the burdens of $239,240 \mathrm{Pu}$ in autopsy samples of livers, lungs, and bone from people exposed to fallout $\mathrm{Pu}$. Table 4 summarizes the geometric standard deviations of the tissue analyses. Most of the researchers found that burdens of $239,240 \mathrm{Pu}$ in organs were lognormally distributed, with GSD values ranging from 1.48 to 2.66 . We have chosen a GSD value of 2 to represent the variability in our dose-conversion factors for those organs, as this represents an intermediate value of the GSDs listed in Table 4. Because the 239,240 Pu burdens in organs are unlikely to be independent, we must also quantify correlations between the doses estimated for the different organs. Bunzl and Kracke (1983), for example, reported positive correlations between $239,240 \mathrm{Pu}$ in 30 autopsy samples of livers and lungs (based on the log-transformed burdens) from individuals who lived in Germany. However, neither they nor Takizawa et al. (1987) found a statistically significant correlation between age and burden. To explore further the relationship between the $239,240 \mathrm{Pu}$ burdens in lungs, liver, and bone, we calculated the linear correlation coefficients between $239,240 \mathrm{Pu}$ burdens in autopsied organs from 28 individuals who had been exposed to $239,240 \mathrm{Pu}$ fallout in Great Britain (Popplewell et al., 1985). The linear correlation coefficient between the log-transformed $239,240 \mathrm{Pu}$ burdens in lung and liver was 0.88 , between lung and bone (femur) it was 0.77 , and between bone and liver it was 0.81 . We will use these correlations when generating correlated random variables representing the $\overline{\mathrm{F}}_{i \text {, in }}$ and $\overline{\mathrm{F}}_{\mathrm{i}}$, out parameters in the Monte-Carlo simulations.

\subsubsection{Organ-Specific Risk Factors}

Several major reviews have been published recently concerning the effectiveness of various forms of radiation to induce cancer in humans; several of these studies are of direct interest here. Broad general reviews have been published by the United Nations Scientific Committee on the Effects of Atomic Radiation (UNSCEAR, 1988), the U.S. National Academy of Sciences' Committee on the Biological Effects of Ionizing Radiation (BEIR) (USNAS, 1990), and the International Commission on Radiological Protection (ICRP, 1991). Other reviews, which specifically consider the effects of alpha radiation, are of more specific interest. These include ICRP Publication 50 (ICRP, 1987), which considers the lung-cancer risk from exposure to radon decay products, and a prior report from the USNAS (1988), which also considered the risk from radon and other internally deposited alpha-emitting radionuclides, specifically including $\mathrm{Pu}$. 
Table 4. Summary of the geometric standard deviations of the $239,240 \mathrm{Pu}$ burdens (i.e., activity/unit mass of tissue) in autopsy samples of livers, lungs; and bone tissue analyzed by various researchers.

\begin{tabular}{llcl}
\hline \multicolumn{1}{c}{ Organ } & Sample size & $\begin{array}{c}\text { Geometric standard } \\
\text { deviation }\end{array}$ & \multicolumn{1}{c}{ Ref. } \\
\hline Liver & 171 (male) & 2.03 & Griffith and Guilmette (1991) \\
Liver & 139 (female) & 1.91 & Griffith and Guilmette (1991) \\
Liver & 10 & 1.93 & Kawamura and Tanaka (1983) \\
Liver & 59 & 2.5 & Takizawa et al. (1987) \\
Liver & $10^{\mathrm{a}}$ & 2.5 & Singh et al. (1983) \\
Liver & $10^{\mathrm{b}}$ & 2.3 & Singh et al. (1983) \\
Liver & 28 & 2.04 & Popplewell et al. (1985) \\
Lung & $10^{\mathrm{a}}$ & 1.5 & Singh et al. (1983) \\
Lung & $10^{\mathrm{b}}$ & 1.9 & Singh et al. (1983) \\
Lung & 10 & 1.48 & Kawamura and Tanaka (1983) \\
Lung & 66 & 2.1 & Takizawa et al. (1987) \\
Lung & 28 & 2.66 & Popplewell et al. (1985) \\
Lung & 25 & 1.48 & Irlweck et al. (1980) \\
Bone & $7^{\mathrm{a}}$ & 1.3 & Singh et al. (1983) \\
Bone & $12^{\mathrm{b}}$ & 1.7 & Singh et al. (1983) \\
Vertebrae & 16 & 2.0 & Takizawa et al. (1987) \\
Femur & 28 & 1.63 & Popplewell et al. (1985) \\
Vertebrae & 6 & 2.30 & Kawamura and Tanaka (1983) \\
\hline \hline
\end{tabular}

a Autopsy samples from Washington, $\mathrm{DC}$.

b Autopsy samples from Grand Junction, $\mathrm{CO}$.

It is well established that most injected Pu ends up in the skeleton and liver (ICRP, 1986), and the latest ICRP metabolic model contains the assumption that of the total amount of Pu

reaching the blood stream $50 \%$ will be retained by the skeleton and $30 \%$ by the liver. Of the remainder, most goes to the muscle and skin. The same situation pertains for inhalation, except that most of the $\mathrm{Pu}$ will be swallowed and pass through the gastrointestinal tract without being absorbed and that which is retained in pulmonary tissue and which will enter the blood has a removal half-time of 500 days (ICRP, 1986).

Thus, the tissues at risk seem clearly to be the lung, liver, and bone. This is borne out by many animal studies, with most cancers occurring in lung and bone. The types of bone-related cancers observed do not include leukemia, but are typically bone sarcomas. This is compatible with the observation that $\mathrm{Pu}$ does concentrate on the bone surfaces, and not in the marrow (USNAS, 1988). A group of 26 white male early Pu workers at Los Alamos with known significant inhalation exposure to $\mathrm{Pu}$ have now been followed up for 42 years (Voelz and Lawrence, 1991). Of the 26, four have died of cancer. Three died of lung cancer, and were 
heavy smokers. One died of an osteosarcoma that is most probably a result of his exposure to $\mathrm{Pu}$.

The risk factor to the lung from exposure to alpha particles has received a great deal of attention lately because of concern about radon. The most recent review of data associated with radon exposures is that published by the ICRP (1991). On the basis of this review, the ICRP concluded that existing studies indicate a lifetime risk of $(1-4) \times 10^{-4}$ per Working Level Month (WLM) of exposure for members of an average population (the risk for non-smokers is less, perhaps by a factor of 4). Based on various dosimetry models of the lung and other assumptions, the calculated dose to the tracheobronchial region per unit of exposure varies from 4-13 mGy $\mathrm{WLM}^{-1}$ (ICRP, 1991). Using the geometric mean of both numbers, we calculate the risk factor to be $280 \times 10^{-4} \mathrm{~Gy}^{-1}$. Further, if we take the two ranges above to represent the $90 \%$ range, the geometric standard deviation (GSD) is calculated to be 1.74. This risk factor is broadly consistent with that recently published by Puskin (1992), who calculated a lifetime risk of $2.24 \times 10^{-4} \mathrm{WLM}^{-1}$ with a $90 \%$ range of $1.4 \times 10^{-4}$ to $5.7 \times 10^{-4} \mathrm{WLM}^{-1}$. From data in Puskin's paper we calculate a geometric standard deviation of 1.53 , whereas the equivalent number for the range of $(1-4) \times 10^{-4} \mathrm{WLM}^{-1}$ is 1.52 .

There have not been as many attempts to derive a risk factor for bone surfaces. The UNSCEAR (1988) stated that the data would not support the derivation of a risk factor. The later report of the ICRP (1991), however, supported the use of a value from USNAS (1988, p. 208), which is derived from a life-table analysis of patients injected with ${ }^{224} \mathrm{Ra}$. The value is $(133 \pm 36) \times 10^{-4} \mathrm{~Gy}^{-1}$, which the ICRP corrected for a lethality factor of 0.7 . To match our desire to use lognormal functions, this was converted to a geometric mean of $90 \times 10^{-4} \mathrm{~Gy}^{-1}$ with a GSD of 1.31. Puskin et al. (1992) have recently pointed out that the original value of $(133 \pm 36) \times 10^{-4} \mathrm{~Gy}^{-1}$ was based on the average skeletal dose, not the dose to the bone surface. As the dose to the tissue at risk, the bone surface, is 7.5 times higher than the average skeletal dose, they argue that the risk factor should be divided by 7.5, if it is to be applied to the calculated dose to the bone surface. This concept has been cautiously endorsed by Bair and Sinclair (1992). This would result in a risk factor of about $10^{-3}$ lethalities $\mathrm{Gy}^{-1}$. However, as mentioned above, there is one case of bone sarcoma amongst the 26 early Pu workers at Los Alamos (Voelz and Lawrence, 1991), and there seems to be little doubt that this rare cancer is a radiogenic sarcoma. From the Voelz and Lawrence paper we have estimated that the collective dose to the bone surface of the 26 workers was $\sim 20$ person-Gy. Thus, the risk factor calculated from this study would be $-500 \times 10^{-4} \mathrm{~Gy}^{-1}$, but the uncertainty (90\% range) is from $26 \times 10^{-4} \mathrm{~Gy}$ to $2120 \times 10^{-4} \mathrm{~Gy}^{-1}$. While the associated uncertainty is large, one would have a difficult time arguing that the actual risk from chronic exposure is near zero or far less than the value of $90 \times 10^{-4}$ derived above. Also, the surviving 22 individuals are now elderly and therefore it is not anticipated that they will accumulate a greatly increased collective dose. At the same time, however, it is quite possible that yet more bone sarcomas will be found.

Lloyd et al. (1993) have recently published the results of a lifespan study of beagles injected with Pu. They extrapolate to man a risk factor of $548 \times 10^{-4} \mathrm{~Gy}^{-1}$ for the average dose to the skeleton. This is equivalent to a risk factor of $70 \times 10^{-4} \mathrm{~Gy}^{-1}$ for dose to the bone surfaces. Thus, we have elected to use the value of $90 \times 10^{-4} \mathrm{~Gy}^{-1}$, but it seems clear that the GSD value of 1.31 is too small. This is especially true with consideration of the reported wide variation in the amount of Pu that does end up in the skeleton (Kathren et al., 1988). Thus, the GSD (1.74) 
for the lung-risk factor has been used as a more likely default value for the GSD for the bonesurface-risk factor.

Even fewer data are available for the induction of liver cancer by radiation. The only solid body of evidence concerns the many individuals who were injected with ${ }^{232} \mathrm{Th}$ in the form of "Thorotrast." Again, the ICRP (1991) refers to the analysis of lifetime excess risk done by the USNAS (1988). The calculated risk coefficient for three major studies varies from $(260-300) \times 10^{-4} \mathrm{~Gy}^{-1}$. For our calculations, we will use the value of $280 \times 10^{-4} \mathrm{~Gy}^{-1}$ and also use the GSD of 1.74 for the lung-risk factor as the default value for the GSD for the liver-risk factor.

\subsection{Predicted Cancer Risks and Associated Uncertainties}

The cancer risks for individuals inhabiting a suburban residence, living in a farm house, or working at a commercial facility at the shot locations were calculated for periods of $100,50,000$, and $100,000 \mathrm{y}$ in order to evaluate the long-term risks associated with the possible loss of institutional controls at the NTS. As a cautionary note, we stress that our risk estimates for such lengthy time frames are predicated on the existence of exposure scenarios that are consistent with our previous characterizations (i.e., activity patterns, housing properties, etc.). Results of the site-specific risk assessments are shown in Table 5 as the 5,50 , and $95 \%$ percentiles of incremental cancer risk from the cumulative probability distributions generated by the MonteCarlo simulations. The resident farmer is shown to have the highest risk of the three exposure scenarios. Principal factors contributing to that risk are long tenure and higher concentrations of $239,240 \mathrm{Pu}$ in indoor air due to the lack of indoor filtration afforded by a central heating/cooling unit. At the median risk level, the resident farmer's risk is more than a factor of three higher than the suburban resident and about a factor of ten higher than the worker at a commercial facility. The resident farmer's estimated risk, though, could be a factor of five to ten higher if additional assumptions were made regarding time spent outside adjacent to a farmhouse and an increased inhalation rate associated with physical labor. These results demonstrate that exposure scenarios incorporating lifestyle factors such as mobility and indoor/outdoor relationships for soil-derived contaminants can result in significant differences in the levels of cancer risk predicted for individuals whose lifestyles match the reference scenarios.

A survey of the predicted cancer risks for the various shot sites given in Table 5 indicates that the highest risks are associated with Area 11 or Plutonium Valley. The resident farmer's cancer risk, for example, exceeds $10^{-4}$ at the 95 th cumulative percentile level calculated for an assumed loss of institutional control at 100 years from the present. At 50,000 and 100,000 y in the future, the predicted cancer risks are all below $10^{-6}$, which indicates that we have covered the principal time domain during which future adverse effects might occur.

To gain additional insights to the sources of uncertainty in the cancer risks, we analyzed how much of the variance in our risk estimates was derived from each of the following parameters: resuspension rates, concentrations of $239,240 \mathrm{Pu}$ in soil, indoor/outdoor concentrations of $239,240 \mathrm{Pu}$, mobility, and organ-specific risk factors for cancer. For this analysis, we completed a series of Monte-Carlo simulations in which only one parameter was allowed to vary randomly, while the other parameters were held constant at their mean value. Because the calculated risks are determined essentially from a multiplicative model, the sum of the individual log variances in 
Table 5. Results of Monte-Carlo simulations of the cancer risks associated with three different land uses at three shot sites at the NTS.

\begin{tabular}{|c|c|c|c|c|c|}
\hline \multirow[b]{2}{*}{ Site } & \multirow[b]{2}{*}{ Year } & \multirow[b]{2}{*}{ Land use } & \multicolumn{3}{|c|}{ Cumulative cancer risk } \\
\hline & & & $5 \%$ & $50 \%$ & $95 \%$ \\
\hline \multirow[t]{12}{*}{ Area 13} & 100 & Residential & $7 \times 10^{-8}$ & $7 \times 10^{-7}$ & $7 \times 10^{-6}$ \\
\hline & & Farm & $1 \times 10^{-7}$ & $2 \times 10^{-6}$ & $2 \times 10^{-5}$ \\
\hline & & Commercial & $2 \times 10^{-8}$ & $3 \times 10^{-7}$ & $3 \times 10^{-6}$ \\
\hline & 10,000 & Residential & $8 \times 10^{-9}$ & $9 \times 10^{-8}$ & $1 \times 10^{-6}$ \\
\hline & & Farm & $2 \times 10^{-8}$ & $3 \times 10^{-7}$ & $3 \times 10^{-6}$ \\
\hline & & Commercial & $5 \times 10^{-9}$ & $5 \times 10^{-8}$ & $5 \times 10^{-7}$ \\
\hline & 50,000 & Residential & $6 \times 10^{-11}$ & $6 \times 10^{-10}$ & $6 \times 10^{-9}$ \\
\hline & & Farm & $2 \times 10^{-10}$ & $2 \times 10^{-9}$ & $2 \times 10^{-8}$ \\
\hline & & Commercial & $9 \times 10^{-11}$ & $9 \times 10^{-10}$ & $3 \times 10^{-9}$ \\
\hline & 100,000 & Residential & $3 \times 10^{-12}$ & $3 \times 10^{-11}$ & $7 \times 10^{-11}$ \\
\hline & & Farm & $4 \times 10^{-12}$ & $4 \times 10^{-11}$ & $8 \times 10^{-11}$ \\
\hline & & Commercial & $2 \times 10^{-12}$ & $2 \times 10^{-11}$ & $5 \times 10^{-11}$ \\
\hline \multirow[t]{12}{*}{ Clean Slate II } & 100 & Residential & $2 \times 10^{-7}$ & $2 \times 10^{-6}$ & $2 \times 10^{-5}$ \\
\hline & & Farm & $5 \times 10^{-7}$ & $7 \times 10^{-6}$ & $5 \times 10^{-5}$ \\
\hline & & Commercial & $8 \times 10^{-8}$ & $1 \times 10^{-6}$ & $1 \times 10^{-5}$ \\
\hline & 10,000 & Residential & $3 \times 10^{-8}$ & $3 \times 10^{-7}$ & $4 \times 10^{-6}$ \\
\hline & & Farm & $9 \times 10^{-8}$ & $9 \times 10^{-7}$ & $9 \times 10^{-6}$ \\
\hline & & Commercial & $2 \times 10^{-8}$ & $2 \times 10^{-7}$ & $2 \times 10^{-6}$ \\
\hline & 50,000 & Residential & $2 \times 10^{-10}$ & $2 \times 10^{-9}$ & $2 \times 10^{-8}$ \\
\hline & & Farm & $8 \times 10^{-10}$ & $8 \times 10^{-9}$ & $6 \times 10^{-8}$ \\
\hline & & Commercial & $3 \times 10^{-10}$ & $3 \times 10^{-9}$ & $9 \times 10^{-9}$ \\
\hline & 100,000 & Residential & $1 \times 10^{-11}$ & $1 \times 10^{-10}$ & $2 \times 10^{-10}$ \\
\hline & & Farm & $2 \times 10^{-11}$ & $2 \times 10^{-10}$ & $4 \times 10^{-10}$ \\
\hline & & Commercial & $8 \times 10^{-12}$ & $8 \times 10^{-11}$ & $2 \times 10^{-10}$ \\
\hline \multirow[t]{12}{*}{ Area 11 D site } & 100 & Residential & $2 \times 10^{-6}$ & $2 \times 10^{-5}$ & $2 \times 10^{-4}$ \\
\hline & & Farm & $4 \times 10^{-6}$ & $6 \times 10^{-5}$ & $5 \times 10^{-4}$ \\
\hline & & Commercial & $6 \times 10^{-7}$ & $8 \times 10^{-6}$ & $9 \times 10^{-5}$ \\
\hline & 10,000 & Residential & $2 \times 10^{-7}$ & $3 \times 10^{-6}$ & $3 \times 10^{-5}$ \\
\hline & & Farm & $7 \times 10^{-7}$ & $8 \times 10^{-6}$ & $8 \times 10^{-5}$ \\
\hline & & Commercial & $1 \times 10^{-7}$ & $1 \times 10^{-6}$ & $1 \times 10^{-5}$ \\
\hline & 50,000 & Residential & $2 \times 10^{-9}$ & $2 \times 10^{-8}$ & $2 \times 10^{-7}$ \\
\hline & & Farm & $1 \times 10^{-8}$ & $1 \times 10^{-7}$ & $5 \times 10^{-7}$ \\
\hline & & Commercial & $3 \times 10^{-9}$ & $3 \times 10^{-8}$ & $8 \times 10^{-8}$ \\
\hline & 100,000 & Residential & $1 \times 10^{-10}$ & $1 \times 10^{-9}$ & $2 \times 10^{-9}$ \\
\hline & & Farm & $3 \times 10^{-10}$ & $3 \times 10^{-9}$ & $5 \times 10^{-9}$ \\
\hline & & Commercial & $7 \times 10^{-11}$ & $7 \times 10^{-10}$ & $1 \times 10^{-9}$ \\
\hline
\end{tabular}


the various input parameters should equal (approximately) the log variance in cancer risk. The fraction of total variance in estimated risk that is attributable to a given parameter is determined simply as the ratio of the log variance in cancer risk due solely to the variation in a given parameter and the total $\log$ variance in risk from all the random variations in the model parameters. In Figure 19 we show the contributions to total variance in the predicted cancer risks for the residential scenario for Area 13 at $100 \mathrm{y}$ from the present. The principal source of variance in cancer risk is the mobility of residents $(68.6 \%)$, followed by the exposure-weighted dose factors $(17.1 \%)$, the ratio $\mathrm{C}_{\mathrm{in}} / \mathrm{C}_{\mathrm{s}}$ used to relate levels of $239,240 \mathrm{Pu}$ in outdoor soil to concentrations in indoor air $(9.4 \%)$, and the cancer-risk factors $(4.9 \%)$. Variation in the resuspension rate and the concentration of $239,240 \mathrm{Pu}$ in soil contributed little to the total variance. However, at 50,000 y the resuspension rate becomes the principal source of variation in predicted risks. This is because the resuspension rate appears within an exponential term as the negative product of time (see Eq. 5), and so as time increases, the value of the resulting exponential term eventually becomes the primary determinant of the concentration of $239,240 \mathrm{Pu}$ in air and hence cancer risk as well. Thus, for any given exposure scenario occurring over a person's lifetime, the resuspension rate will contribute little to overall risk, but when risks are predicted far into the future, the resuspension rate can become an important parameter. 


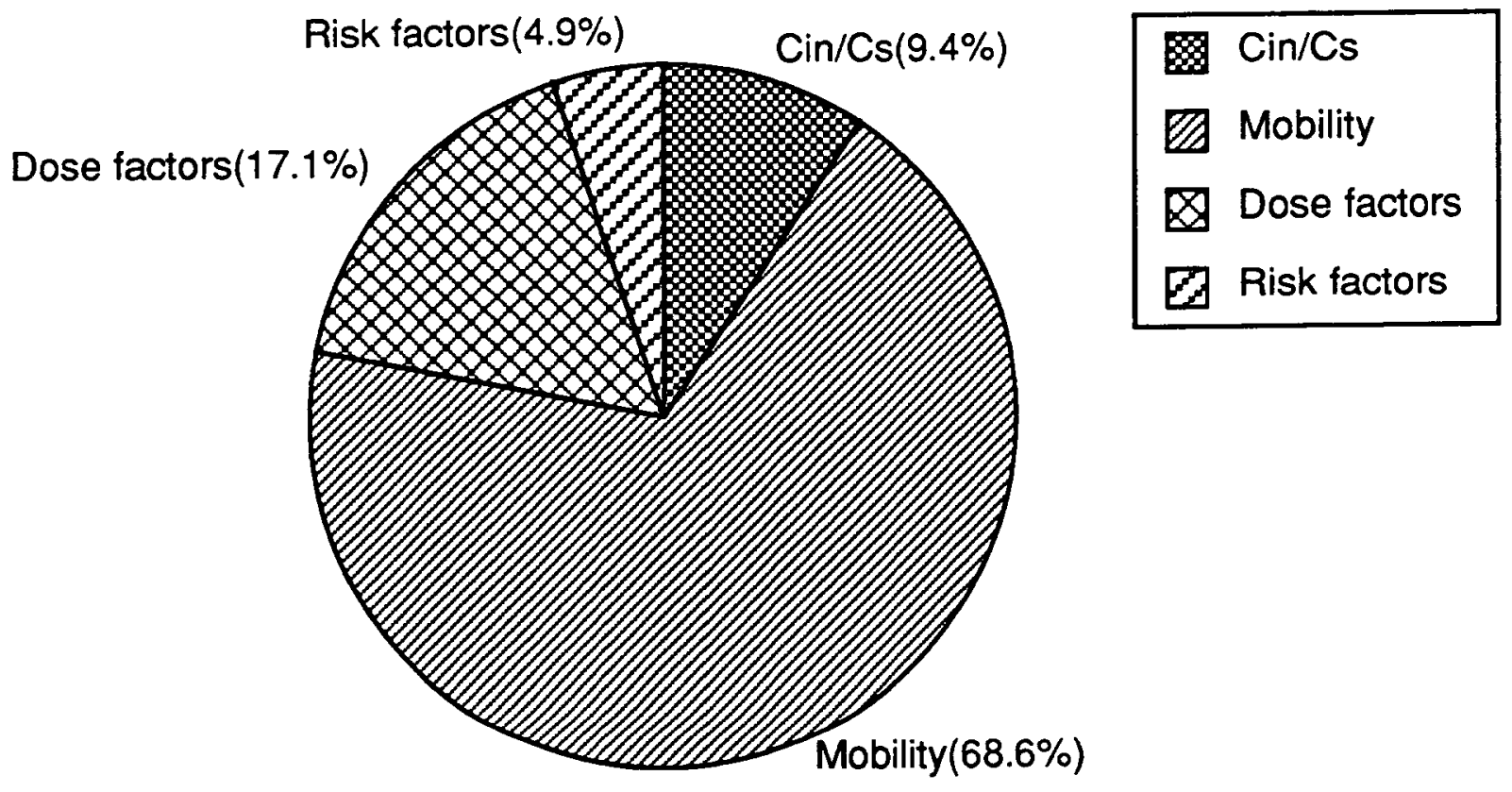

Figure 19. Sources of variance in the estimated cancer risks for the residential exposure scenario for Area 13 at $100 \mathrm{y}$. 
Appendix A

Supporting Data 
Table A-1. Summary of the residual concentrations and inventories of $239,240 \mathrm{Pu}$ in soils at shot sites at the NTS (from Gilbert, 1977).

\begin{tabular}{|c|c|c|c|c|c|c|c|c|}
\hline \multirow[b]{2}{*}{ Site } & \multirow{2}{*}{$\begin{array}{c}\text { Survey } \\
\text { strata }\end{array}$} & \multirow{2}{*}{$\begin{array}{c}\text { Strata Area } \\
\mathrm{m}^{2}\end{array}$} & \multicolumn{3}{|c|}{ Mean Concentration } & \multicolumn{3}{|c|}{ Estimated Inventory } \\
\hline & & & $\mu \mathrm{Ci} \mathrm{m}{ }^{-2}$ & & $( \pm S E)$ & $\mathrm{Ci}$ & & ( \pm SE) \\
\hline \multirow[t]{7}{*}{13} & 1 & $1,245,000$ & 1.9 & \pm & 0.34 & 2.4 & \pm & 0.42 \\
\hline & 2 & $2,547,000$ & 5.8 & \pm & 1.4 & 15 & \pm & 3.6 \\
\hline & 3 & 108,00 & 23 & \pm & 4.3 & 2.5 & \pm & 0.46 \\
\hline & 4 & 74,000 & 54 & \pm & 8.8 & 4.0 & \pm & 0.65 \\
\hline & 5 & 19,000 & 110 & \pm & 19 & 2.1 & \pm & 0.36 \\
\hline & 6 & 24,000 & 820 & \pm & 340 & 20 & \pm & 8.2 \\
\hline & Total & $4,017,000$ & & & & 46 & \pm & 9.0 \\
\hline 5 & 1 & 111,300 & 3.1 & \pm & 0.66 & 0.35 & \pm & 0.073 \\
\hline \multirow[t]{5}{*}{ (GMX) } & 2 & 8,400 & 42 & \pm & 9.1 & 0.35 & \pm & 0.076 \\
\hline & 3 & 800 & 270 & \pm & 64 & 0.22 & \pm & 0.051 \\
\hline & 4 & 1,000 & 530 & \pm & 150 & 0.53 & \pm & 0.15 \\
\hline & 5 & 3,800 & 4.6 & \pm & 1.6 & $\underline{0.02}$ & \pm & 0.006 \\
\hline & Total & 125,300 & 1.5 & \pm & 0.19 & 1.5 & \pm & 0.19 \\
\hline Double & 1 & 176,000 & 6.7 & \pm & 3.5 & 1.2 & \pm & 0.62 \\
\hline \multirow[t]{4}{*}{ Tracks } & 2 & 1,600 & 350 & \pm & 250 & 0.56 & \pm & 0.40 \\
\hline & 3 & 800 & 190 & \pm & 59 & 0.15 & \pm & 0.047 \\
\hline & 4 & 600 & 4.6 & \pm & 1.6 & 1.7 & \pm & 0.60 \\
\hline & Total & 179,000 & & & & 3.6 & \pm & 0.95 \\
\hline Clean & 1 & 157,000 & 15 & \pm & 7.0 & 2.4 & \pm & 1.1 \\
\hline \multirow[t]{4}{*}{ Slate I } & 2 & 10,000 & 64 & \pm & 22 & 0.64 & \pm & 0.22 \\
\hline & 3 & 8,400 & 110 & \pm & 35 & 0.92 & \pm & 0.29 \\
\hline & 4 & 1,700 & 120 & \pm & 39 & 0.20 & \pm & 0.066 \\
\hline & Total & 177,100 & & & & 4.2 & \pm & 1.2 \\
\hline Clean & 1 & 351,000 & 4.1 & \pm & 1.3 & 1.4 & \pm & 0.46 \\
\hline \multirow[t]{4}{*}{ Slate II } & 2 & 82,300 & 73 & \pm & 30 & 6.0 & \pm & 2.5 \\
\hline & 3 & 26,200 & 270 & \pm & 99 & 7.1 & \pm & 2.6 \\
\hline & 4 & 11,000 & 260 & \pm & 65 & 2.9 & \pm & 0.72 \\
\hline & Total & 470,500 & & & & 17 & \pm & 3.7 \\
\hline Clean & 1 & $1,615,000$ & 12 & \pm & 2.2 & 19.4 & \pm & 3.6 \\
\hline \multirow[t]{4}{*}{ Slate III } & 2 & 61,000 & 58 & \pm & 16 & 3.5 & \pm & 0.98 \\
\hline & 3 & 40,000 & 210 & \pm & 63 & 8.4 & \pm & 2.5 \\
\hline & 4 & 16,000 & 370 & \pm & 190 & 5.9 & \pm & 3.0 \\
\hline & Total & $1,732,000$ & & & & 37 & \pm & 5.4 \\
\hline
\end{tabular}


Table A-1. (Continued)

\begin{tabular}{|c|c|c|c|c|c|c|c|c|}
\hline \multirow[b]{2}{*}{ Site } & \multirow{2}{*}{$\begin{array}{c}\text { Survey } \\
\text { strata }\end{array}$} & \multirow{2}{*}{$\begin{array}{c}\text { Strata Area } \\
\mathbf{m}^{2}\end{array}$} & \multicolumn{3}{|c|}{ Mean Concentration } & \multicolumn{3}{|c|}{ Estimated Inventory } \\
\hline & & & $\mu \mathrm{Ci} \mathrm{m} \mathrm{m}^{-2}$ & & $( \pm \mathrm{SE})$ & $\mathbf{C i}$ & & $( \pm \mathbf{S E})$ \\
\hline \multirow{4}{*}{$\begin{array}{l}11 \\
\text { B Site }\end{array}$} & 2 & 8,200 & 30 & \pm & 18 & 0.25 & \pm & 0.15 \\
\hline & 3 & 6,000 & 220 & \pm & 55 & 1.3 & \pm & 0.33 \\
\hline & 4 & 3,300 & 1,400 & \pm & 300 & 4.6 & \pm & 0.99 \\
\hline & Total & 17,500 & & & & 6.2 & \pm & 1.1 \\
\hline \multirow{5}{*}{$\begin{array}{l}11 \\
\text { C Site }\end{array}$} & 2 & 16,400 & 34 & \pm & 22 & 0.56 & \pm & 0.36 \\
\hline & 3 & 13,300 & 88 & \pm & 25 & 0.49 & \pm & 0.14 \\
\hline & 4 & 3,500 & 1,400 & \pm & 390 & 4.9 & \pm & 1.4 \\
\hline & 5 & 300 & 6,200 & \pm & 2,800 & 1.9 & \pm & 0.84 \\
\hline & Total & 25,800 & & & & 7.8 & \pm & 1.7 \\
\hline \multirow{5}{*}{$\begin{array}{l}11 \\
\text { D Site }\end{array}$} & 2 & 32,300 & 46 & \pm & 9.5 & 1.5 & \pm & 0.31 \\
\hline & 3 & 13,300 & 220 & \pm & 86 & 2.9 & \pm & 1.1 \\
\hline & 4 & 4,900 & 990 & \pm & 370 & 4.9 & \pm & 1.8 \\
\hline & 5 & 2,900 & 2,700 & \pm & 840 & 7.8 & \pm & 2.4 \\
\hline & Total & 53,400 & & & & 17.1 & \pm & 3.2 \\
\hline CD Overlap & 6 & 62,200 & 12 & \pm & 5.2 & 0.75 & \pm & 5.2 \\
\hline
\end{tabular}

Table A-2. Summary of data on lead and dust in the indoor environment.

\begin{tabular}{|c|c|c|c|c|c|}
\hline \multirow[b]{2}{*}{ Location } & \multirow{2}{*}{$\begin{array}{c}\text { Number } \\
\text { of } \\
\text { dwellings }\end{array}$} & \multirow{2}{*}{$\begin{array}{c}\mathrm{Pb} \text { in dust } \\
\mu \mathrm{g} \mathrm{g}^{-1}\end{array}$} & \multicolumn{2}{|c|}{ Loadings on floor/carpets } & \multirow[b]{2}{*}{ References } \\
\hline & & & $\mu \mathrm{g} \mathrm{Pb} \mathrm{m}{ }^{-2}$ & mg Dust $m^{-2}$ & \\
\hline \multirow[t]{2}{*}{ Christchurch, NZ } & 65 & 515 & 423 & 804 & $\begin{array}{l}\text { Fergusson and } \\
\text { Schroeder, } 1985\end{array}$ \\
\hline & 22 & 590 & 349 & 525 & \\
\hline Edinburgh, Scotland & 10 & 381 & 52 & 136 & Laxen et al., 1988 \\
\hline Birmingham, UK & 97 & 336 & 60 & 179 & Davies et al., 1990 \\
\hline \multicolumn{6}{|l|}{ Cincinnati, $\mathrm{OH}^{\mathbf{a}}$} \\
\hline Public & 12 & 350 & 200 & 571 & Clark et al., 1985 \\
\hline Rehabilitated & 46 & 623 & 370 & 594 & \\
\hline Private & 33 & 1410 & 750 & 532 & \\
\hline Champaign-Urban, IL & 12 & 500 & 440 & 870 & $\begin{array}{l}\text { Solomon and } \\
\text { Hartford, } 1976\end{array}$ \\
\hline \multirow[t]{2}{*}{$\begin{array}{l}\text { Arnhem, The } \\
\text { Netherlands }\end{array}$} & 107 & $\begin{array}{c}282 \\
\text { (coarse) }\end{array}$ & 123 & 255 & Diemel et al., 1981 \\
\hline & & $\begin{array}{r}957 \\
\text { (fine) }\end{array}$ & & & \\
\hline
\end{tabular}

a Excludes deteriorating and dilapidated housing 


\section{References}

Allott, R.W., M. Kelly, and C.N. Hewitt (1992), "Behavior of Urban Dust Contaminated by Chernobyl Fallout: Environmental Half-Lives and Transfer Coefficients," Environ. Sci. Technol. 26, 2142-2147.

Anspaugh, L.R. and P.L. Phelps (1974), "Results and Data Analysis: Resuspension Element Status Report," in The Dynamics of Plutonium in Desert Environments, Nevada Applied Ecology Group Progress Report, P.B. Dunaway and M.G. White, Eds., U.S. Atomic Energy Commission, Nevada Operations Office, NVO-142, 265-297.

Anspaugh, L.R., P.L. Phelps, N.C. Kennedy, J.H. Shinn and J.M. Reichman (1976), "Experimental Studies on the Resuspension of Plutonium from Aged Sources at the Nevada Test Site," in Atmosphere-Surface Exchange of Particulate and Gaseous Pollutants, Proceedings of a Symposium held at Richland, Washington, September 4-6, 1974, Technical Information Center, Energy Research and Development Administration, Washington, DC, pp. 727-743.

Anspaugh, L.R., J.H. Shinn and D.W. Wilson (1974), "Evaluation of the Resuspension Pathway Toward Protective Guidelines for Soil Contamination with Radioactvity," in Population Dose Evaluation and Standards for Man and His Environment, International Atomic Energy Agency, Vienna, pp. 513-524.

Anspaugh, L.R., J.H. Shinn, P.L. Phelps and N.C. Kennedy (1975), "Resuspension and Redistribution of Plutonium in Soils," Health Phys. 29, 571-582.

Bair, W.J. and W.K. Sinclair (1992), "Response to Drs. Puskin and Nelson Note," Health Phys. 63,590 .

Bunzl, K. and W. Kracke (1983), "Fallout 239/240 Pu and 238Pu in Human Tissues from the Federal Republic of Germany," Health Phys. 44, Suppl. 1, 441-449.

Calabrese, E.J. and E.J. Stanek (1992), "What Proportion of Household Dust is Derived from Outdoor Soil?" J. Soil Contamin. 1, 253-263.

Clark, C.S., R.L. Bornschein, P. Succop, S.S. Que Hee, P.B. Hammond and B. Peace (1985), "Condition and Type of Housing as an Indicator of Potential Environmental Lead Exposure and Pediatric Blood Lead Levels," Environ. Res. 38, 46-53.

Cohen, A.F. and B.L. Cohen (1980), "Protection from Being Indoors Against Inhalation of Suspended Particulate Matter of Outdoor Origin," Atmos. Environ. 14, 183-184.

Davies, D.J.A., I. Thornton, J.M. Watt, E.B. Culbard, P.G. Harvey, H.T. Delves, J.C. Sherlock, G.A. Smart, J.F.A. Thomas and M.J. Quinn (1990), "Lead Intake and Blood Lead in TwoYear-Old U.K. Urban Children," Sci. Total Environ. 90, 13-29.

Diemel, J.A.L., B. Brunekreef, J.S.M. Boleij, K. Biersteker and S.J. Veenstra (1981), "The Arnhem Lead Study II. Indoor Pollution, and Indoor/Outdoor Relationships," Environ. Res. $25,449-456$. 
Engelmann, R.J. (1992), "Sheltering Effectiveness Against Plutonium Provided by Buildings," Atmos. Environ. 26A, 2037-22044.

Fergusson, J.E., E.A. Forbes, R.J. Schroeder and D.E. Ryan (1986), "The Elemental Composition and Sources of House Dust and Street Dust," Sci. Total Environ. 50, 217-221.

Fergusson, J.E. and R.J. Schroeder (1985), "Lead in House Dust of Christchurch, New Zealand: Sampling, Levels and Sources," Sci. Total Environ. 46, 61-72.

Gilbert, R.O. (1977), "Revised Total Amounts of $239,240 \mathrm{Pu}$ in Surface Soil at Safety-Shot Sites," in Transuranics in Desert Ecosystems, M.G. White, P.B. Dunaway and D.L. Wireman, Eds., U.S. Department of Energy, Nevada Operations Office, Las Vegas, NV, NVO-181, pp. 423429.

Gilbert, R.O., L.L. Eberhardt, E.B. Fowler, E.M. Romney, E.H. Essington, and J.E. Kinnear (1975), "Statistical Analysis of $239,240 \mathrm{Pu}$ and ${ }^{241} \mathrm{Am}$ Contamination of Soil and Vegetation on NAEG Study Sites," in The Radioecology of Plutonium and other Transuranics in Desert Environments, U.S. Energy Research and Development Administration, Nevada Operations Office, Las Vegas, NV (NVO-153).

Gilbert, R.O. and L.L. Eberhardt (1974), "Statistical Analysis of Pu in Soils at the Nevada Test Site-Some Results," in The Dynamics of Plutonium in Desert Environments, P.B. Dunaway and M.G. White, Eds., U.S. Atomic Energy Commission, Nevada Operations Office, Las Vegas, NV, NVO-142.

Griffith, W.C. and R.A. Guilmette (1991), "Multiparameter Analysis of Fall-Out Plutonium Burdens in Human Liver," Radiat. Prot. Dosim. 38, 113-119.

Hartmann, G., C. Thom and K. Bächmann (1989), "Sources for Pu in Near Surface Air," Health Phys. 56, 55-69.

Hayes, S.R. (1989), "Estimating the Effect of Being Indoors on Total Personal Exposure to Outdoor Air Pollution," J. Air Poll. Control Assoc. 39, 1453-1461.

Healy, J.W. (1971), Surface Contamination: Decision Levels, Los Alamos Scientific Laboratory, Los Alamos, NM, LA-4558-MS.

ICRP (1979), Limits for Intakes of Radionuclides by Workers, ICRP Publication 30 Part 1, Pergamon Press, New York, NY.

ICRP (1986), "The Metabolism of Plutonium and Related Elements," Annals ICRP 16 (2/3).

ICRP (1987), "Lung Cancer Risk from Indoor Exposures to Radon Daughters," Annals ICRP 17 (1).

ICRP (1990), Age-Dependent Doses to Members of the Public from Intake of Radionuclides: Part 1, ICRP Publication 56, Pergamon Press, New York, NY.

ICRP (1991), "1990 Recommendations of the International Commission on Radiological Protection," Annals ICRP 21 (1-3).

Irlweck, K., C. Friedmann, and T. Schonfeld (1980), "Plutonium in the Lungs of Austrian Residents," Health Phys. 39, 95-99. 
Kathren, R.L., J.F. McInroy, M.M. Reichert, and M.J. Swint (1988), "Partitioning of 238Pu, ${ }^{239} \mathrm{Pu}$ and ${ }^{241} \mathrm{Am}$ in Skeleton and Liver of U.S. Transuranium Registry Autopsy Cases," Health Phys. 54: 181-188.

Kawamura, H. and G. Tanaka (1983), "Actinides Concentrations in Human Tissues," Health Phys. 44, Suppl. 1, 451-456.

Kercher, J.R. and L.R. Anspaugh (1991), "Analysis of the Nevada-Applied-Ecology-Group Model of Transuranic Radionuclide Transport and Dose," J. Environ. Radioact. 13, 191-216.

Laxen, D.P.H., F. Lindsay, G.M. Raab, R. Hunter, G.S. Fell and M. Fulton (1988), "The Variability of Lead in Dusts Within the Homes of Young Children," Environ. Geochem. Health 10, 3-9.

Layton, D.W. (1993), "Metabolically Consistent Breathing Rates for use in Dose Assessments," Health Phys. 64, 23-36.

Lefcoe, N.M. and I.I. Inculet (1975), "Particulates in Domestic Premises II. Ambient Levels and Indoor-Outdoor Relationships," Arch. Environ. Health 30, 565-570.

Leggett, R.W. (1985), "A Model of the Retention, Translocation and Excretion of Systemic Pu," Health Phys. 49, 1115-1137.

Lloyd, R.D., G.N. Taylor, W. Angus, F.W. Bruenger, and S.C. Miller (1993), "Bone Cancer Occurrence among Beagles Given ${ }^{239} \mathrm{Pu}$ as Young Adults," Health Phys. 64, 45-51.

Market Engineering Corporation (1991), Crystal Ball: A Forecasting and Risk Management Program for the Macintosh, Ver. 2.0, Market Engineering Corporation, Denver, CO.

Martin, W.E. and S.G. Bloom (1980), "Nevada Applied Ecology Group Model for Estimating Plutonium Transport and Dose to Man," in Transuranic Elements in the Environment, W.C. Hanson, Ed., U.S. Dept. of Energy, DOE/TIC-22800.

McArthur, R.D. (1991), Radionuclides in Surface Soil at the Nevada Test Site, Desert Research Institute, University of Nevada, Las Vegas, Water Resources Center, Publ. 45077, DOE/NV/10845-02.

Milford, J.B. and C.I. Davidson (1985), "The Sizes of Particulate Trace Elements in the Atmosphere-A Review," J. Air Pollut. Control Assoc. 35, 1249-1260.

Murphy, B.L. and J.E. Yocom (1986), Migration Factors for Particulates Entering the Indoor Environment, For Presentation at the 79th Annual Meeting of the Air Pollution Control Association, Minneapolis, MN, June 22-27, 1986, Paper number 86-7.2, pp. 2-15.

Nazaroff, W.W., S.M. Doyle, A.V. Nero and R.G. Sextro (1987), "Potable Water as a Source of Airborne 222Rn in U.S. Dwellings: A Review and Assessment," Health Phys. 52, 281-295.

Nicholson, K.W. (1988), “A Review of Particle Resuspension,” Atmos. Environ. 22, 2639-2651.

Ng, Y.C., L.R. Anspaugh and R.T. Cederwall (1990), “ORERP Internal Dose Estimates for Individuals," Health Phys. 59, 693-713.

Popplewell, D.S., G.J. Ham, T.E. Johnson, and S.F. Barry (1985), "Plutonium in Autopsy Tissues in Great Britain, Health Phys. 49, 304-309. 
Puskin, J.S. (1992), "An Analysis of the Uncertainties in Estimates of Radon-Induced Lung Cancer, Risk Anal. 12: 277-285.

Puskin, J.S., N.S. Nelson, and C.B. Nelson (1992), "Bone Cancer Risk Estimates," Health Phys. $63,579-580$.

Raunemaa, T., M. Kulmala, H. Saari, M. Olin and M.H. Kulmala (1989), "Indoor Air Aerosol Model-Transport Indoors and Deposition of Fine and Coarse Particles," Aerosol Sci. Technol. 11, 11-25.

Riumallo, J.A., D. Schoeller, G. Barrera, V. Gattas, and R. Uauy (1989), "Energy Expenditure in Underweight Free-Living Adults: Impact of Energy Supplementation as Determined by Doubly Labeled Water and Indirect Calorimetry," Am. J. Clin. Nutr. 49, 239-246.

Sehmel, G.A. (1980), "Particle Resuspension: A Review," Environ. Int. 4, 107-127.

Shah, J.J., R.L. Johnson, E.K. Heyerdahl, and J.J. Huntzicker (1986), "Carbonaceous Aerosol at Urban and Rural Sites in the United States," J. Air Poll. Control Assoc. 36, 254-257.

Shinn, J.H., E.H. Essington, F.L. Miller, T.P. O'Farrell, J.A. Orcutt, E.M. Romney, J.W. Shugart and E.R. Sorom (1989), "Results of a Cleanup and Treatment Test at the Nevada Test Site: Evaluation of Vacuum Removal of Pu-Contaminated Soil," Health Phys. 57, 771-779.

Shinn, J.H., D.N. Homan and C.B. Hoffmann (1986), A Summary of Plutonium Aerosol Studies: Resuspension at the Nevada Test Site, Lawrence Livermore National Laboratory, Livermore, CA, UCRL-90746.

Sinclair, J.D., L.A. Psota-Kelty and C.J. Weschler (1985), "Indoor/Outdoor Concentrations and Indoor Surface Accumulations of Ionic Substances," Atmos. Environ. 19, 315-323.

Sinclair, J.D., L.A. Psota-Kelty, G.A. Peins, and A.O. Ibidunni (1992), "Indoor/Outdoor Relationships of Airborne Ionic Substances: Comparisons of Electronic Equipment Room and Factory Environments," Atmos. Environ. 26A, 871-882.

Singh, N.P., M.E. Wrenn, and S.A. Ibrahim (1983), "Plutonium Concentration in Human Tissues: Comparison toThorium," Health Phys. 44, Suppl. 1, 469-476.

Smith, W.J., F.W. Whicker and H.R. Meyer (1982), "Review and Categorization of Saltation, Suspension, and Resuspension Models," Nucl. Safety 23, 685-699.

Solomon, R.L. and J.W. Hartford (1976), "Lead and Cadmium in Dusts and Soils in a Small Urban Community," Environ. Sci. Techol. 10, 773-777.

Stannard, J.N. (1988), Radioactivity and Health, A History, Pacific Northwest Laboratory, Hanford, WA, DE88013791, DOE/RL/018300-T59.

Takizawa, Y., A. Hisamatsu, and T. Abe (1987), "Concentration of Fallout Plutonium in Tissues of Japanese who Died during 1980-1984," Radiat. Res. 109, 245-255.

UNSCEAR, Sources, Effects and Risks of Ionizing Radiation. 1988 Report to the General Assembly, with annexes, (United Nations Scientific Committee on the Effects of Atomic Radiation, New York, 1988).

US Bureau of the Census (1991), American Housing Survey for the United States in 1989, U.S. Government Printing Office, Washington, DC, Current Housing Reports, H-150/89. 
US Bureau of the Census (1991), Statistical Abstract of the United States 1991, 111th ed., Superintendent of Documents, U. S. Government Printing Office, Washington, DC.

US Department of Energy (1988), CERCLA Preliminary Assessment of DOE's Nevada Operations Office Nuclear Weapons Testing Areas, Vol. 1, US Department of Energy, Nevada Operations Office, Las Vegas, NV.

USNAS, Health Risks of Radon and Other Internally Deposited Alpha-Emitters (BEIR IV), (U.S. National Academy of Sciences, Washington, 1988).

USNAS, Health Effects of Exposure to Low Levels of Ionizing Radiation (BEIR V), (U.S. National Academy of Sciences, Washington, 1990).

Voelz, G.L. and J.N.P. Lawrence (1991), "A 42-y Medical Follow-Up of Manhattan Project Plutonium Workers," Health Phys. 61: 181-190.

Weschler, C.J., S.P. Kelty, and J.E. Lingousky (1983), "The Effect of Building Fan Operation on Indoor-Outdoor Dust Relationships," J. Air Poll. Control Assoc. 33, 624-629.

Wiley, J.A. (1991), Study of Children's Activity Patterns, Research Division, California Air Resources Board, Sacramento, CA.

Wiley, J.A., J.P. Robinson, T. Piazza, K. Garrett, K. Cirksena, Y.T. Cheng, and G. Martin (1991), Activity Patterns of California Residents, Research Division, California Air Resources Board, Sacramento, CA.

Wolfram, S. (1991), Mathematica, Addison-Wesley Co., Redwood City, CA. 


\title{
4. Risk-Based Screening Analysis of Ground Water Contaminated by Radionuclides Introduced at the Nevada Test Site (NTS)
}

\author{
J. I. Daniels*, R. Andricevic ${ }^{\dagger}$, L. R. Anspaugh* ${ }^{*}$ R. L. Jacobson ${ }^{\dagger}$
}

The Nevada Test Site (NTS) is located in Nye County, Nevada, about $105 \mathrm{~km}$ (65 mi) northwest of the city of Las Vegas. Since 1951, the NTS has been used primarily for conducting tests of nuclear weapons devices; nearly all of the tests performed after late 1962 occurred underground in sealed vertical shafts or in horizontal tunnels (Wruble and McDowell, 1990). Figure 1 shows the location of the NTS in southern Nevada, the designated areas into which the NTS has been divided, and the buffer zone of restricted access formed by the Nellis Air Force Base Range Complex. Together, the NTS and the surrounding U.S. Air Force property occupy an area of about $14,200 \mathrm{~km}^{2}\left(5,470 \mathrm{mi}^{2}\right)$, which represents one of the largest unpopulated land areas in the U.S. today (Wruble and McDowell, 1990).

Many of the underground tests of nuclear weapons devices at the NTS have been conducted at depths near or below the water table (Marsh, 1992). In Area 20, testing has occured below the water table near the boundary of the NTS. (The dot in Fig. 1 denotes approximately where testing occurred.) This boundary is also the closest site to existing groundwater wells offsite. These offsite wells are located to the southwest of the Area 20 boundary, beyond the buffer zone, in the Oasis Valley north of Beatty, NV. The wells are believed to be in the general direction of groundwater flow from Area 20.

Following underground detonation of nuclear weapons devices (also known as "shots") near or below the water table, a cavity is formed (see Fig. 2) and ground water that is displaced by explosive forces typically returns to fill the cavity. Although there have been only a very limited number of groundwater samples taken from or near shot cavities, the few samples-of-opportunity that have been collected reveal that many different radionuclides have been introduced into the returning ground water.

There are a number of reasons why the public is not considered in jeopardy of being exposed in the immediate future to the radionuclide-contaminated ground water beneath the NTS. First, access to the NTS (and its subterranean environment, including any radionuclide contaminated ground water), continues to be strictly controlled for security reasons. Second, slow groundwater movement and exceedingly slow downward movement of water in the overlying saturated zone at the NTS indicate that any radionuclides appearing in a deep groundwater aquifer are not likely to be transported rapidly to accessible locations offsite. Finally, there is no reported evidence to date to suggest that contaminated ground water from beneath the NTS has ever migrated offsite to an accessible area.

\footnotetext{
* Lawrence Livermore National Laboratory, Livermore, CA.

$\dagger$ Desert Research Institute, Las Vegas, NV.
} 


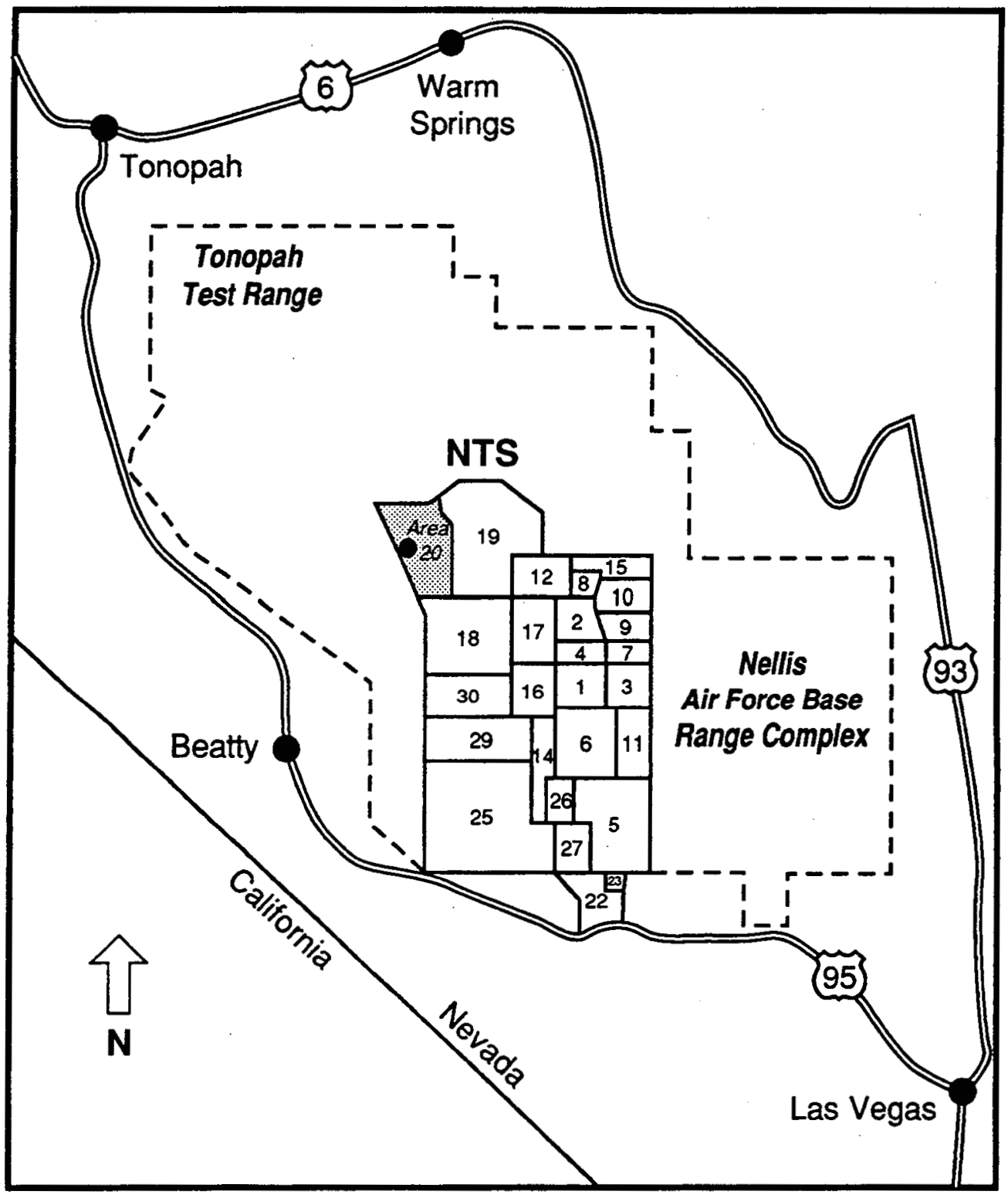

Figure 1. The Nevada Test Site (NTS) and vicinity in southern Nevada. Adapted from Wruble and McDowell (1990). 
Ground surface

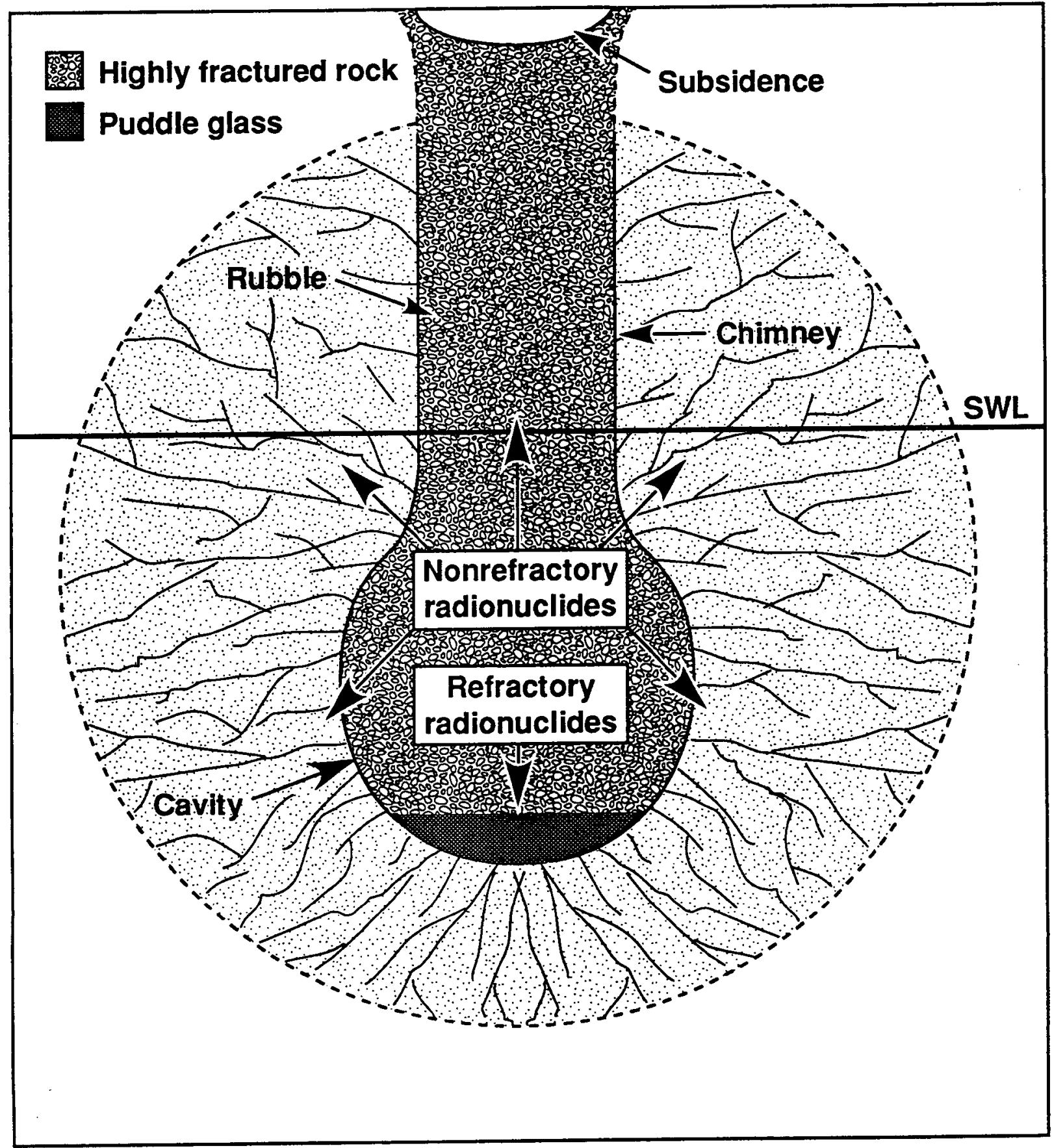

Figure 2. Cavity formation and other relevant geophysical features following detonation of a nuclear device below the standing water level (SWL) beneath the NTS. 
Recently, however, two issues have emerged that have led to a concern that future generations could become exposed to the radionuclide-contaminated ground water from the NTS. The southern part of Nevada and, specifically, the greater metropolitan area of Las Vegas, continue to experience a dramatic growth in population and development. This situation has created an ever increasing demand for a most limited resource in this arid region-water (Spencer, 1992). Pumping more ground water from beneath the agricultural lands nearest the NTS may be a way to provide some of the water needed to support this growth. Any radionuclide-contaminated ground water underneath the NTS that migrates to these offsite locations could then be pumped to the surface for purposes of consumption by humans. The other issue occurs because there is a temporary nuclear test moratorium in the U.S., which might become permanent before the end of the twentieth century; there is also a question of how long the U.S. Air Force range complex will exist in its present form and continue to provide a buffer zone around the NTS. Accordingly, the ultimate disposition and institutional control of the NTS and its buffer zone are now somewhat uncertain. A possible consequence of losing such institutional control is human intrusion onto or immediately next to the NTS. In this situation, the radionuclide-contaminated ground water from directly beneath the NTS could be pumped to the surface.

A sensible and effective strategy for addressing the concern raised by the issues just described is to estimate, as realistically and pragmatically as data permit, the magnitude and uncertainty of the potential public health risk associated with exposure to the radionuclidecontaminated ground water on the NTS and offsite in the direction of groundwater flow. The exposures associated with unacceptable levels of risk should then receive the most consideration with respect to devoting resources to their limitation or prevention, or further examination.

To accomplish this objective, a risk-based screening analysis was implemented to quantify the magnitude and uncertainty of the potential excess cancer mortality risk from the pertinent data available concerning this ground water at the NTS. Such pertinent data were so limited that it was necessary to adopt several conservative assumptions about radionuclide concentrations in the ground water, and about directions of groundwater flow, as well as about the exposure period (to include adults as well as infants and children).

Specifically, the risk-based screening analysis is designed to furnish conceivable ranges for the maximum potential incremental cancer mortality risk applicable to an exposed individual. Exposed individuals are considered to be those in future generations who might consume the ground water from the NTS over a 70-y lifetime either at a location on that border of the NTS (assuming loss of institutional control after $100 \mathrm{y}$ ) nearest the accessible offsite environment where ground water could be obtained, or at a location offsite in that nearby environment (considering groundwater migration).

The boundary of Area 20 was selected to represent the onsite location. It is the boundary of the NTS in closest proximity to existing groundwater wells offsite (in the Oasis Valley). A location $19 \mathrm{~km}$ away from the boundary of Area 20, in the Oasis Valley, was selected to represent the offsite location. This offsite location is considered to be in the general direction of groundwater flow from Area 20 and to be the nearest accessible offsite environment to the NTS for obtaining ground water.

The conceivable ranges for risk based on potential intakes of the NTS ground water at these onsite and offsite locations are more useful to decision makers than calculating maximum point 
estimates. For example, a conceivable range for risk reflects the combined uncertainty in the applicable input parameters. Additionally, a range for risk having significantly elevated upper and lower limits implies that a potentially serious threat to pubic health could be associated with intake of the NTS ground water at that particular location or perhaps at other locations in that category (e.g., onsite or offsite).

\subsection{Approach}

As mentioned previously, underground tests of nuclear weapons devices conducted at or below the water table at the NTS have contaminated the ground water with a variety of different radionuclides. Unfortunately, the radionuclides themselves and their concentrations in this ground water have not been well characterized. For this reason a sequence of steps was developed to determine a conceivable range for the maximum incremental cancer risk for an individual consuming the NTS ground water either onsite at the Area 20 boundary beginning after $100 \mathrm{y}$, or offsite, $19 \mathrm{~km}$ away in the Oasis Valley after possible migration of the ground water from the Area 20 boundary.

The first step in the approach involves identifying those radionuclides and their maximum concentrations that are representative of the mix that could be present in the ground water beneath the Area 20 boundary today. This collection of radionuclides and their maximum concentrations then serve as the source term for the next step, projecting maximum groundwater concentrations for these radionuclides at the specific onsite and offsite locations for each year during an entire 70-y lifetime. In the third step, the potential lifetime internal doses are determined for an individual at each location. The last step entails estimating the probability of developing a fatal cancer per unit dose, and then using that estimate to compute maximum potential excess lifetime-cancer-mortality risk for each of the potential lifetime internal doses. Because parameter uncertainties and correlations are assessed and propagated throughout the entire process, the calculated estimates of maximum potential excess lifetime-cancer-mortality risk are expressed as ranges of values that reflect the overall uncertainty.

\subsection{Source Term}

Published measurements of radionuclide concentrations in ground water sampled from shot cavities beneath the NTS were used to ascertain the representative mix of radionuclides and their maximum concentrations that could be present today in the ground water beneath the Area 20 boundary. Included among these radionuclides are those with short or long half lives and those that are radiologically important in terms of producing adverse health effects following intake.

Unfortunately, relevant groundwater sampling data were available from only three shot cavities created at different locations beneath the NTS. However, each of these three shot cavities was at or below the water table and the groundwater samples were taken either by penetration of the shot cavity or the geologic material immediately near it. Figure 3 shows the designated areas of the NTS; some major natural topographic features, including the Oasis Valley; and the locations of the three shot cavities (Cheshire in Area 20, Bilby in Area 3, and Cambric in Area 5) from which the groundwater samples-of-opportunity were obtained. For purposes of this assessment, the basis for reasonable first approximations for the representative mix and corresponding maximum concentrations of radionuclides that could be present today in 
ground water beneath the Area 20 boundary are the radionuclides and their associated maximum concentrations measured at the time of collection in the groundwater samples-of-opportunity obtained from the three shot cavities. This representative mix of radionuclides, along with their maximum observed concentrations $\left(\mathrm{Bq} \mathrm{L}^{-1}\right)$ and original sampling locations, are presented in Table 1.

As indicated in Figure 3, the approximate distance from the southwestern boundary of Area 20 to that part of the Oasis Valley just outside the buffer zone is $19 \mathrm{~km}(12 \mathrm{mi})$. Ground water flows in volcanic rocks beneath Area 20 in the general direction of the Oasis Valley. The water table below Area 20 typically is found at depths from about 580 to $730 \mathrm{~m}$ (1,900 to $2,400 \mathrm{ft}$ ) and contains water ranging in age from 10,000 to 15,000 years before present time. It is hypothesized that the most dramatic movement within this system would probably occur along highly transmissive fractures, many of which could be present beneath the NTS. The characteristics of this aquifer system are described in detail by Winograd and Thordarson (1975).

Table 1. Maximum observed concentrations $\left(\mathrm{Bq} \mathrm{L}^{-1}\right)$ of radionuclides measured at the time of collection in groundwater samples-of-opportunity from three different shot cavities under the Nevada Test Site, representative of the mix at Area 20.

\begin{tabular}{|c|c|c|c|}
\hline Radionuclide & $\begin{array}{l}\text { Maximum observed } \\
\text { concentration } \\
\left(\mathrm{Bq} \mathrm{L}^{-1}\right)^{\mathbf{a}}\end{array}$ & $\begin{array}{l}\text { NTS sampling } \\
\text { location (shot cavity) }\end{array}$ & Reference \\
\hline Americium-241 & $9.2 \times 10^{-2}$ & Area 20 (Cheshire) & Buddemeier and Isherwood (1985) \\
\hline Antimony-125 & $4.4 \times 10^{+2}$ & Area 5 (Cambric) & Hoffman et al. (1977) \\
\hline Cerium-144 & $8.1 \times 10^{-1}$ & Area 20 (Cheshire) & Buddemeier and Isherwood (1985) \\
\hline Cesium-137 & $1.8 \times 10^{+2}$ & Area 5 (Cambric) & Hoffman et al. (1977) \\
\hline Cobalt -60 & $1.2 \times 10^{-1}$ & Area 20 (Cheshire) & Buddemeier (1988) \\
\hline Europium-152 & $4.1 \times 10^{-1}$ & Area 20 (Cheshire) & Buddemeier and Isherwood (1985) \\
\hline Iodine-129 & $4.1 \times 10^{-1}$ & Area 5 (Cambric) & Fraser (1982) \\
\hline Plutonium-239 & $2.3 \times 10^{-1}$ & Area 5 (Cambric) & Hoffman et al. (1977) \\
\hline Radium-226 & $1.1 \times 10^{-1}$ & Area 3 (Bilby) & Erikson and Jacobson $(1990)^{b}$ \\
\hline Ruthenium-106 & $3.3 \times 10^{-1}$ & Area 5 (Cambric) & Hoffman et al. (1977) \\
\hline Strontium-90 & $1.5 \times 10^{+2}$ & Area 5 (Cambric) & Hoffman et al. (1977) \\
\hline Technetium-99 & $2.6 \times 10^{+0}$ & Area 3 (Bilby) & Silva et al. (1986) \\
\hline Tritium [H-3] & $2.8 \times 10^{+8}$ & Area 5 (Cambric) & Hoffman et al. (1977) \\
\hline Uranium-234 & $1.8 \times 10^{-1}$ & Area 3 (Bilby) & Erikson and Jacobson (1990)c \\
\hline Uranium-235 & $3.2 \times 10^{-2}$ & Area 3 (Bilby) & Buddemeier and Isherwood (1985) \\
\hline Uranium-238 & $1.0 \times 10^{+0}$ & Area 3 (Bilby) & Buddemeier and Isherwood (1985) \\
\hline \multicolumn{4}{|c|}{ a Rounded values; to convert $\mathrm{Bq} \mathrm{L}^{-1}$ to $\mathrm{pCi} \mathrm{mL}^{-1}$ multiply $\mathrm{Bq} \mathrm{L}^{-1}$ by $2.7 \times 10^{-2}$} \\
\hline \multicolumn{4}{|c|}{$\begin{array}{l}\text { U.S. Environmental Protection Agency (EPA) raw data collected in } 1974 \text { as part of the } 1974 \text { U.S. EPA Long-Term } \\
\text { Hydrologic Monitoring Program (LTHM). }\end{array}$} \\
\hline \multicolumn{4}{|c|}{$\begin{array}{l}\text { U.S. Environmental Protection Agency (EPA) raw data collected in } 1973 \text { as part of the } 1973 \text { U.S. EPA Long-Term } \\
\text { Hydrologic Monitoring Program (LTHM). }\end{array}$} \\
\hline
\end{tabular}




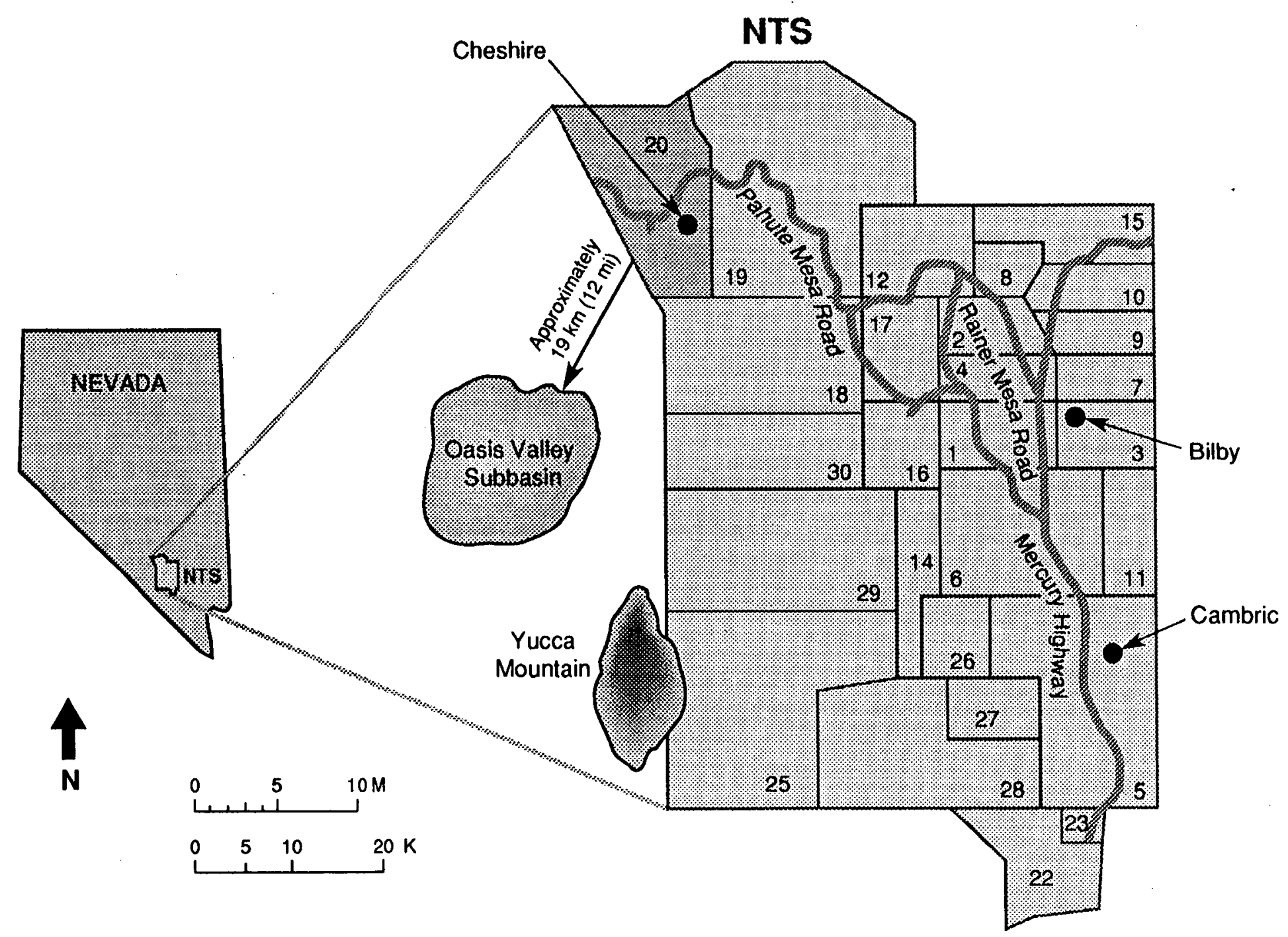

Figure 3. Relatlve location of the NTS in the State of Nevada; the designated areas Into which the NTS has been divided; some major topographical features near the NTS, Including the Oasis Valley; and the locations of the shot cavities in Areas 3, 5, and 20 on the NTS from which the groundwater samples-of-opportunity were collected. Adapted from figures presented by Erikson and Jacobson (1991), and Marsh (1992). 


\subsection{Estimation of Maximum Annual Concentrations of Radionuclides in Ground Water at Locations of Interest}

Water consumption by an individual at the boundary of Area 20 is assumed to begin $101 \mathrm{y}$ in the future. Water consumption $19 \mathrm{~km}$ away from the Area 20 boundary in the Oasis Valley is considered to commence at the beginning of a hypothetical.70-y interval when all of the radionuclides in the ground water from the Area 20 boundary are predicted to have arrived at the Oasis Valley and to be present at their respective maximum annual concentrations. At both locations of potential exposure, an individual is considered to consume the ground water for an entire 70-y lifetime.

Because data describing the movement of radionuclides in ground water at the NTS is so limited, the concentrations of the radionuclides in the ground water are considered to be affected only by radioactive decay. Therefore, no account is taken of possible removals through sorption of radionuclides on geologic material along the groundwater-flow path, nor are the radionuclide concentrations assumed to be diluted by the inflow of noncontaminated ground water. On the basis of these conservatisms, the projected annual concentrations for the representative mix of radionuclides at both locations are regarded as estimates of maximum values.

\subsubsection{Radionuclide Concentrations at the Area 20 Boundary}

As a consequence of these assumptions, the maximum annual concentrations of radionuclides in the ground water at the Area 20 boundary can be calculated for each year of a 70-y interval beginning $101 \mathrm{y}$ in the future using the first-order decay equation:

$$
A(t)=A(0) e^{-\lambda t} .
$$

In Equation 1, $\mathrm{A}(\mathrm{t})$ is the concentration $\left(\mathrm{Bq} \mathrm{L}^{-1}\right)$ at time $\mathrm{t}(\mathrm{y})$ in the future at the Area 20 boundary, $A(0)$ is the maximum concentration assumed to be present today at the Area 20 boundary ( $\mathrm{Bq} \mathrm{L}^{-1}$ appearing in Table 1$)$, and $\lambda$ is the radioactive decay constant $[0.693 /$ half life (y) for the radionuclide of interest]. Table 2 shows the ranges for the predicted annual concentrations of the radionuclides in the ground water at the Area 20 boundary during the 70-y interval beginning $101 \mathrm{y}$ hence.

\subsubsection{Radionuclide Concentrations at Oasis Valley}

The second location for estimating radionuclide intake is at the edge of the Oasis Valley, $19 \mathrm{~km}(12 \mathrm{mi}$ ) southwest of the Area 20 boundary (see Fig. 3). To determine the potential maximum annual radionuclide concentrations in the ground water over a 70-y interval in the future, allowance must be made for the radioactive decay of the radionuclides during the time of their migration in the ground water from the Area 20 boundary. Again, it is assumed that the initial concentrations of the representative mix of radionuclides at the Area 20 boundary today equate to the maximum concentrations of these radionuclides measured at the time of collection in the samples-of-opportunity from the Cambric, Cheshire, and Bilby shot cavities. 
Table 2. Predicted ranges for the maximum annual concentrations $\left(\mathrm{Bq} \mathrm{L} \mathrm{L}^{-1}\right)$ in ground water of the representative mix of radionuclides during a 70-y interval in the future at the Area 20 boundary (after decay), and $19 \mathrm{~km}$ away, offsite in the Oasis Valley (after migration). ${ }^{\mathrm{a}}$

\begin{tabular}{|c|c|c|c|c|c|c|c|}
\hline \multirow{3}{*}{$\begin{array}{c}\text { Radionuclide } \\
\text { Americium-241 }\end{array}$} & \multicolumn{7}{|c|}{$\begin{array}{l}\text { Range for maximum annual } \\
\text { concentrations }\left(\mathrm{Bg} \mathrm{L}^{-1}\right)^{\mathrm{b}} \text { over } 70-\mathrm{y} \text { period }\end{array}$} \\
\hline & \multicolumn{3}{|c|}{$\begin{array}{l}\text { Area } 20 \text { boundary } \\
\text { (101 to } 170 \text { y due to decay) }\end{array}$} & \multicolumn{3}{|c|}{$\begin{array}{l}\text { Oasis Valley } \\
\text { offsite }\end{array}$} & \multirow{2}{*}{$\frac{\begin{array}{c}\text { (70-y interval } \\
\text { due to travel) }\end{array}}{(344 \text { to } 413)}$} \\
\hline & $7.8 \times 10^{-2}$ & to & $7.0 \times 10^{-2}$ & $2.6 \times 10^{-5}$ & to & $2.7 \times 10^{-5}$ & \\
\hline Antimony-125 & $7.8 \times 10^{-9}$ & to & $3.0 \times 10^{-16}$ & $2.3 \times 10^{-27}$ & to & $3.6 \times 10^{-7}$ & (1 to 70$)$ \\
\hline Cerium-144 & $2.0 \times 10^{-38}$ & to & $2.1 \times 10^{-64}$ & $8.9 \times 10^{-32}$ & to & $8.1 \times 10^{-13}$ & (1 to 70$)$ \\
\hline Cesium-137 & $1.8 \times 10^{+1}$ & to & $3.7 \times 10^{+0}$ & $8.9 \times 10^{-4}$ & to & $1.2 \times 10^{-3}$ & (72 to 141 ) \\
\hline Cobalt-60 & $2.6 \times 10^{-7}$ & to & $3.1 \times 10^{-11}$ & $5.6 \times 10^{-24}$ & to & $2.6 \times 10^{-9}$ & (1 to 70$)$ \\
\hline Europium-152 & $2.2 \times 10^{-3}$ & to & $5.9 \times 10^{-5}$ & $7.4 \times 10^{-8}$ & to & $2.6 \times 10^{-7}$ & (28 to 97 ) \\
\hline Iodine-129 & $4.1 \times 10^{-1}$ & to & $4.1 \times 10^{-1}$ & $2.4 \times 10^{-4}$ & to & $2.4 \times 10^{-4}$ & (539 to 608 ) \\
\hline Plutonium-239 & $2.3 \times 10^{-1}$ & to & $2.3 \times 10^{-1}$ & $1.4 \times 10^{-4}$ & to & $1.4 \times 10^{-4}$ & (533 to 602) \\
\hline Radium-226 & $1.1 \times 10^{-1}$ & to & $1.0 \times 10^{-1}$ & $5.2 \times 10^{-5}$ & to & $5.2 \times 10^{-5}$ & (461 to 530 ) \\
\hline Ruthenium-106 & $2.6 \times 10^{-28}$ & to & $4.4 \times 10^{-49}$ & $6.7 \times 10^{-24}$ & to & $1.3 \times 10^{-9}$ & (1 to 70 ) \\
\hline Strontium-90 & $1.4 \times 10^{+1}$ & to & $2.7 \times 10^{+0}$ & $6.7 \times 10^{-4}$ & to & $8.9 \times 10^{-4}$ & (70 to 139) \\
\hline Technetium-99 & $2.6 \times 10^{+0}$ & to & $2.6 \times 10^{+0}$ & $1.6 \times 10^{-3}$ & to & $1.6 \times 10^{-3}$ & (539 to 608$)$ \\
\hline Tritium [H-3] & $1.1 \times 10^{+6}$ & to & $2.3 \times 10^{+4}$ & $3.3 \times 10^{+1}$ & to & $1.4 \times 10^{+2}$ & (25 to 94 ) \\
\hline Uranium-234 & $1.9 \times 10^{-1}$ & to & $1.9 \times 10^{-1}$ & $1.1 \times 10^{-4}$ & to & $1.1 \times 10^{-4}$ & (539 to 608) \\
\hline Uranium-235 & $2.6 \times 10^{-2}$ & to & $2.6 \times 10^{-2}$ & $1.9 \times 10^{-7}$ & to & $1.9 \times 10^{-7}$ & (539 to 608 ) \\
\hline Uranium-238 & $1.0 \times 10^{+0}$ & to & $1.0 \times 10^{+0}$ & $5.9 \times 10^{-4}$ & to & $5.9 \times 10^{-4}$ & (539 to 608 ) \\
\hline
\end{tabular}

a Based on maximum concentrations reported for these radionuclides at the time of the collection of groundwater samples-of-opportunity from three shot cavities on NTS (see Table 1 and Fig. 3).

b Rounded values; to convert $\mathrm{Bq} \mathrm{L}^{-1}$ to $\mathrm{pCi} \mathrm{mL}^{-1}$ multiply Bq $\mathrm{L}^{-1}$ by $2.7 \times 10^{-2}$.

c The 70-y period during which the maximum annual concentrations for a radionuclide are predicted to be present at the Oasis Valley, based on the results of the travel-time transport model.

Precise hydrogeological data concerning groundwater migration from the NTS to offsite locations, such as the Oasis Valley, are not available. Therefore, a classical hydrological transport model that would employ such information and accurately predict a point estimate of activity of a radionuclide at a particular location spatially and temporally cannot be employed. Instead, the travel-time-transport approach, which is not dependent on such detailed information, will be used. The principal output of the model is a probability-density function (pdf) conditioned on the set of parameters used to describe processes such as velocity, advection, dispersion, and radioactive decay. Importantly, the travel-time-transport model takes into consideration parameter uncertainty and any possible correlation among parameters.

Flux-averaged concentrations, which are defined in terms of the ratio of solute flux to water flux (Kreft and Zuber, 1978), are used as input parameters. Therefore, the maximum concentrations for the representative mix of radionuclides assumed to be present in ground water 
beneath the Area 20 boundary today (see Table 1) are considered to represent flux-averaged concentrations and are input directly into the model.

The travel-time distribution is derived from the Lagrangian concept of particle displacement (Taylor, 1921; Dagan, 1982, 1984, 1987; Shapiro and Cvetkovic, 1988; Dagan and Nguyen, 1989). In this concept, the solute is represented as a collection of particles transported by ground water under advection, dispersion, and other physical and chemical processes. The groundwaterflow velocity $(\mathrm{Vx}, \mathrm{Vy}$, and $\mathrm{Vz}$ ) satisfies Darcy's law and the equation of continuity and will fluctuate from one point $(x, y, z)$ to another because of locally variable hydrogeologic conditions. We assume that the velocity distribution can be decomposed into (i.e., represented as) a mean, or average value of magnitude $U$ aligned with the $x$ axis, and a fluctuating part whose spatial average is zero. The travel time for a solute particle to move a distance $L$ in the mean-flow ( $x$ ) direction may be estimated from (Shapiro and Cvetkovic, 1988)

$$
t(L)=\int_{0}^{L} \frac{d x}{V x},
$$

where $V x=V x(x, 0,0)$ is the $x$-component of the velocity along the $x$ axis. For our purposes, the $x$ axis will be anchored at the boundary of Area 20 and point toward the Oasis Valley. Radionuclide transport and travel-time analyses will be considered along this path using $\mathrm{L}=19 \mathrm{~km}$. On the basis of the limited data available for NTS hydrogeology, the velocity component, $\mathrm{Vx}$, of the ground water migrating in the direction of the Oasis Valley is considered to be a lognormally distributed variable with an expected value (arithmetic mean), U, equal to $17 \mathrm{~m} / \mathrm{y}$ (derived from data presented by Blankennagel and Weir, 1973; and Winograd and Thordarson, 1975). As a consequence of the uncertainties in the transport mechanism, such as estimation of parameters characterizing flow and transport, and spatial variability of the aquifer properties, such as permeability and porosity, radionuclide arrival at Oasis Valley in ground water migrating from the Area 20 boundary will be distributed in time and described by a lognormal travel-time pdf, $\mathrm{p}[\mathrm{t} ; \mathrm{L} \mid \mathrm{U}]$ (Andricevic et al., 1993). Different velocities associated with locally variable hydrogeologic conditions will tend to transport different elements of an initial pulse of mass at different rates; hence, downstream arrival times will be distributed according to $\mathrm{p}[\mathrm{t} ; \mathrm{L} / \mathrm{U}]$. The product of $\mathrm{p}[\mathrm{t} ; \mathrm{L} / \mathrm{U}]$ and a time interval, $\mathrm{dt}$, represents the fraction of mass released at $x=0, t=0$ that arrives at $x=L$ between $t$ and $t+d t$, conditioned on a mean velocity, $\mathrm{U}$ (as we see later, the estimate of this average may, in fact, be uncertain, and may be associated with its own lognormal pdf, $\mathrm{p}[\mathrm{U}])$. The incorporation of radioactive decay in the travel-time-transport model will result in a modified travel-time pdf, $\tilde{p}[t ; L \mid U]$, because longer travel times will become less likely as a result of decay along travel paths:

$$
\tilde{p}[t ; L \mid U]=\exp \left(-\frac{\ln 2}{\frac{t_{1}}{2}} t\right) p[t ; L \mid U]
$$


Here, $t$ is the travel time $(y), t_{\frac{1}{2}}$ is the radioactive half-life $(y)$ of the radionuclide of interest, and $\mathrm{p}[\mathrm{t} ; \mathrm{L} \mid \mathrm{U}]$ is the travel-time pdf of the solute conditioned on the uncertainty coming from the estimated mean velocity, $U$, and which takes the form of the lognormal distribution. The modified travel-time pdf has to be normalized to obtain the full travel-time pdf; this is accomplished by dividing the right side of that equation by the constant $\mathrm{C}$, which is obtained from the following expression:

$$
C=\int_{0}^{\infty} \exp \left(-\frac{\ln 2}{t_{\frac{1}{2}}} t\right) p[t ; L \mid U] d t
$$

Thus, the unconditional travel-time cumulative distribution function (cdf), G[t*;L], can be expressed mathematically as

$$
G\left[t^{*} ; L\right]=\int_{0}^{t^{*}} \int_{0}^{\infty} \exp \left(-\frac{\ln 2}{t_{\frac{1}{2}}} t\right) p[t ; L \mid U] p[U] d t d U
$$

where $t^{*}$ is the travel time of interest $(y), t_{\frac{1}{2}}$ is the radioactive half-life of the radionuclide of interest; and $\mathrm{p}[\mathrm{t} ; \mathrm{L} \mid \mathrm{U}]$ is the travel-time pdf of the solute. This last parameter is lognormal, conditioned on the uncertainty coming from the estimated mean velocity, $U$, and accounts for advection and hydrodynamic dispersion. The term, $\mathrm{p}[\mathrm{U}]$, is the pdf of the mean velocity estimate, which also takes the form of the lognormal distribution. The integration of the cdf equation is performed numerically. The cdf expression is used to estimate the accumulation over time of each radionuclide at Oasis Valley following transport in ground water from the Area 20 boundary. This information is then employed to determine the 70 maximum annual concentrations of each radionuclide in the ground water at Oasis Valley and the corresponding 70-y interval during which these concentrations occur. ${ }^{*}$ The range of maximum annual concentrations for each radionuclide of interest in groundwater at Oasis Valley is shown in Table 2, along with the 70-y interval associated with these concentrations.

The maximum annual concentrations appearing in Table 2 are assumed to be geometric mean values of lognormally distributed variables, and the geometric standard deviation corresponding to each of the values for Oasis Valley is assumed to equal 2.0. By not incorporating into the travel-time-transport calculations the possibility of sorption of radionuclides on geologic material along the flow path, the remote possibility is addressed that radionuclides sorbed to geologic material could still be transported in ground water as a result of the movement of the geologic material as a colloid from the Area 20 boundary to the Oasis Valley.

Figure 4 graphically illustrates the impact of radioactive decay on the travel-time pdf for radionuclides arriving at Oasis Valley in ground water migrating from the Area 20 boundary. As

\footnotetext{
* The concentration of a radionuclide in any single year can be derived from the model. The 70-y interval containing the maximum annual concentrations are then selected for this assessment.
} 


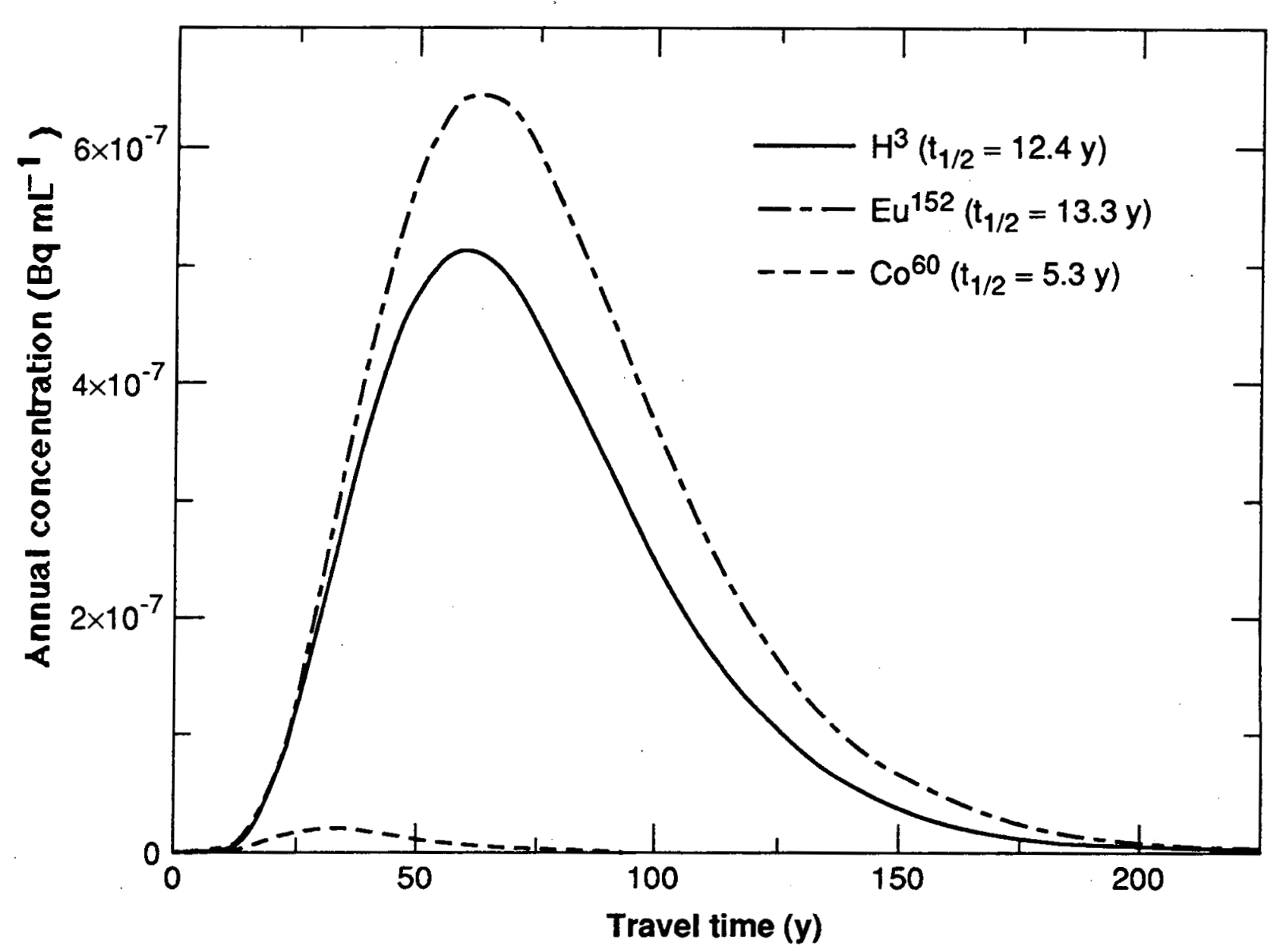

Figure 4. The impact of radioactive decay on travel-time probability-density function (pdf) for three different radionuclides.

stated previously, retention of individual radionuclides on geologic material along the flow path to the Oasis Valley was not taken into consideration. For simplicity, all three radionuclides used in this illustration are considered to be at the same initial concentration in ground water at the Area 20 boundary. Comparison of the curves in Figure 4 reveals that the shorter the radioactive half-life, the more the peak of the pdf flattens (i.e., the maximum values of the maximum annual concentrations are reduced) and shifts toward the origin, with a smaller total quantity of radioactive material arriving at the Oasis Valley, annually and cumulatively. Accordingly, it is only because there is an infinitesimally small probability of relatively fast groundwater flow, such as might occur through fractures, caves, or along faults (as manifested in a tail of the lognormal model of the velocity distribution), that any radionuclide with a short radioactive halflife would be predicted to arrive at the Oasis Valley. 


\subsection{Intake of Radionuclide-Contaminated Ground Water}

The first scenario to be examined concerns an individual living on the NTS in the immediate vicinity of the Area 20 boundary, some 101 years from now, when institutional control of the NTS is assumed to have been lost. Although access to the deep ground water at this location is considered feasible, acquisition of this ground water would be difficult and expensive because of its depth. Nonetheless, for purposes of this assessment, it is assumed that the deep ground water at this location will be accessible, this water will represent the only source of drinking water, an individual will consume exclusively this water and its radionuclide constituents, and that such exposure will begin at birth and continue without interruption over an entire 70-y lifespan.

The second scenario focuses on an individual living in the immediate vicinity of the springs at Oasis Valley, presumably as a consequence of northward expansion of the nearby community of Beatty (see Figs. 1 and 3). Again, this offsite vicinity is of interest because it represents the nearest practical location to any boundary of the NTS where potential human exposure to ground water migrating from the NTS could occur. The ground water in this offsite vicinity is much shallower and will be more accessible as a source of drinking water, both technically and financially, than on the NTS itself.

Because the travel-time transport model indicates that the 70-y interval of maximum annual concentrations will be different for many of the radionuclides arriving at the Oasis Valley from the Area 20 boundary (see last column of Table 2), it is highly unlikely that an individual could be exposed to ground water containing all of the radionuclides together at their 70 predicted maximum annual concentrations (ranges also shown in Table 2). Nevertheless, estimates of dose and health risk are derived. This approach is taken to ascertain whether one radionuclide could dominate the dose more than any of the others, and whether the estimate of risk is of sufficient concern to indicate that a more realistic, but far more complicated, analysis of risk is warranted. Again, it is assumed that the ground water in the Oasis Valley will be accessible, will represent the only source of drinking water, will be consumed exclusively, and that such exposure will begin at birth and continue without interruption over an entire 70-y lifespan.

Data compiled by Ershow and Cantor (1989) from a U.S. survey of tapwater intake shows that the rate of intake increases with age, and can vary by geographic region (presumably as a consequence of climate) for both sexes and all seasons of the year. In that survey, tap water was assumed to be from a local source and was defined as water consumed either directly for drinking, or indirectly, in preparation of foods or other beverages, such as tea and coffee. Of primary interest was tapwater intake from birth to age 70 for an individual living in the southern part of Nevada. Therefore, dose estimations for someone living on or near the NTS are based on age-specific tapwater intake for both sexes and broad age categories for the western region of the U.S., quantified by Ershow and Cantor (1989).

The rate of tapwater intake is assumed to be a lognormally distributed variable. Shown in Table 3 are the weighted arithmetic mean $\left(\bar{x}_{e}\right)$ and standard deviation $\left(s_{e}\right)$ values for age-specific annual tapwater intake for the western United States reported by Ershow and Cantor (1989). Table 3 also contains the corresponding geometric mean $\left(\mathrm{GM}_{\mathrm{e}}\right)$ and geometric standard deviation 
Table 3. Summary of annual tapwater intake $\left(\mathrm{L} \mathrm{y}^{-1}\right)$ for both sexes by broad age category and over all seasons for the western United States, including Nevada (from Ershow and Cantor, 1989) ${ }^{b}$.

\begin{tabular}{|c|c|c|c|c|}
\hline \multirow[b]{2}{*}{$\begin{array}{c}\text { Age } \\
\text { (y) }\end{array}$} & \multicolumn{2}{|c|}{ Weighted arithmetic } & \multicolumn{2}{|c|}{ Corresponding geometric } \\
\hline & Mean $\left(\bar{x}_{e}\right)$ & $\begin{array}{c}\text { Standard deviation } \\
\left(\mathbf{s}_{\mathrm{e}}\right)\end{array}$ & Mean $\left(G_{\mathbf{e}}\right)$ & $\begin{array}{c}\text { Standard deviation } \\
\text { (GSD) }\end{array}$ \\
\hline 0 to1 & $1.3 \times 10^{2}$ & $1.0 \times 10^{2}$ & $1.0 \times 10^{2}$ & 1.97 \\
\hline 1 to 1 & $2.8 \times 10^{2}$ & $1.5 \times 10^{2}$ & $2.5 \times 10^{2}$ & 1.65 \\
\hline 11 to 20 & $3.6 \times 10^{2}$ & $2.1 \times 10^{2}$ & $3.1 \times 10^{2}$ & 1.72 \\
\hline 20 to 65 & $5.3 \times 10^{2}$ & $3.0 \times 10^{2}$ & $4.6 \times 10^{2}$ & 1.69 \\
\hline 65 to 70 & $5.6 \times 10^{2}$ & $2.3 \times 10^{2}$ & $5.2 \times 10^{2}$ & 1.48 \\
\hline
\end{tabular}

a Rounded values.

b Weighted arithmetic mean and standard deviation are reported in $\mathrm{mL} \mathrm{d}^{-1}$ by

Ershow and Cantor (1989), and converted to $\mathrm{L} \mathrm{y}^{-1}$ by multiplying by $365 \mathrm{~d} \mathrm{y}^{-1}$ and dividing by $10^{3} \mathrm{~mL} \mathrm{~L}^{-1}$.

$\left(G S D_{e}\right)$ values based on these reported age- and region-specific annual rates of tapwater intake. Because the logarithm of tapwater intake is assumed to be a normally distributed variable (i.e., tapwater intake is lognormally distributed), the respective $\mathrm{GM}_{e}$ and $\mathrm{GSD}_{e}$ terms in Table 3 are derived using the following expressions (from $\mathrm{Ng}$ et al., 1990):

$$
\begin{aligned}
& \mathrm{GM}_{\mathrm{e}}=\frac{\overline{\mathrm{x}}_{\mathrm{e}}^{2}}{\sqrt{\overline{\mathrm{x}}_{\mathrm{e}}^{2}+\mathrm{s}_{\mathrm{e}}^{2}}} \text {, and } \\
& \mathrm{GSD}_{\mathrm{e}}=\exp \sqrt{\ln \left[1+\left(\frac{\mathrm{s}_{\mathrm{e}}^{2}}{\overline{\mathrm{x}}_{\mathrm{e}}^{2}}\right)\right]} .
\end{aligned}
$$

\subsection{Dose Corresponding To Intake}

Before the potential excess-cancer risk for an individual consuming radionuclidecontaminated ground water can be quantified, it is first necessary to estimate the internal radiation dose corresponding to these exposures. Because ingestion of the contaminated ground water represents the primary exposure pathway, other potential pathways (e.g., inhalation and dermal absorption associated with bathing, and ingestion of contaminated locally grown fruits and vegetables) will not be considered to contribute substantially to the internal dose.

The approach for constructing an individual's lifetime estimate of internal radiation dose is based on the dosimetric formalisms adopted for this purpose by the International Commission on Radiological Protection (ICRP) and described in ICRP Publication 60 (ICRP, 1991a). The ICRP methodology was developed for the purpose of radiation protection and readily addresses a substantial number of radionuclides. By design, it provides an estimate of the total dose an individual is committed to receive from an internally deposited radionuclide, which equates not 
only to the dose delivered during the year of intake but also to any dose delivered in the future as a result of the continued presence of the radionuclide in the body (NCRP, 1987). However, for those radionuclides that are retained in the body for only a short amount of time or have short radioactive half lives (i.e., equating to effective half lives of less than or equal to about three months), the committed total dose from a single intake will numerically approximate the annual dose from a continuous intake for one year. Thus, the committed total dose determined by this process will overestimate only the committed annual dose from the intake of those radionuclides that have both long radioactive half lives and long physiological retention times (i.e., lengthy effective half lives). Because radionuclides of both types are considered to be in the NTS ground water, only some of these radionuclides will contribute to any overestimate of the total ingested dose. Revising the ICRP methodology to reduce such error is unnecessary, as this procedure is being used here primarily to screen for those radionuclides making the greatest contribution to potential excess lifetime dose and risk and to indicate the possible magnitude of such risk. Additionally, such error will be small should a radionuclide with a short effective half-life (e.g., tritium) be shown to dominate the dose.

The procedure for calculating an individual's dose from the intake of a specific radionuclide over a 70-y lifetime involves summing over that exposure period the products of (1) the appropriate age-specific dose-conversion factor for each year of a 70 -y lifespan ( $\mathrm{Sv} \mathrm{Bq}{ }^{-1}$ ), (2) the corresponding age-related annual intake of tap water $\left(\mathrm{L} \mathrm{y}^{-1}\right)$, and (3) the annual estimate of the concentrations of the radionuclide in the water $\left(\mathrm{Bq} \mathrm{L}^{-1}\right)$ at a specific location. The latter two factors have already been described. In the sections that follow, the age-specific dose-conversion factors are derived. Then the derivation and estimation of the maximum 70-y lifetime dose, including the associated uncertainties, are presented for an individual exposed to the maximum annual radionuclide concentrations in ground water at either the Area 20 boundary or offsite at Oasis Valley.

\subsubsection{Dose-Conversion Factors for Intake by Ingestion}

Age-dependent, organ-specific, committed equivalent doses per unit of radioactive material ingested $\left(\mathrm{Sv} \mathrm{Bq}{ }^{-1}\right)$ for the most radiologically significant radionuclides released into the environment were compiled for the general public in ICRP Publication 56 (ICRP, 1990). These committed equivalent doses were calculated by the ICRP using biokinetic data and dosimetric models. In this process, the absorbed dose averaged over a specific target tissue or organ $\left(\mathrm{Gy} \mathrm{Bq}{ }^{-1}\right.$ ) is weighted by a factor that relates the type and energy emitted by the radionuclide to the effectiveness of that radiation, compared to other radiations, for inducing stochastic effects. This term is the radiation weighting factor. Also addressed in these calculations is the effect of age on both the biokinetics of a radionuclide and on human physiological and anatomical properties. Additionally, the committed equivalent doses for radionuclides tabulated in ICRP Publication 56 represent total equivalent doses accumulated by tissues or organs as a consequence of varying dose rate and protraction of exposure over a time period following intake. This time period is considered to be $70 \mathrm{y}$ for infants, children, and adolescents, and $50 \mathrm{y}$ for adults.

The concept of committed effective dose (ICRP, 1991a) allows doses resulting from tissue or organ (partial-body) exposures, which can result from ingestion of radionuclides, to be converted into a dose to the whole body that has an equal level of risk associated with it (Moeller, 1992). 
In this approach, age-dependent committed effective doses are derived from age-dependent, organ-specific committed equivalent doses using tissue-weighting factors. Specifically, age-dependent committed effective doses per unit intake of activity $\left(\mathrm{Sv} \mathrm{Bq}{ }^{-1}\right)$ are calculated by summing the products of organ-specific, committed equivalent doses for an age category and the tissue-weighting factors assigned to each of the specified tissues and organs of the body. As discussed by Moeller (1992), tissue-weighting factors represent the contributions to the total risk associated with exposures to specific tissues and organs, and they are determined by taking into consideration parameters that include the likelihood that radiation can induce a given cancer or genetic effect, and that account for years of life lost for those who die of latent cancers. Tissue weighting factors were revised in ICRP Publication 60 (ICRP, 1991a) to be consistent with the most current understanding of radiobiology, and thus the committed effective dose factors presented in ICRP Publication 56 (ICRP 1990) are no longer current.

Only 8 of the 16 radionuclides that are considered representative of the mix of radionuclides that are present today at the Area 20 boundary and that were measured in ground water collected from the three specific shot cavities (see Table 1) have age-dependent, organ-specific committed equivalent doses tabulated in ICRP Publication 56 (ICRP, 1990). To calculate age-dependent committed effective doses for these eight radionuclides-(1) Americium-241 (Am-241), (2) Cerium-144 (Ce-144), (3) Cesium-137, (4) Iodine-129 (I-129), (5) Plutonium-239 (Pu-239), (6) Ruthenium-106, (7) Strontium-90, and (8) Tritium (H-3)-each organ-specific committed equivalent dose in a given age category for each radionuclide was multiplied by its respective tissue-weighting factor and the products for that age category were then summed. The resulting age-category-dependent committed effective doses agree with those calculated for these radionuclides and age-categories by Jain et al. (1992) using an analogous procedure. For purposes of this report, these age-category specific committed effective doses ( $\mathrm{Sv} \mathrm{Bq}{ }^{-1}$ ) were considered to apply to each year of life identified for that age category by the ICRP (1990) in ICRP Publication 56. Consequently, these annual age-specific committed effective doses are the dose-conversion factors used for estimating the lifetime dose for each of these eight radionuclides in NTS ground water.

Similar dose-conversion factors were calculated for each of the remaining eight radionuclides of interest (see Table 1)-(9) Antimony-125 (Sb-125), (10) Cobalt-60 (Co-60), (11) Europium-152 (Eu-152), (12) Radium-226 (Ra-226), (13) Technetium-99 (Tc-99), (14) Uranium-234 (U-234), (15) Uranium-235 (U-235), and (16) Uranium-238 (U-238)—using the recommended annual limit on intake (ALI) for occupational exposures resulting from ingestion of these radionuclides. These ALIs are published in ICRP Publication 61 (ICRP, 1991b). The ALI (Bq) for any radionuclide for occupational exposure through ingestion is derived by dividing the recommended annual average effective dose limit for occupational exposure $(0.02 \mathrm{~Sv})$ by the committed effective dose per unit of radioactive material ingested (Sv Bq ${ }^{-1}$ ) for the 50-y period following intake by an adult. Thus, even though the ICRP has not yet explicitly provided revised values of committed effective doses per unit of activity for these eight radionuclides, the committed effective dose per unit of radionuclide intake for a $50-y$ period following intake during any year of life in the adult-age category can still be determined. For the public, however, adjustments must be made in these age-dependent committed effective doses (i.e., increasing the dose commitment from 50 to $70 \mathrm{y}$ ). The result of this adjustment is the annual age-specific committed effective dose for a 70 -y period following intake of each 
radionuclide. This quantity is considered to be the dose-conversion factor applicable to all ages beginning at birth and lasting over an entire 70-y lifespan.

For those radionuclides having a relatively long biological half-life (i.e., retained in tissues or organs), compared to a 70-y lifetime of chronic ingestion exposure, protracted internal exposure can occur. The adjustment factor with the least amount of error for converting the committed effective dose for adult ages to one applicable to all ages for these radionuclides equates to the ratio of a radionuclide-specific retention function, integrated over $70 \mathrm{y}$, to the same retention function integrated over $50 \mathrm{y}$. The radionuclides in this category are Ra-226, U-234, U-235, and U-238. The adjustment factor for Ra-226 is 1.2 and was estimated from the integrals of the retention function for the whole body for infinite time after exposure (which was used as a surrogate for $70 \mathrm{y}$ after exposure) and for $50 \mathrm{y}$ after exposure. These integrals of the retention function for the whole body for Ra-226 are presented in Table 36 of ICRP Publication 20 (ICRP, 1973). The adjustment factor for all three isotopes of uranium $(234,235$, and 238) is 1.1, and was obtained from the ratio of the retention function for bone integrated over $70 \mathrm{y}$ and over $50 \mathrm{y}$. The retention function for bone for uranium is presented in ICRP Publication 30, Part 1 (ICRP, 1979).

For radionuclides with biological half lives that are relatively negligible compared to a 70-y lifetime, the adjustment factor is obtained by dividing 70 y by $50 \mathrm{y}$ (i.e., 1.4). The radionuclides for which this adjustment factor was used are Sb-125, Co-60, Eu-152, and Tc-99.

Table 4 summarizes the radionuclide-specific, age-dependent dose-conversion factors calculated for all 16 radionuclides of interest. Each value is assumed to represent the geometric mean (GM) of a lognormally distributed variable. The geometric standard deviation (GSD) associated with each GM in Table 4 is assumed to be equal to 1.8. This assumption is based on the one made by $\mathrm{Ng}$ et al. (1990) in which a default geometric standard deviation of 1.8 is assumed for ingestion dose factors for all target organs for which a GSD is not specified.

\subsubsection{Maximum Dose and Associated Uncertainty}

As previously indicated, it is assumed that the estimates of the (1) annual concentrations $\left(\mathrm{Bq} \mathrm{L}^{-1}\right)$ for the radionuclides of interest in ground water at a particular location, (2) agedependent annual rates of tapwater intake $\left(\mathrm{L} \mathrm{y}^{-1}\right)$ for individuals in Nevada, and (3) agedependent dose-conversion factors $\left(\mathrm{Sv} \mathrm{Bq}^{-1}\right)$ for the radionuclides of interest, are all lognormally distributed variables. Lognormality was assumed for these variables because in all three instances, two conditions commonly used as criteria for making this assumption are satisfied: the values are constrained to be positive, and the variability for each quantity is considered relatively large with respect to the mean (Puskin, 1992). As a result of making this assumption, the mathematical procedures described by Hoffman and Gardner (1983) and by $\mathrm{Ng}$ et al. (1990) can be applied to estimate the statistical parameters and their uncertainty for the distribution resulting from the combination of these lognormally distributed variables.

Table 5 contains the arithmetic means and variances for the lifetime committed effective doses received by an individual from ingestion of the respective radionuclides in ground water during their respective 70-y intervals of maximum annual concentrations (or intakes) at either the 
Table 4. Summary of estimated radionuclide-specific, age-dependent (committed effective) dose-conversion factors $\left(\mathrm{Sv} \mathrm{Bq}{ }^{-1}\right)$ for the 16 radionuclides of interest; all values are assumed to be geometric means and to have geometric standard deviations equal to 1.8 .

\begin{tabular}{|c|c|c|c|c|c|c|}
\hline \multirow[b]{2}{*}{ Radionuclide } & \multicolumn{6}{|c|}{ Chronological age category (applicable time period) } \\
\hline & $\begin{array}{c}3 \text { mo } \\
\text { (1 year) }\end{array}$ & $\begin{array}{c}1 \mathrm{y} \\
\text { (1 year) }\end{array}$ & $\begin{array}{c}5 y \\
(5 \text { years) }\end{array}$ & $\begin{array}{c}10 y \\
(5 \text { years) }\end{array}$ & $\begin{array}{c}15 y \\
\text { (5 years) }\end{array}$ & $\begin{array}{c}\text { Adult } \\
\text { (53 years) }\end{array}$ \\
\hline Am-241 ${ }^{a}$ & $7.3 \times 10^{-6}$ & $7.3 \times 10^{-7}$ & $5.7 \times 10^{-7}$ & $4.8 \times 10^{-7}$ & $4.7 \times 10^{-7}$ & $4.5 \times 10^{-7}$ \\
\hline $\mathrm{Sb}-125^{\mathrm{b}}$ & $1.4 \times 10^{-9}$ & $1.4 \times 10^{-9}$ & $1.4 \times 10^{-9}$ & $1.4 \times 10^{-9}$ & $1.4 \times 10^{-9}$ & $1.4 \times 10^{-9}$ \\
\hline $\mathrm{Ce}-144^{\mathrm{a}}$ & $1.1 \times 10^{-7}$ & $6.2 \times 10^{-8}$ & $3.0 \times 10^{-8}$ & $1.9 \times 10^{-8}$ & $1.0 \times 10^{-8}$ & $8.4 \times 10^{-9}$ \\
\hline Cs-137 & $2.0 \times 10^{-8}$ & $1.1 \times 10^{-8}$ & $8.9 \times 10^{-9}$ & $9.7 \times 10^{-9}$ & $1.3 \times 10^{-8}$ & $1.3 \times 10^{-8}$ \\
\hline $\mathrm{Co}-60^{b}$ & $4.0 \times 10^{-9}$ & $4.0 \times 10^{-9}$ & $4.0 \times 10^{-9}$ & $4.0 \times 10^{-9}$ & $4.0 \times 10^{-9}$ & $4.0 \times 10^{-9}$ \\
\hline $\mathrm{Eu}-152^{b}$ & $2.8 \times 10^{-9}$ & $2.8 \times 10^{-9}$ & $2.8 \times 10^{-9}$ & $2.8 \times 10^{-9}$ & $2.8 \times 10^{-9}$ & $2.8 \times 10^{-9}$ \\
\hline$I-129^{a}$ & $1.9 \times 10^{-7}$ & $2.2 \times 10^{-7}$ & $1.7 \times 10^{-7}$ & $1.9 \times 10^{-7}$ & $1.4 \times 10^{-7}$ & $1.1 \times 10^{-7}$ \\
\hline $\mathrm{Pu}-239^{\mathrm{a}}$ & $9.0 \times 10^{-6}$ & $9.0 \times 10^{-7}$ & $7.2 \times 10^{-7}$ & $5.9 \times 10^{-7}$ & $5.6 \times 10^{-7}$ & $5.5 \times 10^{-7}$ \\
\hline$R a-226^{b}$ & $2.8 \times 10^{-7}$ & $2.8 \times 10^{-7}$ & $2.8 \times 10^{-7}$ & $2.8 \times 10^{-7}$ & $2.8 \times 10^{-7}$ & $2.8 \times 10^{-7}$ \\
\hline$R u-106^{a}$ & $1.2 \times 10^{-7}$ & $7.3 \times 10^{-8}$ & $3.7 \times 10^{-8}$ & $2.1 \times 10^{-8}$ & $1.3 \times 10^{-8}$ & $1.0 \times 10^{-8}$ \\
\hline Sr-90 & $1.2 \times 10^{-7}$ & $8.1 \times 10^{-8}$ & $3.6 \times 10^{-8}$ & $3.4 \times 10^{-8}$ & $4.5 \times 10^{-8}$ & $2.9 \times 10^{-8}$ \\
\hline Tc-99b & $9.3 \times 10^{-10}$ & $9.3 \times 10^{-10}$ & $9.3 \times 10^{-10}$ & $9.3 \times 10^{-10}$ & $9.3 \times 10^{-10}$ & $9.3 \times 10^{-10}$ \\
\hline $\mathbf{H}-\mathbf{3}^{\mathbf{a}}$ & $5.5 \times 10^{-11}$ & $4.1 \times 10^{-11}$ & $2.6 \times 10^{-11}$ & $1.9 \times 10^{-11}$ & $1.6 \times 10^{-11}$ & $1.6 \times 10^{-11}$ \\
\hline$U-234^{b}$ & $3.0 \times 10^{-8}$ & $3.0 \times 10^{-8}$ & $3.0 \times 10^{-8}$ & $3.0 \times 10^{-8}$ & $3.0 \times 10^{-8}$ & $3.0 \times 10^{-8}$ \\
\hline$U-235^{b}$ & $3.0 \times 10^{-8}$ & $3.0 \times 10^{-8}$ & $3.0 \times 10^{-8}$ & $3.0 \times 10^{-8}$ & $3.0 \times 10^{-8}$ & $3.0 \times 10^{-8}$ \\
\hline $\mathrm{U}-238^{\mathrm{b}}$ & $2.6 \times 10^{-8}$ & $2.6 \times 10^{-8}$ & $2.6 \times 10^{-8}$ & $2.6 \times 10^{-8}$ & $2.6 \times 10^{-8}$ & $2.6 \times 10^{-8}$ \\
\hline
\end{tabular}

a Derived according to the method described in the text from age-dependent, organ-specific committed equivalent doses appearing in ICRP Publication 56 (ICRP, 1990). Results agree with those computed by Jain et al. (1992) using a similar procedure.

b Derived according to the method described in the text from the annual limit on intake (ALI) for ingestion as given in ICRP Publication 61 (ICRP, 1991b).

boundary of Area 20 or at the Oasis Valley. According to these figures, at each location, tritium (H-3) is calculated to be responsible for nearly $90 \%$ of the total lifetime committed effective dose. These estimates were derived using the following procedures.

First, the geometric mean of an annual committed effective dose $\left(\mathrm{GM}_{\mathrm{CED}}\right)$ was calculated for a particular radionuclide by multiplying together the geometric mean values for each of the three factors identified above. Next, the total log-transformed variance for this annual dose was computed, and any correlation was accounted for between dose-conversion factor and annual intake. 
Table 5. Lifetime maximum 70-y committed effective doses (Sv) for radionuclides of interest at Area 20 and offsite, $19 \mathrm{~km}$ away at the Oasis Valley.

\begin{tabular}{|c|c|c|c|c|}
\hline \multirow[b]{4}{*}{ Radionuclide } & \multicolumn{4}{|c|}{ Lifetime committed effective dose (Sv) } \\
\hline & \multicolumn{2}{|c|}{ Area 20 boundary } & \multicolumn{2}{|c|}{ Oasis Valley } \\
\hline & \multicolumn{2}{|c|}{ Arithmetic } & \multicolumn{2}{|c|}{ Arithmetic } \\
\hline & mean & variance & mean & variance \\
\hline Americium-241 & $1.2 \times 10^{-3}$ & $5.4 \times 10^{-7}$ & $5.6 \times 10^{-7}$ & $3.3 \times 10^{-13}$ \\
\hline Antimony-125 & $1.6 \times 10-14$ & $1.7 \times 10^{-28}$ & $6.4 \times 10^{-12}$ & $6.6 \times 10^{-23}$ \\
\hline Cerium-144 & $4.4 \times 10^{-43}$ & $4.4 \times 10^{-86}$ & $4.6 \times 10^{-17}$ & $1.6 \times 10^{-33}$ \\
\hline Cesium-137 & $4.5 \times 10^{-3}$ & $2.1 \times 10^{-5}$ & $7.8 \times 10^{-7}$ & $1.3 \times 10^{-12}$ \\
\hline Cobalt-60 & $3.0 \times 10^{-12}$ & $6.1 \times 10^{-24}$ & $2.7 \times 10^{-13}$ & $1.2 \times 10^{-25}$ \\
\hline Europium-152 & $5.3 \times 10^{-8}$ & $2.0 \times 10^{-15}$ & $3.0 \times 10^{-11}$ & $1.4 \times 10^{-21}$ \\
\hline Iodine-129 & $1.5 \times 10^{-3}$ & $1.4 \times 10^{-7}$ & $1.1 \times 10^{-6}$ & $7.3 \times 10^{-13}$ \\
\hline Plutonium-239 & $4.8 \times 10^{-3}$ & $7.8 \times 10^{-6}$ & $3.6 \times 10^{-6}$ & $1.3 \times 10^{-11}$ \\
\hline Radium-226 & $1.1 \times 10^{-3}$ & $8.6 \times 10^{-7}$ & $7.2 \times 10^{-7}$ & $8.2 \times 10^{-13}$ \\
\hline Ruthenium-106 & $7.7 \times 10^{-33}$ & $1.2 \times 10^{-65}$ & $9.3 \times 10^{-14}$ & $6.7 \times 10^{-27}$ \\
\hline Strontium-90 & $6.5 \times 10^{-3}$ & $8.8 \times 10^{-6}$ & $1.1 \times 10^{-6}$ & $9.2 \times 10^{-13}$ \\
\hline Technetium-99 & $9.4 \times 10^{-5}$ & $6.0 \times 10^{-9}$ & $7.1 \times 10^{-8}$ & $8.1 \times 10^{-15}$ \\
\hline Tritium [H-3] & $1.4 \times 10^{-1}$ & $3.4 \times 10^{-3}$ & $7.7 \times 10^{-5}$ & $4.7 \times 10^{-9}$ \\
\hline Uranium-234 & $2.2 \times 10^{-4}$ & $3.2 \times 10^{-8}$ & $1.6 \times 10^{-7}$ & $4.3 \times 10^{-14}$ \\
\hline Uranium-235 & $3.8 \times 10^{-5}$ & $9.5 \times 10^{-10}$ & $2.8 \times 10^{-10}$ & $1.3 \times 10^{-19}$ \\
\hline Uranium-238 & $1.0 \times 10^{-3}$ & $7.1 \times 10^{-7}$ & $7.8 \times 10^{-7}$ & $9.6 \times 10^{-13}$ \\
\hline
\end{tabular}

The total log-transformed variance for an annual dose, where correlation between two terms is possible, was calculated using the following equation:

$$
\sigma_{1_{A}}^{2}=\sum_{i=a}^{c}\left(\ln G_{S D}\right)^{2}+2 r\left(\ln G S D_{a}\right)\left(\ln G_{S D}\right)
$$

where $\sigma_{I_{A}}^{2}$ is the total annual log-transform variance for the combined log-transformed variances and the variance attributable to correlated parameters; $\mathrm{GSD}_{\mathrm{i}}$ is the geometric standard deviation of the i-th variable (e.g., GSDs for annual dose-conversion factor, annual intake, and annual concentrations in ground water); $r$ is the linear correlation coefficient between two parameters (e.g., annual dose-conversion factor and annual rate of intake); and $\mathrm{GSD}_{\mathrm{a}}$ and $\mathrm{GSD}_{\mathrm{b}}$ are the geometric standard deviations of the correlated parameters. This equation and its application has been described by Hoffman and Gardner (1983) and by Ng et al. (1990).

Of course, it is not possible to examine the correlation between the dose-conversion factors and the intake for the eight radionuclides with dose-conversion factors derived from ALIs (i.e., $\mathrm{Sb}-125, \mathrm{Co}-60, \mathrm{Eu}-152, \mathrm{Ra}-226$, Tc-99, and U-234, U-235, and U-238). Consequently, the 
assumption was made that there is no correlation, and the correlation coefficient for these radionuclides has been set equal to zero. Because any real correlations would likely be negative, the net effect is to overestimate the variance.

For seven of the eight radionuclides that were calculated from ICRP Publication 56, the linear correlation coefficient was negative and was about -0.40 for both Am-241 and Pu-239; about -0.60 for Sr-90; about -0.70 for Ce-144, Ru-106, and H-3; and was highest for I-129, at a value of about -0.90 . The linear correlation coefficient was positive for Cs-137, at a value of about +0.40 , because the biological half-life of this radionuclide increases with age (Leggett, 1986).

The arithmetic mean of the annual committed effective dose, $\bar{x}_{\mathrm{CED}_{\mathrm{A}}}$, was then determined using the following equation:

$$
\overline{\mathrm{x}}_{\mathrm{CED}_{\mathrm{A}}}=\mathrm{GM}_{\mathrm{CED}_{\mathrm{A}}} \times \exp \left(\frac{1}{2} \sigma_{I_{\mathrm{A}}}^{2}\right)
$$

where $\mathrm{GM}_{\mathrm{CED}}$ is the geometric mean of the annual committed effective dose (Sv) and $\sigma_{I_{A}}^{2}$ is the total annual log-transform variance. The corresponding annual arithmetic variance, $s_{\mathrm{CED}_{\mathrm{A}}}^{2}$, was calculated according to the following expression:

$$
\mathrm{s}_{\mathrm{CED}_{\mathrm{A}}}^{2}=\left(\mathrm{GM}_{\mathrm{CED}_{\mathrm{A}}}\right)^{2}\left[\exp \left(\sigma_{I_{\mathrm{A}}}^{2}\right) \times\left(\exp \left(\sigma_{I_{\mathrm{A}}}^{2}\right)-1\right)\right] \text {. }
$$

The arithmetic mean and arithmetic variance of the annual committed effective dose for each year of a 70-y period of exposure was used to calculate the arithmetic mean and arithmetic variance of the lifetime committed effective dose. The arithmetic mean of the lifetime committed effective dose $\left(\bar{x}_{\mathrm{CED}_{1}}\right)$ for an individual radionuclide is simply the sum of the annual arithmetic means for that radionuclide. The arithmetic variance has two terms: the sum of the annual arithmetic variances and a co-variance term addressing the correlation between the presence of a radionuclide in the ground water in one year being positively correlated with its presence in the ground water during the next year. The linear correlation coefficient for this relationship is considered to be equal to 0.8 .

The total variance in the lifetime committed effective dose, $\mathrm{s}_{\mathrm{T}_{\mathrm{L}}}^{2}$, is then the sum of the annual arithmetic variances and the sum of covariance terms that account for the correlations between years to the total dose:

$$
s_{\mathrm{T}_{\mathrm{L}}}^{2}=\sum_{\mathrm{j}=1}^{70} \mathrm{~s}_{\mathrm{j}_{\mathrm{CED}_{\mathrm{A}}}^{2}}+2 \mathrm{r}_{\mathrm{k}, 1} \sum_{\mathrm{k}=1}^{70-1} \sum_{\mathrm{l}=\mathrm{k}+1}^{70} \mathrm{~s}_{\mathrm{kCED}_{\mathrm{A}}} \mathrm{s}_{\mathrm{C}_{\mathrm{CED}_{\mathrm{A}}}}
$$

where $s_{\mathrm{j}_{C E D}}^{2}$ is the annual arithmetic variance, $\mathrm{r}_{\mathrm{k}, 1}$ is the correlation coefficient describing the correlation in committed effective dose between years (i.e., assumed to be 0.8 ), and $\mathrm{s}_{\mathrm{kED}_{\mathrm{A}}}$ and 
$\mathrm{s}_{\mathrm{l}_{\mathrm{CED}}}$ are the arithmetic standard deviations of annual variance for a radionuclide from year $\mathrm{k}$ and year 1 .

Because an estimate of the maximum potential risk confronting an individual ingesting NTS ground water either at the boundary of Area 20 or at the Oasis Valley is of primary interest, the maximum dose must first be calculated. At the Area 20 boundary on NTS, the maximum dose is that dose resulting from ingestion of all the radionuclides considered to be representative of those in the ground water during the 70-y interval beginning $101 \mathrm{y}$ in the future. At Oasis Valley, the maximum dose is that considered to result from ingesting the 70 maximum annual concentrations of each of the representative mix of radionuclides that have been modeled to be present at this location following transport in the ground water from the boundary of Area 20. Although the likelihood of all such radionuclides being present at the Oasis Valley simultaneously at their maximum concentration is very small, it is not impossible and, given the limited nature of the data concerning radionuclide concentrations in ground water beneath the NTS and their rate of movement, this assumption is not regarded as overly conservative.

The next item to be computed was the geometric mean and geometric standard deviation for the lognormally distributed committed effective dose associated with exposure to the maximum concentrations of all radionuclides of concern present simultaneously over a 70-y interval either at the Area 20 boundary or at the Oasis Valley. This was accomplished using the respective arithmetic means and arithmetic standard deviations for these radionuclides appearing in Table 5.

First, the arithmetic means of the lifetime committed effective doses associated with individual radionuclides at a specific location are summed to yield an arithmetic mean for the maximum potential lifetime committed effective dose from exposure to maximum concentrations from the grand total of all 16 radionuclides of concern, $\bar{x}_{\mathrm{CED}_{\mathrm{GTL}}}$. The associated arithmetic variance in the maximum possible committed effective dose over a 70-y lifetime has two terms: the sum of the arithmetic variances of the committed effective doses over a 70-y lifetime for each radionuclide and a co-variance term addressing the correlation between contributions of pairs of radionuclides to the total lifetime committed effective dose. Based on the linear correlation coefficients derived by $\mathrm{Ng}$ et al. (1990) for several radionuclides, the linear correlation coefficient for this relationship was assumed to be equal to 0.8 . The total variance in the lifetime committed effective dose from all radionuclides of concern, $\mathrm{s}_{\mathrm{CED}}^{2}{ }_{\mathrm{GTL}}$, at a specific location was then calculated according to the following equation:

$$
s_{\mathrm{CED}_{\mathrm{GL}}}^{2}=\sum_{\mathrm{T}=1}^{\mathrm{N}} \mathrm{s}_{\mathrm{T}_{\mathrm{L}}}^{2}+2 \mathrm{r}_{\mathrm{k}, \mathrm{l}} \sum_{\mathrm{k}=1}^{\mathrm{N}-1} \sum_{\mathrm{l}=\mathrm{k}+1}^{\mathrm{N}} \mathrm{s}_{\mathrm{CED}_{\mathrm{L}}} s_{\mathrm{l}_{\mathrm{CED}_{\mathrm{L}}}} \text {, }
$$

where $\mathrm{s}_{\mathrm{T}_{\mathrm{L}}}^{2}$ is the total lifetime arithmetic variance for an individual radionuclide; $\mathrm{r}_{\mathrm{k}, 1}$ is the linear correlation coefficient between lifetime committed effective doses from radionuclides $\mathrm{k}$ and 1 (i.e., assumed to be 0.8 ); $\mathrm{s}_{\mathrm{CED}_{\mathrm{L}}}$ and $\mathrm{s}_{\mathrm{CEED}_{\mathrm{L}}}$ are the arithmetic standard deviations of the lifetime committed effective dose from radionuclides $\mathrm{k}$ and $\mathrm{l}$; and $\mathrm{N}$ equals 16.

The geometric mean of the lifetime committed effective dose from exposure to the grand total of all 16 radionuclides of concern $\left(\mathrm{GM}_{\mathrm{CED}} \mathrm{GTL}_{\mathrm{G}}\right)$ at a specific location is determined from the grand total arithmetic mean and arithmetic variance of the committed effective dose: 


$$
\mathrm{GM}_{\mathrm{CED}_{\mathrm{GTL}}}=\frac{\overline{\mathrm{x}}_{\mathrm{CED}_{\mathrm{GL}}}^{2}}{\sqrt{\overline{\mathrm{x}}_{\mathrm{CED}_{\mathrm{CTL}}^{2}}+\mathrm{s}_{\mathrm{CED}_{\mathrm{GT}}}^{2}}} .
$$

The associated geometric standard deviation of the lifetime committed effective dose from exposure to all 16 radionuclides $\left(\mathrm{GSD}_{\mathrm{CED}} \mathrm{GTL}_{\mathrm{GT}}\right)$ also is computed from the arithmetic mean and arithmetic variance of the committed effective dose for lifetime exposure to the grand total of all 16 radiounuclides:

$$
\operatorname{GSD}_{\mathrm{CED}_{\mathrm{GTL}}}=\exp \left(\sqrt{\ln \left(1+\frac{\mathrm{s}_{\mathrm{CED}_{\mathrm{GT}}}^{2}}{\overline{\mathrm{x}}_{\mathrm{CED}_{\mathrm{Gr}}}^{2}}\right)}\right) .
$$

For an individual exposed from birth for a 70-y lifetime at the Area 20 boundary, the $\mathrm{GM}_{\mathrm{CED}} \mathrm{FTL}_{\mathrm{G}}$ equals $1.5 \times 10^{-1} \mathrm{~Sv}$ and the corresponding GSD $_{C E D_{G T L}}$ equals 1.4. Similarly, for the individual exposed from birth for a 70-y lifetime at Oasis Valley, the $G_{C E D_{G T L}}$ equals $6.5 \times 10^{-5} \mathrm{~Sv}$ and the corresponding $\mathrm{GSD}_{\mathrm{CED}} \mathrm{GTL}_{\mathrm{GT}}$ equals 2.1. As a minor point, it should be noted that the Am-241 still will be growing in from the decay of its parent, Pu-241. As the measured value of Am-241 was reported seven years after its associated event (the nuclear weapons test that served as its source), it is estimated that the final Am-241 concentration will be about three times higher. Even so, Am-241 would be less important than Sr-90, and Pu-239; and tritium would still dominate overwhelmingly the contribution to dose.

\subsection{Estimate of Cancer Risk and Associated Uncertainty}

The ICRP (1991a) in ICRP Publication 60, and the National Research Council (NRC) Committee on the Biological Effects of Ionizing Radiation (BEIR) in the BEIR V report (NRC, 1990) provide important reviews regarding the effectiveness of various forms of radiation to induce fatal cancers in humans and, specifically, the associated risks. The information in these reviews was directly applicable for identifying an appropriate estimate of the risk factor for radiation induced fatal cancer related to intake of radionuclides in ground water and for evaluating the uncertainty in this estimate.

On the basis of the data regarding excess mortality due to radiation induced cancers for human populations that are discussed in the BEIR V report (NRC, 1990), the risk factor for fatal cancer was considered to be a lognormally distributed variable. In ICRP Publication 60 , the ICRP (1991a) averaged various estimates of the risk factor for radiation induced fatal cancers from different studies, including the BEIR V report (NRC, 1990), and arrived at a nominal risk value of $5 \times 10^{-2}$ per Sv of lifetime committed effective dose for the probability of induced fatal cancer in a population of all ages following chronic low-dose exposure. For purposes of this report, this risk factor is considered to be the geometric mean value $\left(\mathrm{GM}_{\mathrm{RF}}\right)$ of a lognormally distributed variable. Also, the assumption is made that the population for which this risk factor is applicable remains stationary, has the age distribution of the current U.S. population, and a male to female ratio of unity - population characteristics that will not change over time.

Discussions contained in the BEIR V report (NRC, 1990) and in ICRP Publication 60 (ICRP, 1991a) indicate that the total variability associated with the risk factor for fatal cancer 
from chronic low-dose exposure is attributed primarily to uncertainties contributed by (1) the chance sampling variation in the available epidemiological data from Japanese survivors of the 1945 atomic bomb explosions that are used for describing the relationship between increased cancer mortality and an elevated acute whole-body dose in predictive models; (2) the dose-rate effectiveness factor (DREF) that is used to adjust dose-response data for elevated acute wholebody dose to agree with evidence from animal studies and limited human data suggesting that cancer induction at low doses and low dose rates is likely to be lower than that observed after high doses and dose rates; and (3) elements external to model parameters, including model misspecification with regard to males and females, population differences (e.g., Oriental vs. Occidental), uncertainty in the actual dosimetry estimates, and the accuracy of the estimated doses to the people on whom these risk factors are based (most particularly, the Japanese survivors of the atomic bombs). In fact, a review of the estimated doses to the Japanese survivors currently is in progress and the results could lead to future adjustments in the risk factor.

Each of these three components is assumed to be lognormally distributed and the associated geometric standard deviations are derived using the applicable data appearing in BEIR V (NRC, 1990). For example, the geometric standard deviation for the first two components $\left(\mathrm{GSD}_{\mathrm{c}}\right)$ is obtained by inserting the $95 \%$ upper confidence limit (UCL) and 5\% lower confidence limit (LCL) describing the range of the $90 \%$ confidence interval for each component into the following equation:

$$
\mathrm{GSD}_{\mathrm{c}}=\left(\frac{95 \% \mathrm{UCL}}{5 \% \mathrm{LCL}}\right)^{\frac{1}{3.29}}
$$

The geometric standard deviation of the third component was obtained by combining the GSDs for males and females for all cancers that were constructed from estimates of the GSDs for all nonmodel attributes contributing to the total variability in this component.

Because of sampling variation alone, the $90 \%$ confidence interval for risk of increased cancer mortality due to an acute whole-body dose for males and females combined was reported to range from 0.11 per $S v$ to 0.24 per $S v$, yielding a $G S D_{c}$ for this component of 1.3. It is assumed that the narrow range from 2 to 5 reported for the DREF, as a result of a review of laboratory animal studies focusing on tumorigenesis, represents the limits for the $90 \%$ confidence interval, and the resulting $\mathrm{GSD}_{\mathrm{c}}$ for this component also is 1.3 . Finally, the $\mathrm{GSD}_{\mathrm{c}}$ associated with overall uncertainty contributed by all of the elements considered external to model parameters was assumed to equal that calculated by adding in quadrature the natural logarithms of the male GSD of 1.31 and the female GSD of 1.27. The mathematical expression for deriving the GSD $\mathrm{c}_{\mathrm{c}}$ for this third component is

$$
\mathrm{GSD}_{\mathrm{c}}=\exp \sqrt{\left(\ln \mathrm{GSD}_{\text {male }}\right)^{2}+\left(\ln \mathrm{GSD}_{\text {female }}\right)^{2}}
$$

and it produces a value equal to 1.4. The geometric standard deviation of the total error for the risk factor (GSDTRF), which reflects the contribution to overall uncertainty from all three components, is derived using a formula similar to Eq. 16: 


$$
\mathrm{GSD}_{\mathrm{TRF}}=\exp \sqrt{(\ln 1.3)^{2}+(\ln 1.3)^{2}+(\ln 1.4)^{2}}
$$

Accordingly, the GSD ${ }_{\text {TRF }}$ equals 1.65 .

The geometric mean of the maximum potential excess lifetime risk of cancer mortality (GMMPR) for an individual either at Area 20 or at Oasis Valley from ingestion of the estimated maximum annual concentrations of the 16 radionuclides of interest in ground water at these locations was obtained as the product of the geometric mean of the total committed effective dose $\left(\mathrm{GM}_{\mathrm{CED}} \mathrm{GTL}_{\mathrm{G}}\right)$ and the geometric mean of the risk factor $\left(\mathrm{GM}_{\mathrm{RF}}=0.05 \mathrm{~Sv}^{-1}\right)$. The total geometric standard deviation for this risk is determined by solving the following equation, which is analogous to Equation 16:

$$
\mathrm{GSD}_{\mathrm{MPR}}=\exp \sqrt{\left(\ln \mathrm{GSD}_{\mathrm{CED}_{\mathrm{CTL}}}\right)^{2}+\left(\ln \mathrm{GSD}_{\mathrm{TRF}}\right)^{2}} .
$$

For an individual at the Area 20 boundary, the GMMPR equals $7 \times 10^{-3}$ and the GSDMPR equals about 1.9. For an individual in the Oasis Valley, the $\mathrm{GM}_{\mathrm{MPR}}$ equals $7 \times 10^{-7}$ and the corresponding GSDMPR equals about 2.5 . The $90 \%$ confidence interval is obtained in both cases by multiplying the respective GMMPR by the corresponding $\mathrm{GSD}_{M P R} \pm 1.645$. The resulting range of risk for an individual in Oasis Valley is from $7 \times 10^{-7}$ to $1 \times 10^{-5}$, and for an individual at the Area 20 boundary the range of risk is from $3 \times 10^{-3}$ to $2 \times 10^{-2}$.

\subsection{Discussion}

Clearly, there is a scarcity of useful data available concerning the concentrations of radionuclides in the ground water beneath the NTS today, and regarding the rates and directions of the flow of this ground water. Therefore, some conservative assumptions were adopted in order to assess responsibly the potential human health risks from the possible intake of such radionuclide-contaminated ground water by individuals in the future, either at a location onsite (assuming a loss of institutional control after $100 \mathrm{y}$ ) or at one offsite (as a result of transport in migrating groundwater). For example, none of the radionuclides of concern were considered to undergo adsorption and retention on geologic material. Also, any potential for dilution of the radionuclide-contaminated ground water by uncontaminated water was ignored. Yet, these conservative assumptions, and even the use of the concept of committed effective dose, do not appear to lead to gross overestimates of dose and risk, providing the approximations of maximum concentrations of radionuclides in ground water that are used are reasonable. The reason for this is that tritium, which moves as water and has a short effective half-life (both physical and biological half-life are short), was found to be responsible for nearly $90 \%$ of the total lifetime committed effective dose, when the representative mix of radionuclides are considered to be present together at their maximum annual concentrations at either the onsite or the offsite locations of interest. Consequently, adsorption and retention of any radionuclide other than tritium on geologic media will mean the reduction of that particular radionuclide's concentration in the ground water, and a corresponding reduction in the contribution to the total ingested dose from that radionuclide. Based on the ICRP methodology for calculating dose, this reduction will be more for a radionuclide having a lengthy effective half-life. Accordingly, the 
tritium contribution to the total dose will be even greater than $90 \%$ : Under such circumstances, the corresponding contribution of tritium to the total risk will also increase. Additionally, the travel-time transport model actually indicates that the risk from tritium at the offsite location in the Oasis Valley is likely to be greatest for an individual exposed between 25 and $94 \mathrm{y}$ in the future (see Table 2) and so exposures to ground water and the corresponding dose and risk occurring at this location before or after this 70-y interval will be lower.

Although only ingestion of radionuclide-contaminated ground water was considered, this pathway of exposure probably accounts for substantially more than $50 \%$ of the total dose of tritium. Accordingly, the predicted ranges for risk might be greater, but probably only by as much as a factor of two, if all other possible exposure pathways also are considered. This possible increase is not very meaningful, given the variability in the available data, and so rigorously addressing such additional pathways is unnecessary for purposes of this screening exercise.

\subsection{Conclusions}

The results from the risk-based screening analysis are based on conservative assumptions, and, where possible, defined estimates of uncertainty. These results indicate that tritium will likely be the radionuclide constituting the dominant contribution to dose and risk for humans exposed to ground water from the NTS.

Incorporating the maximum observed concentrations of a representative mix of radionuclides obtained from groundwater samples-of-opportunity into the travel-time transport model yields projected concentrations for these radionuclides offsite that do not appear to pose a serious concern for human exposure and risk. For example, the U.S. Environmental Protection Agency (USEPA, 1990) has established a goal for excess risk from exposure to contaminants in environmental media of $1 \times 10^{-6}$, but also acknowledges that an excess risk as large as $1 \times 10^{-4}$ may be acceptable. Clearly, the $90 \%$ confidence interval for excess cancer mortality risk at Oasis Valley, which is from $7 \times 10^{-7}$ to $1 \times 10^{-5}$, concurs with this guidance. However, should tritium be present beneath the NTS today at 10 or 100 times the concentration considered to be maximum (see Table 1), then predicted ranges for risk could also be 10 to 100 times higher, respectively, according to the approach that has been used. These concentrations may be unlikely, but would be of possible concern, especially for individuals offsite.

The results of the risk-based screening analysis that was performed using maximum observed concentrations of radionuclides in ground water samples-of-opportunity also strongly suggest that a contingency plan may need to be developed for continuing institutional control of the NTS, and its subterranean mineral and water rights, beyond $100 \mathrm{y}$ in the future. This conclusion is evident as a direct consequence of the possibility that a $90 \%$ confidence interval for the maximum possible cancer mortality risk for an individual consuming NTS ground water for a 70 -y lifetime beginning $101 \mathrm{y}$ in the future was determined to range from $3 \times 10^{-3}$ to $2 \times 10^{-2}$, and neither end of this range of risk would be considered acceptable according to the USEPA (1990), or probably any other state or federal agency.

More definitive conclusions with regard to the possible risk from lifetime exposure to radionuclide contaminated tap water, both on the NTS and offsite, may be obtained given a better understanding of the relationship between the radionuclides produced by underground weapons 
tests (radiochemical source term) and their presence in ground water (hydrologic source term). For example, the maximum concentrations of the radionuclides used in our risk-based screening analysis, even for tritium, were all measured in ground water obtained as samples-of-opportunity. Although the existence of higher radionuclide concentrations in NTS ground water than were assumed here remain speculative, such higher concentrations may be considered possible, at least until the data base is improved. Thus, a dedicated groundwater-sampling strategy, in combination with a realistic estimate of the quantities of radioactive material introduced beneath the NTS can lead to refined estimates of risk and improved decision making, especially with respect to contingency plans for institutional control and the dedication of limited resources for groundwater cleanup. On the basis of the data available today, the risk-based screening analysis provides a reasonable indication that dedicating limited resources for the cleanup of radionuclide contaminated ground water beneath the NTS may not be necessary. However, planning well into the future for maintaining institutional control of the NTS and/or its subterranean minerals and ground water resources is probably prudent. 


\section{References}

Andricevic, R., J. I. Daniels, and R. L. Jacobson (1993), "Radionuclide Migration Using Travel Time Transport Approach and Its Application in Risk Analysis," Desert Research Institute, Water Resources Center, Las Vegas, NV (Draft; submitted for publication to J. Hydrol.).

Blankennagel, R. K., and J. E. Weir (1973), Geohydrology of the Eastern Part of Pahute Mesa, Nevada Test Site, Nye County, Nevada, U.S. Government Printing Office, Washington, DC, U.S. Geological Survey Professional Paper 712-B.

Buddemeier, R. W. (1988), Hydrology and Radionuclide Migration Program 1985-1986 Progress Report, Lawrence Livermore National Laboratory, Livermore, CA, UCRL-53779.

Buddemeier, R. W., and D. Isherwood (1985), Radionuclide Migration Project 1984 Progress Report, Lawrence Livermore National Laboratory, Livermore, CA, UCRL-53628.

Dagan, G. (1982), "Stochastic Modeling of Groundwater Flow by Unconditional and Conditional Probabilities, 2. The Solute Transport," Water Resour. Res. 18, 835-848.

Dagan, G. (1984), “Solute Transport in Heterogeneous Porous Formations,” J. Fluid Mech. 145, 151-177.

Dagan, G. (1987), “Theory of Solute Transport by Groundwater,"Annu. Rev. Fluid Mech. 19, 183-215.

Dagan, G., and V. Nguyen (1989), "A Comparison of Travel Time and Concentration Approaches to Modeling Transport by Groundwater," J. Contam. Hydrol. 4, 79-91.

Erikson, S., and R. L. Jacobson (1990, Draft), Overview of Radionuclide Migration Investigations Conducted on the Nevada Test Site, Water Resources Center, Desert Research Institute, University of Nevada System, Reno and Las Vegas, NV, DRAFT Publication \#45071; DOE/NV/10384-30 [Concentration maxima at time of collection obtained from raw data recorded by the U.S. Environmental Protection Agency (EPA) as part of the 1973 or 1974 U.S. EPA Long-Term Hydrologic Monitoring Program (LTHM)].

Ershow, A. G., and K. P. Cantor (1989), Total Water and Tapwater Intake in the United States: Population-Based Estimates of Quantities and Sources, Federation of American Societies for Experimental Biology, Bethesda MD, National Cancer Institute Order \#263-MD-810264.

Fraser, S. L. (1982), Radiochemical Determination of Iodine-129 in Water Pumped from the Site of an Underground Nuclear Explosion, Los Alamos National Laboratory, Los Alamos, NM, LA-UR-82-2468.

Hoffman, D. C., R. Stone, and W. W. Dudley, Jr. (1977), Radioactivity in the Underground Environment of the Cambric Nuclear Explosion at the Nevada Test Site, Los Alamos National Laboratory, Los Alamos, NM, LA-6877-MS (Informal Report).

Hoffman, F. O., and R. H. Gardner (1983), "Evaluation of Uncertainties in Radiological Assessment Models," in Radiological Risk Assessment: A Textbook on Environmental Dose Analysis, J. E. Till and H. R. Meyer, Eds., U. S. Nuclear Regulatory Commission, Washington, DC, NUREG/CR-3332, ORNL-5968, pp. 11-1 to 11-55. 
International Commission on Radiological Protection (ICRP) (1973), ICRP Publication 20. Alkaline Earth Metabolism in Adult Man (Pergamon Press, New York, NY).

International Commission on Radiological Protection (ICRP) (1979), ICRP Publication 30, Part 1. Limits for Intakes of Radionuclides by Workers (Pergamon Press, New York, NY), Volume 2 No. $3 / 4$.

International Commission on Radiological Protection (ICRP) (1990), ICRP Publication 56. AgeDependent Doses to Members of the Public from Intake of Radionuclides: Part 1 (Pergamon Press, New York, NY), Volume 20 No. 2.

International Commission on Radiological Protection (ICRP) (1991a), ICRP Publication 60. 1990 Recommendations of the International Commission on Radiological Protection (Pergamon Press, New York, NY), Volume 21 No. 1-3.

International Commission on Radiological Protection (ICRP) (1991b), ICRP Publication 61. Annual Limits on Intake of Radionuclides by Workers Based on the 1990 Recommendations (Pergamon Press, New York, NY), Volume 21 No. 4.

Jain, S. C., A. Nagaratnam, A. R. Reddy, M. M. Gupta, and S. C. Mehtall (1992), "Revised AgeDependent Doses to Members of the Public from Intake of Radionuclides Using the New Tissue Weighting Factors," Radiat. Prot. Dosim. 40, 111-115.

Kreft, A., and A. Zuber (1978), "On the Physical Meaning of the Dispersion Equation and Its Solution for Different Initial and Boundary Conditions," Chem. Eng. Sci. 33, 1471-1480.

Leggett, R. W. (1986), "Predicting the Retention of Cs in Individuals," Health Phys. 50, 747-759.

Marsh, K. V. (1992), “Appendix A. Tests Fired Near or Below the Water Table," in Hydrology and Radionuclide Migration Program 1987 Progress Report, Lawrence Livermore National Laboratory, Livermore, CA, UCRL-53779-89.

Moeller, D. W. (1992), "Chapter 10. Standards," in Environmental Health (Harvard University Press, Cambridge, MA), pp. 205-228.

National Council on Radiation Protection and Measurements (NCRP) (1987), Recommendations on Limits for Exposure to Ionizing Radiation, National Council on Radiation Protection and Measurements, Bethesda, MD, NCRP Report №.91.

National Research Council (NRC) (1990), Health Effects of Exposure to Low Levels of Ionizing Radiation, BEIR V (National Academy Press, Washington, DC).

Ng, Y. C., Anspaugh, L. R., and R. T. Cederwall (1990), “ORERP Internal Dose Estimates for Individuals," Health Phys. 59, 693-713.

Puskin, J. S. (1992), "An Analysis of the Uncertainties in Estimates of Radon-Induced Lung Cancer," Risk Analysis 12, 277-285.

Shapiro, A. M., and V. Cvetkovic (1988), "Stochastic Analysis of Solute Arrival Time in Heterogeneous Porous Media," Water Resour. Res. 24, 1711-1718. 
Silva, R. J., R. Evans, J. H. Rego, and R. W. Buddemeier (1986), "Technetium Analyses in the Radionuclide Migration Project," in Nuclear Chemistry Division FY 86 Annual Report, R. J. Borg, Scientific Ed., Lawrence Livermore National Laboratory, Livermore, CA, UCAR 10062/86, p. 3-14.

Spencer, L. (1992), “Water: The West's Most Misallocated Resource," Forbes 149(9), 68-74.

Taylor, G. I. (1921), "Diffusion by Continuous Movements," Proc. London. Math. Soc. 2, 196-212.

United States Environmental Protection Agency (USEPA) (1990), "National Oil and Hazardous Substances Pollution Contingency Plan, Final Rule (40 CFR Part 300)," Fed. Regist. 55(46), 8666-8865.

Winograd, I. J., and W. Thordarson (1975), Hydrogeologic and Hydrochemical Framework, South-Central Great Basin, Nevada-California, with Special Reference to the Nevada Test Site, U.S. Government Printing Office, Washington, DC, U.S. Geological Survey Professional Paper 712-C.

Wruble, D. T., and E. M. McDowell, Eds. (1990), Nevada Test Site Annual Site Environmental Report-1989, Volume I, U.S. Department of Energy, Nevada Operations Office, Las Vegas, NV, DOE/NV/10630-11 Volume 1. 